\title{
Volatiles in glasses from the HSDP2 drill core
}

\author{
Caroline Seaman ${ }^{1}$, Sarah Sherman $^{2}$, Michael Garcia $^{2}$, Michael Baker $^{1}$, Brian Balta $^{1}$, \\ and Edward Stolper ${ }^{1}$
}

(submitted to Geochemistry, Geophysics, Geosystems, 6/03; revised 4/04)

\section{Abstract}

$\mathrm{H}_{2} \mathrm{O}, \mathrm{CO}_{2}, \mathrm{~S}, \mathrm{Cl}$, and $\mathrm{F}$ concentrations are reported for 556 glasses from the submarine section of the 1999 phase of HSDP drilling in Hilo, Hawaii, providing a high-resolution record of magmatic volatiles over $200 \mathrm{Ky}$ of a Hawaiian volcano's lifetime.

Glasses range from undegassed to having lost significant volatiles at near-atmospheric pressure. Nearly all hyaloclastite glasses are degassed, compatible with formation from subaerial lavas that fragmented on entering the ocean and were transported by gravity flows down the volcano flank. Most pillows are undegassed, indicating submarine eruption. The shallowest pillows and most massive lavas are degassed, suggesting formation by subaerial flows that penetrated the shoreline and flowed some distance under water. Some pillow-rim glasses have $\mathrm{H}_{2} \mathrm{O}$ and $\mathrm{S}$ contents indicating degassing but elevated $\mathrm{CO}_{2}$ contents that correlate with depth in the core; these tend to be more fractionated and could have formed by mixing of degassed, fractionated magmas with undegassed magmas during magma-chamber overturn or by resorption of rising $\mathrm{CO}_{2}$-rich bubbles by degassed magmas. Intrusive glasses are undegassed and have $\mathrm{CO}_{2}$ contents similar to adjacent pillows, indicating intrusion shallow in the volcanic edifice.

$\mathrm{Cl}$ correlates weakly with $\mathrm{H}_{2} \mathrm{O}$ and $\mathrm{S}$, suggesting loss during low-pressure degassing, although most samples appear contaminated by sea-water-derived components. F behaves as an involatile incompatible element.

Fractionation trends were modeled using MELTS. Degassed glasses require fractionation at $\mathrm{p}_{\mathrm{H}_{2} \mathrm{O}}$ $\approx 5-10$ bars. Undegassed low- $\mathrm{SiO}_{2}$ glasses require fractionation at $\mathrm{p}_{\mathrm{H}_{2} \mathrm{O}} \approx 50$ bars. Undegassed and partially degassed high- $\mathrm{SiO}_{2}$ glasses can be modeled by coupled crystallization and degassing.

Eruption depths of undegassed pillows can be calculated from their volatile contents assuming vapor saturation. The amount of subsidence can be determined from the difference between this depth and the sample's depth in the core. Assuming subsidence at $2.5 \mathrm{~mm} / \mathrm{y}$, the amount of subsidence suggests ages of $\sim 500 \mathrm{Ka}$ for samples from the lower $750 \mathrm{~m}$ of the core, consistent with radiometric ages.

$\mathrm{H}_{2} \mathrm{O}$ contents of undegassed low- $\mathrm{SiO}_{2} \mathrm{HSDP} 2$ glasses are systematically higher than those of high- $\mathrm{SiO}_{2}$ glasses, and their $\mathrm{H}_{2} \mathrm{O} / \mathrm{K}_{2} \mathrm{O}$ and $\mathrm{H}_{2} \mathrm{O} / \mathrm{Ce}$ ratios are higher than typical tholeiitic pillowrim glasses from Hawaiian volcanoes.

\section{Introduction}

The concentrations of volatile components such as $\mathrm{H}_{2} \mathrm{O}, \mathrm{CO}_{2}, \mathrm{~S}$, and the halogens in volcanic glasses can provide constraints on petrogenesis and the nature of volcanic processes. For example, $\mathrm{H}_{2} \mathrm{O}, \mathrm{S}$, and $\mathrm{Cl}$ contents of glasses can distinguish between magmas erupted under

\footnotetext{
${ }^{1}$ Division of Geological and Planetary Sciences, California Institute of Technology, Pasadena, CA 91125, USA

${ }^{2}$ Department of Geology and Geophysics, University of Hawaii at Manoa, Honolulu, HI 96822, USA
} 
subaerial and shallow and deep submarine conditions [e.g., Moore and Fabbi, 1971; Moore and Schilling, 1973; Killingley and Muenow, 1975; Moore and Clague, 1992; Garcia and Davis, 2001; Davis et al., 2003], providing insight into the eruptive history of individual samples. $\mathrm{H}_{2} \mathrm{O}$ and $\mathrm{CO}_{2}$ contents of glasses from submarine and intrusive glasses can also provide quantitative constraints on the pressure of eruption or emplacement [e.g., Fine and Stolper, 1985b; Dixon et al., 1991; Newman et al., 2000; Wallace, 2002], and the speciation of water can provide information on thermal histories and the role of low temperature hydration in the formation of water-rich glasses [Zhang et al., 1991; Dixon et al., 1995; Zhang et al., 1995; Newman et al., 2000]. And, perhaps most importantly, for samples that retain volatile contents inherited from melting and other processes in the mantle, concentrations of $\mathrm{H}_{2} \mathrm{O}, \mathrm{CO}_{2}$, etc. can provide critical information on the role of volatiles in petrogenesis and the nature of heterogeneity in mantle sources of basaltic magmas [e.g., Michael, 1988; Stolper and Newman, 1994; Michael, 1995; Newman et al., 2000; Dixon and Clague, 2001; Dixon et al., 2002; Hauri, 2002; Michael and Kamenetsky, 2002; Saal et al., 2002; Wallace, 2002; Davis et al., 2003].

In this paper we report concentrations of $\mathrm{H}_{2} \mathrm{O}, \mathrm{CO}_{2}, \mathrm{~S}, \mathrm{Cl}$, and $\mathrm{F}$ in a suite of 556 glasses from the submarine section (i.e., at depths greater than 1079 meters below sea level, or mbsl) recovered by the 1999 phase of drilling at Hilo, Hawaii of the Hawaii Scientific Drilling Project (referred to hereafter as HSDP2, to distinguish it from the pilot hole, or HSDP1, drilled in1993). These samples are presumed to represent output from the Mauna Kea volcano [Hawaii Scientific Drilling Project, 2001]. The potential of volatile components for answering petrological, volcanological, and geochemical questions of the sort posed above is particularly great for the submarine parts of the HSDP2 section, since fresh glass is abundant [Hawaii Scientific Drilling Project, 2001; Stolper et al., 2004]. Moreover, submarine glasses from the HSDP2 core represent a detailed sequence spanning $\sim 200 \mathrm{Ky}$, providing the opportunity to study the variation of volatiles and what they can tell us about volcanic processes and petrogenesis over a considerable fraction of the shield-building stage of a Hawaiian volcano. 


\section{Sample descriptions and locations}

The 556 samples studied here were described in Stolper et al. [2004], who report electron microprobe analyses of 531 of these glasses. The stratigraphy of the HSDP2 drill core is summarized in Hawaii Scientific Drilling Project [2001]: The drill core penetrated subaerial Mauna Loa lavas until reaching subaerial Mauna Kea lavas at $245 \mathrm{mbsl}$. At $\sim 1079 \mathrm{mbsl}$, the core passed into submarine Mauna Kea deposits including hyaloclastites, pillow basalts, intrusive units, and so-called "massive" basalts. During core logging at the drill site, units were designated as "massive" if they could not be definitively identified as either pillows or intrusive units; thus this designation includes units with a range of morphologies and characteristics. Nearly all of the massive units in the core are from 1100-1800 mbsl, and all of those included in this study are from this depth range.

Samples were collected from glass fragments in hyaloclastites and from pillow margins, intrusive margins, contacts of massive basalts, and glassy zones within massive basalts. There are actually two independent data sets, one from the University of Hawaii (UH) and one from Caltech, but in the interests of a coherent presentation, we have chosen to report them in a single publication. The UH sample suite was collected on site during drilling as part of the core logging procedure for each core box. Samples in this suite span the $\sim 1100-3100$ mbsl depth range; sampling was particularly dense (roughly every $3 \mathrm{~m}$ ) deeper than $\sim 1500 \mathrm{mbsl}$. The Caltech suite was collected at Caltech during the summer of 2000 as a "reference suite" for further glass analyses after all core logs were completed and revised. In addition to regularly spaced samples (roughly every $50 \mathrm{~m}$ ), preliminary major element chemistry of whole rocks [Rhodes and Vollinger, 2004] and glasses (from the UH sample suite) were used as guides for additional sampling at Caltech to ensure coverage of major geochemical trends and boundaries. Additional details on the samples, their collection, and their preparation are reported in Stolper et al. [2004]. 


\section{Petrography}

Because of the large number of samples studied in this project, we have limited our petrographic descriptions primarily to reflected light microscopy of the polished microprobe mounts of the Caltech reference suite of glasses. Observations on phenocryst and microphenocryst assemblages and on the presence/absence of sulfides and vesicles are reported in Table 1.

The glass chips are brown both macroscopically and in thin section. Alteration rinds occur both on the exterior surfaces of the glass chips and less commonly along fractures within chips and on interior surfaces of some vesicles. The extent of alteration varies widely. Many samples display no obvious alteration while other samples have rinds that are up to $100 \mu \mathrm{m}$ thick. In all cases, these alteration rinds were avoided during electron microprobe analysis. Although we have not quantified the abundance of altered glass in each sample (since the chips in each probe mount were selected based on their glassy appearance and are not necessarily representative of the larger collection of chips that make up each sample), visual inspection of the microprobe mounts suggests that the extent of alteration roughly increases with increasing depth. In addition, several intrusive glasses and pillow glasses from near intrusive units have heterogeneous and elevated molecular water contents (see section 6.2), suggesting some localization of alteration processes

Olivine is the only phenocryst phase (defined as grains $>0.5 \mathrm{~mm}$ in longest dimension) in the reference glasses. Microphenocrysts $(0.05-0.5 \mathrm{~mm}$ in longest dimension) include olivine, plagioclase, augite, and more rarely spinel. Plagioclases in a few of the samples have high aspect ratios $(>10)$, and on the basis of length would be classified as phenocrysts, but given their elongate habit, we have chosen to classify them as microphenocrysts. One orthopyroxene grain ( $\sim 0.5 \mathrm{~mm}$ in longest dimension) partially rimmed by augite is present in SR0907-2.8, a pillow basalt (unit 321) from 2789.5 mbsl. Orthopyroxene was also found in SR0714-11.5, an intrusive (unit 263) from 1883.0 mbsl (Mark Kurz, personal communication). The rarity of orthopyroxene in our sample suite and the fact that low-pressure MELTS calculations on selected glass 
compositions (see section 8) do not predict orthopyroxene crystallization suggests that orthopyroxene is not an important low-pressure crystallizing phase in these samples. Spinel inclusions are common in the olivine phenocrysts and microphenocrysts. Sulfides were not observed in any of the Caltech glasses. However, four polished mounts of the UH glasses contain sulfide blebs in the groundmass glass (SR0913-11.80, SR0914-10.50, SR0916-7.40, SR0967-2.0), and sulfide blebs are present in olivine-hosted melt inclusions in another two UH samples (SR0969-11.30, SR0965-1.40). Note that we only examined 11 of the UH samples for sulfides, chosen because they were relatively rich in $\mathrm{FeO}^{*}$ and $\mathrm{S}$, and in all six cases where sulfides were present, they are extremely rare, with only one or two blebs observed on the polished surface of each sample.

Vesicles are observed in all but five of the polished Caltech glass samples (SR0694-4.9, SR724-9.6, SR754-9.9, SR771-7.5, and SR0859-1.0). Vesicles are $10-450 \mu \mathrm{m}$ in diameter; some samples have vesicles spanning a wide size range, while others have a narrow size distribution. We measured the diameters of the five largest vesicles in each sample (or fewer, if there were $<5$ vesicles in the sample); the median of these measured vesicle size for the degassed glasses is similar to that for the partially degassed and undegassed glasses ( $80 \mathrm{vs.} 90$ $\mu \mathrm{m})$. Because of the small surface areas of the mounted glasses, only approximate modal abundances of vesicles (based on visual estimates) are reported for the Caltech samples in Table 1 ; these estimates of vesicularity range from zero to $5-10 \%$ (vesicle abundances were not estimated for any of the UH samples). Note that some of these estimates probably underestimate the actual vesicularity because vesicles along the edge of a mounted chip were not included in the volume estimate unless the vesicle appeared to be more than $50 \%$ enclosed by glass. All but one of the of the degassed samples have $<5 \%$ vesicles and most have $<2 \%$; the only degassed sample with more than 5\% vesicles is SR0848-12.0 with 5-10\%. Seven of the partially degassed and undegassed samples have $2-10 \%$ vesicles, while the remaining 15 samples have $<2 \%$ vesicles. In neither the degassed nor the undegassed and partially degassed glasses does vesicle volume correlate with measured water content. 


\section{Analytical methods}

\subsection{Infrared spectroscopy}

Fourier Transform infrared (FTIR) spectroscopy was performed on doubly-polished glass chips. Transmission spectra were collected with a Nicolet Continuum Infrared Microscope connected to a Nicolet 860 Magna series FTIR using a globar source, a KBr beamsplitter, and a MCT/A detector. Most spectra were collected with 128 scans. Glass chips were 22-300 $\mu \mathrm{m}$ thick; thickness for each sample was based on the average of three measurements taken on the same spot before each analysis; $1 \sigma$ on the thickness measurement was typically less than $1 \mu \mathrm{m}$. Glass density was assumed to be $2800 \mathrm{~g} / 1$ [Dixon et al., 1991].

The concentration of total dissolved water (i.e., dissolved as hydroxyl groups plus molecular water) was calculated from the intensity of the absorption band at $\sim 3550 \mathrm{~cm}^{-1}$. The molar absorptivity of this band was taken to be $63 \pm 51 / \mathrm{mol}-\mathrm{cm}$ [see summary in Newman et al., 2000] and assumed to be compositionally independent over the range of compositions in this study. The background for the 3550 band was assumed to be linear and fixed by the spectrum at $\sim 3740$ and $\sim 2510 \mathrm{~cm}^{-1}$.

Dixon et al. [1995] found that concentrations of molecular water calculated using the $1630 \mathrm{~cm}^{-1}$ and $5200 \mathrm{~cm}^{-1}$ absorption bands are indistinguishable within error. Therefore, given the higher sensitivity of the $1630 \mathrm{~cm}^{-1}$ band and the low concentrations of water in most of our samples, the $1630 \mathrm{~cm}^{-1}$ band was used to determine molecular water contents. Except for three anomalous intrusive samples with elevated molecular water contents and detectable molecular $\mathrm{CO}_{2}$ (see section 6.2), all carbon dioxide in the HSDP2 glasses is dissolved as carbonate, manifested by a doublet in the absorption spectrum with maxima at $\sim 1515$ and $1435 \mathrm{~cm}^{-1}[$ Fine and Stolper, 1985b], and the intensity of this doublet was used to quantify dissolved $\mathrm{CO}_{2}$ contents of the glasses. To determine the intensities of these bands, we first subtracted the spectrum of a volatile-poor pillow-rim glass (SR754-9.9) scaled to the same thickness as the unknown. Each background-subtracted spectrum in the region $1800-1400 \mathrm{~cm}^{-1}$ was then modeled as the sum of a $1630 \mathrm{~cm}^{-1}$ molecular $\mathrm{H}_{2} \mathrm{O}$ band and a $1515-1435 \mathrm{~cm}^{-1}$ carbonate 
doublet; the absorbances of the molecular $\mathrm{H}_{2} \mathrm{O}$ and carbonate bands were the coefficients of these bands in the best-fit model spectrum. Concentrations of molecular water were calculated using a value of $25 \pm 2 \mathrm{1} / \mathrm{mol}-\mathrm{cm}^{-1}$ for the molar absorptivity of the $1630 \mathrm{~cm}^{-1}$ band; this is the average (and $1 \sigma$ ) of values calculated for the HSDP2 glasses using the equations of Dixon et al. [1995]. Carbonate concentrations were calculated using a value of $355 \pm 5 \mathrm{l} / \mathrm{mol}-\mathrm{cm}$, based on values calculated for the HSDP2 glasses using the results of Dixon and Pan [1995]. The detection limit for $\mathrm{CO}_{2}$ depends upon sample thickness, the quality of the spectrum, and the details of the background subtraction procedures, but it is typically 20-50 ppm; because of the same factors, analytical precision can degrade to several tens of percent at concentrations below 50-100 ppm [Fine and Stolper, 1985b].

Results of the infrared analyses are listed in Table 1 of Stolper et al. [2004]. Total water contents are reported for 172 samples; molecular water contents are reported for 91 and carbon dioxide contents for 77 of these samples. Multiple spectra (2-5) were obtained for each sample; analyses and uncertainties reported in Table 1 of Stolper et al. [2004] and shown in the figures in this paper are the mean and $1 \sigma$ of the distribution of these replicate analyses. The average uncertainties for the FTIR determinations of water content, molecular water content, and carbon dioxide dissolved as carbonate are 0.014 wt.\%, 0.09 wt.\%, and 8 ppm, respectively.

\subsection{Ion microprobe}

Because of the difficulties of making precise FTIR measurements at the low $\mathrm{CO}_{2}$ contents of the HSDP2 glasses (all are $<120$ ppm based on FTIR measurements), we undertook a comparison between FTIR and ion microprobe measurements using our sample suite. Ion microprobe measurements were made with a modified Cameca $3 \mathrm{f}$ ion probe at the Lawrence Livermore National Laboratory using a 2-3 nA beam of $\mathrm{Cs}^{+}$ions accelerated at $10 \mathrm{kV}$; an electron flood gun was used to prevent positive charging of the sample surfaces. Sputtered ions were accelerated at a nominal voltage of $4.5 \mathrm{kV}$ through a double-focusing mass spectrometer and ${ }^{12} \mathrm{C}^{+}$ions were measured with an electron multiplier. A zero energy offset was used for all analyses, and the mass-resolving power was 1100. 
Measured ${ }^{12} \mathrm{C}^{+} /{ }^{30} \mathrm{Si}^{+}$ratios in the HSDP2 glasses were converted to wt. $\% \mathrm{CO}_{2}$ with a calibration curve constructed using two natural basaltic glasses [Hutcheon, 2001] and the basaltic run products from two moderate-pressure experiments [Stolper and Holloway, 1988]. The $\mathrm{CO}_{2}$ and $\mathrm{SiO}_{2}$ concentrations for the four standard glasses are in the ranges $29-550 \mathrm{ppm}$ and $50.53-$ 51.05 wt. \%. The standards were analyzed each day over a six-day period and the calibration curve consists of 45 analyses with a correlation coefficient $(\mathrm{R})$ of 0.9985 . The mean deviation between the 45 standard analyses and the values predicted for these standards by the calibration is $5.2 \%$ relative. Considering only the three standards with the highest $\mathrm{CO}_{2}$ contents (152-550 $\mathrm{ppm}$ ), the mean deviation drops to $2.6 \%$; for the standard glass with the lowest $\mathrm{CO}_{2}$ content, the mean deviation is $\sim 12 \%$. Two Kilauea basaltic glasses with 50.6 and 51.7 wt. $\% \mathrm{SiO}_{2}$ [Hutcheon, 2001] were also analyzed as secondary standards and the mean ion probe $\mathrm{CO}_{2}$ values $(138 \pm 7,254 \pm 7)$ overlap with those determined by FTIR $(117 \pm 20,278 \pm 20)$ at the $1 \sigma$ level.

In addition to the four primary and two secondary glass standards discussed above, six experimentally produced glasses quenched from $\mathrm{CO}_{2}$-saturated liquids (containing up to $\sim 400$ ppm $\mathrm{CO}_{2}$ ), and 35 glass samples from the Caltech reference suite were analyzed for $\mathrm{CO}_{2}$ by ion microprobe (based on the calibration curve, four of the reference glasses had $\mathrm{CO}_{2}$ contents less than zero). The results of these measurements are shown in Figure 1 and tabulated in Stolper et al. [2004]. Although there is an overall correlation between the two methods $(\mathrm{R}=0.964)$, the best-fit line does not pass through the origin: i.e., for detectable concentrations $<120 \mathrm{ppm} \mathrm{CO}_{2}$ (based on FTIR measurements), the concentrations determined by FTIR are systematically lower than the ion probe determinations, suggesting a problem with background corrections for one or both techniques at low concentrations. Despite these differences, both data sets show similar trends at the level of interpretation that we present below. Given this similarity and that $\mathrm{CO}_{2}$ solubility models in the literature have been calibrated using FTIR measurements [Dixon and Stolper, 1995; Dixon, 1997], that the $\mathrm{CO}_{2}$ contents of most basaltic glasses in the literature have been measured by FTIR [e.g., Fine and Stolper, 1985b; Dixon et al., 1988; Dixon et al., 1991; Stolper and Newman, 1994; Dixon et al., 1997; Newman et al., 2000; Dixon and Clague, 2001; 
Wallace, 2002; Davis et al., 2003], and that we have a larger number of FTIR measurements of $\mathrm{CO}_{2}$ contents than ion microprobe measurements, we restrict our discussion of $\mathrm{CO}_{2}$ contents in the following sections to the FTIR measurements.

\subsection{Electron microprobe}

Major element and S concentrations of 531 of the glasses were determined by electron microprobe analysis at the University of Hawaii or Caltech; F and $\mathrm{Cl}$ concentrations were determined at the University of Hawaii for 99 of these samples. Analytical procedures and results are reported in Stolper et al. [2004].

\section{Results}

$\mathrm{H}_{2} \mathrm{O}, \mathrm{S}, \mathrm{CO}_{2}, \mathrm{Cl}$, and $\mathrm{F}$ contents of the HSDP2 glasses are listed in Table 1 of Stolper et al. [2004] and shown as functions of depth in the drillcore in Figure 2 and versus $\mathrm{SiO}_{2}$ in Figure 3. Results on the speciation of water in the HSDP2 glasses are shown in Figure 4.

All samples are from the submarine part of the section (i.e., deeper than $1079 \mathrm{mbsl}$ ). Following Stolper et al. [2004], we have divided the samples into a high- $\mathrm{SiO}_{2}$ group ( $\left.\geq 50 \%{ }^{*}\right)$ and a low $-\mathrm{SiO}_{2}$ group $(<50 \%)$, and they are differentiated by color in all figures. Glasses from each rock type (i.e., hyaloclastites, pillows, intrusive units, massive lavas) are shown as distinctive symbols in most figures. Based on the distributions of the high- and low- $\mathrm{SiO}_{2}$ glasses with depth, Stolper et al. [2004] divided the submarine part of the core into the four zones shown in Figure 2.

Glasses are referred to in this paper as either "undegassed" $\left(\mathrm{H}_{2} \mathrm{O} \geq 0.45 \%\right.$ and $\mathrm{S} \geq$ 0.09\%), "partially degassed" $\left(0.45>\mathrm{H}_{2} \mathrm{O} \geq 0.21 \% ; 0.09>\mathrm{S} \geq 0.04 \%\right)$, or "degassed" $\left(\mathrm{H}_{2} \mathrm{O}<\right.$ $0.21 \%$ and $\mathrm{S}<0.04 \%$ ); this classification is based largely on concentrations in subaerial vs. submarine glasses [Moore and Clague, 1992; Garcia and Davis, 2001; Sherman et al., 2002]. It is well known that $\mathrm{H}_{2} \mathrm{O}$ and $\mathrm{S}$ degas significantly from Hawaiian liquids only at relatively low total pressures such as those pertaining to subaerial or shallow submarine environments or to

\footnotetext{
*All concentrations are in weight percent, unless otherwise indicated.
} 
high-level magma chambers connected to the atmosphere. The point of this classification is thus that the "degassed" samples lost water and sulfur at pressures approaching atmospheric, whereas the "undegassed" samples did not experience total pressures of less than $\sim 40-50$ bars for sufficient time to vesiculate significantly [Stolper et al., 2004].

In this section, we describe the volatile concentrations, their relationship to rock type, and their variations with chemical composition. In section 7 , we describe the variations in volatile contents with depth in the core.

\subsection{Water and sulfur contents}

Figures $3 \mathrm{a}$ and $\mathrm{b}$ show $\mathrm{SiO}_{2}$ contents vs. $\mathrm{H}_{2} \mathrm{O}$ and $\mathrm{S}$ contents of the analyzed glasses. Water contents are $0.06-3.85 \%$ and $\mathrm{S}$ contents are $0.001-0.15 \%$. The undegassed and partially degassed glass samples define a low- $\mathrm{SiO}_{2}$ group (48.3-49.8\% $\mathrm{SiO}_{2}$ ) and a high- $\mathrm{SiO}_{2}$ group (50.5$52.0 \% \mathrm{SiO}_{2}$ ) separated by a gap in $\mathrm{SiO}_{2}$ in which there are no undegassed or partially degassed samples. Degassed samples span the full range of $\mathrm{SiO}_{2}$ contents, filling in the gap in $\mathrm{SiO}_{2}$ content defined by the undegassed samples. There is also a relationship between water content and $\mathrm{MgO}$ content, such that the more fractionated samples (i.e., with lower $\mathrm{MgO}$ contents) tend to be degassed. Although there is not a one-to-one correlation, the overall relationship is apparent in Figures $3 \mathrm{a}$ and $\mathrm{b}$, in which samples with $\geq 7 \% \mathrm{MgO}$ (shown by filled symbols) are concentrated among the undegassed samples, and samples with $<7 \% \mathrm{MgO}$ (shown by open symbols) are concentrated among the degassed samples. This relationship between degassing and fractionation is developed in more detail below (see section 9.1). Finally, Figures $3 a$ and $b$ show that $\mathrm{H}_{2} \mathrm{O}$ and $\mathrm{S}$ contents are bimodally distributed: i.e., there are few partially degassed glasses, a feature also observed for $\mathrm{S}$ in submarine glasses from other Hawaiian volcanoes [e.g., Clague et al., 2002; Johnson et al., 2002; Sherman et al., 2002; Shinozaki et al., 2002; Davis et al., 2003]. This reflects primarily the relatively narrow depth interval over which samples partially degas: i.e., only a small fraction of the depth interval of the core corresponds to the pressures at which submarine magmas would partially degas, so most samples erupted either subaerially (degassing fully) or deeper than 500 mbsl (without degassing). 
Although the distinction in terms of silica content between the high- and low-silica groups may at first appear arbitrary because there is a continuous (though bimodal) distribution of silica contents [and other major and minor elements — Stolper et al., 2004], these groups are also distinguishable using several isotopic and incompatible trace element ratios, so the formation of the high- and low- $\mathrm{SiO}_{2}$ magmatic groups must have involved compositionally distinguishable mantle sources. Moreover, the observations presented in the preceding paragraph led Stolper et al. [2004] to propose that there are two dominant, non-overlapping magma series for the HSDP2 rocks, not a continuum, because among the undegassed glasses there are unambiguously two distinct groups of glasses. They further proposed that most glasses with intermediate silica contents were produced by mixing of the high- $\mathrm{SiO}_{2}$ and low-SiO 2 magmas. Finally, the observations that glasses with intermediate silica contents are always degassed and that degassed glasses tend to be more fractionated suggest that the site(s) of mixing are at high levels in the volcanic edifice where pressures are low enough for significant degassing to occur and that mixing, degassing, and crystallization are connected in the evolution of the Mauna Kea magmas sampled in the HSDP2 core. The possible nature of this connection is developed in section 9.1. Note that there is a group of low- $\mathrm{SiO}_{2}$ glasses identified by Stolper et al. [2004] with slightly elevated $\mathrm{CaO}, \mathrm{Al}_{2} \mathrm{O}_{3}$, and $\mathrm{SiO}_{2}$ contents; these are all degassed and appear to be the dominant low- $\mathrm{SiO}_{2}$ mixing end member in samples from the shallower parts of the core.

As shown in Figure 5a, $\mathrm{H}_{2} \mathrm{O}$ and $\mathrm{S}$ are positively correlated. This is not surprising since they are known to degas over similar relatively low-pressure intervals [e.g., Dixon et al., 1991; Moore and Clague, 1992; Garcia and Davis, 2001; Hauri, 2002; Davis et al., 2003]. In detail, however, the high- and low- $\mathrm{SiO}_{2}$ groups are distinguished in this figure. The high-SiO 2 glasses form a continuous linear array with roughly constant $\mathrm{H}_{2} \mathrm{O} / \mathrm{S}$ ratio of $\sim 4-5$, presumably representing a degassing trend. The low- $\mathrm{SiO}_{2}$ glasses are, however, mostly undegassed, with a higher $\mathrm{H}_{2} \mathrm{O} / \mathrm{S}$ ratio of $\sim 5-7$. Figure $3 \mathrm{a}$ and Figure $5 \mathrm{a}$ show that primitive, undegassed low- $\mathrm{SiO}_{2}$ and high- $\mathrm{SiO}_{2}$ glasses have distinguishable average $\mathrm{H}_{2} \mathrm{O}$ contents: excluding the intrusive and 
pillow-rim glasses suspected of alteration (see section 6.2), the 70 undegassed low- $\mathrm{SiO}_{2}$ glasses with $\mathrm{MgO} \geq 7 \%$ have $0.55-0.85 \% \mathrm{H}_{2} \mathrm{O}$ (averaging $0.67 \pm 0.06 \%\{1 \sigma\}$ ), whereas the 33 undegassed high- $\mathrm{SiO}_{2}$ glasses with $\mathrm{MgO} \geq 7 \%$ have $0.46-0.64 \% \mathrm{H}_{2} \mathrm{O}$ (averaging $0.52 \pm 0.05 \%$ $\{1 \sigma\})$. The $\mathrm{S}$ contents of the two groups are not as readily distinguished, with the undegassed, $\mathrm{MgO}-$ rich, unaltered low-SiO ${ }_{2}$ glasses having 0.91-0.119\% S (averaging $0.104 \pm 0.006 \%\{1 \sigma\}$ ) and the equivalent high- $\mathrm{SiO}_{2}$ glasses having 0.092-0.133\% (averaging $0.114 \pm 0.012 \%\{1 \sigma\}$ ). However, as shown in Figure 6a, the FeO* vs. S relations of the HSDP2 glasses suggest that the $\mathrm{MgO}-$ rich high- $\mathrm{SiO}_{2}$ glasses are indeed typically slightly richer in $\mathrm{S}$ than $\mathrm{MgO}$-rich low- $\mathrm{SiO}_{2}$ glasses; moreover, petrographic observations (Figure 6b) and comparison with the observed conditions of sulfide saturation for mid-ocean ridge basalts (Figure 6) suggest that the most Srich high- $\mathrm{SiO}_{2}$ glasses are sulfide saturated, whereas all low- $\mathrm{SiO}_{2}$ glasses are undersaturated with respect to an immiscible sulfide liquid.

In addition to the relationships between chemical composition and $\mathrm{H}_{2} \mathrm{O}$ and $\mathrm{S}$ contents, there are also patterns in volatile contents with respect to rock type:

\subsubsection{Hyaloclastites}

Nearly all of the hyaloclastite glasses are degassed (i.e., $95 \%$ of 261 samples have $0.06-$ $0.16 \% \mathrm{H}_{2} \mathrm{O}$ or $\left.0.001-0.037 \% \mathrm{~S}\right)$. This suggests that they represent subaerial or shallow submarine eruptions that vitrified and fragmented on reaching the shoreline and that their presence in the HSDP2 core reflects subsequent slumping of oversteepened near-shore fragmental deposits [Hawaii Scientific Drilling Project, 2001]. This interpretation is consistent with the presence of highly vesicular lithic clasts and the occurrence of charcoal (although this is rare) in the hyaloclastites [Hawaii Scientific Drilling Project, 2001], both of which indicate derivation from near-shore environments. A small number of hyaloclastites (all from $>2460$ mbsl) have elevated $\mathrm{H}_{2} \mathrm{O}$ contents (two samples from zone 3, SR0837-21.0 and -21.1, both at $2477.9 \mathrm{mbsl}$, 0.55\%; one sample from zone 4, SR0921-14.10, $2860.9 \mathrm{mbsl}, 0.67 \%$ ) and/or S contents (fourteen samples: $0.062-0.129 \%$ ), perhaps indicating the presence of deep-water 
hyaloclastites at depth in the core [e.g., Smith and Batiza, 1989; Maicher et al., 2000; Head and Wilson, 2003].

Stolper et al. [2004] emphasized the occurrence of high- $\mathrm{CaO}-\mathrm{K}_{2} \mathrm{O}$, low- $\mathrm{SiO}_{2}$ hyaloclastite glasses at $\sim 1765-1810 \mathrm{mbsl}$. Figure $2 \mathrm{~b}$ shows that these glasses are all degassed and that they are lower in $\mathrm{S}$ than the high- $\mathrm{SiO}_{2}$ glasses from around this depth interval. We do not currently have an explanation for the unusually low $\mathrm{S}$ contents of the low- $\mathrm{SiO}_{2}$ glasses from this depth interval.

\subsection{2. $\underline{\text { Massive lavas }}$}

Ten of the 11 glasses we analyzed from the massive flows are degassed $(0.07-0.12 \%$ $\left.\mathrm{H}_{2} \mathrm{O} ; 0.014-0.021 \% \mathrm{~S}\right)$. Given that most massive units in the core are from shallower than 1800 mbsl in the submarine section and most of those we analyzed are substantially degassed, we suggest that most of the massive units represent subaerial flows that penetrated the subaerialsubmarine boundary at the shoreline and flowed, perhaps in tubes, some distance under water down the flank of the volcano [Moore et al., 1973; Tribble, 1991; Garcia and Davis, 2001; Hawaii Scientific Drilling Project, 2001; Davis et al., 2003].

The single undegassed massive glass is sample SR0508-8.00 at $1283.5 \mathrm{mbsl}(0.46 \%$ $\left.\mathrm{H}_{2} \mathrm{O}\right)$ from the base of unit 191, a thick ( $\left.>23 \mathrm{~m}\right)$, olivine-rich ( $\sim 30 \%$ phenocrysts $)$ unit. There are no internal contacts, suggesting a single, thick magmatic unit. One possibility is that this was a submarine-erupted lava lake comparable to the flat-topped structures described by Clague et al. [2000b], in which case the retention of volatiles would not be surprising. However, it is also possible that olivine-rich magma at the base of such a thick unit might not degas even if it had erupted subaerially; alternatively, magma at the base of such a thick flow could have assimilated and retained water from the underlying hyaloclastites.

\subsubsection{Intrusive glasses}

All 33 of the glasses from the margins of intrusive units (including 4 intrusive breccias; Stolper et al. [2004]) have undegassed $\mathrm{H}_{2} \mathrm{O}$ contents (0.48-3.85\%) and undegassed to partially degassed S contents $(0.063-0.143 \%)$. The glasses with the highest $\mathrm{H}_{2} \mathrm{O}$ contents from this study 
are from intrusive units (Figure 3a and Figure 4c). Although the elevated molecular water contents of the most $\mathrm{H}_{2} \mathrm{O}$-rich intrusive glasses suggest they were secondarily hydrated (see section 6.2), not all of the intrusive glasses show such evidence of hydration

\subsubsection{Pillows}

Glasses from pillow rims cover nearly the full range of $\mathrm{S}(0.008-0.148 \%)$ and $\mathrm{H}_{2} \mathrm{O}(0.09$ $0.81 \%$ ) contents. Most pillows ( $~ 80 \%\{201$ of 251$\})$ and particularly those from deeper than 2233 mbsl ( $\sim 94 \%\{201$ of 213$\})$ are undegassed or partially degassed magmas (note that all of the undegassed and partially degassed pillows are from greater than $2233 \mathrm{mbsl}$ ). This suggests that most magmas feeding pillow eruptions did not pass through the shallow levels of the magmatic plumbing system of the volcano and that they erupted under water (as opposed to having erupted subaerially, then flowing across the shoreline and being emplaced as pillows). However, glasses from the shallowest pillow lavas (1984-2136 mbsl; comprising 15\% of the pillow-rim samples) form a distinctive group. They are all degassed and nearly all fall in the gap in silica content between the undegassed high- and low- $\mathrm{SiO}_{2}$ groups that dominate the deeper pillows; this is also the most significant occurrence of the $\mathrm{CaO}-\mathrm{Al}_{2} \mathrm{O}_{3}$-enriched group of glasses in the core [Stolper et al., 2004]. The degassed nature of these pillows could signify either that the magmas from which they formed degassed as they passed through high-level magma chamber(s) or that, as we suggested above for the massive units, they formed from subaerial lava flows that penetrated the subaerial-submarine boundary at the shoreline and flowed some distance under water down the flank of the volcano [e.g., Moore et al., 1973; Tribble, 1991; Garcia and Davis, 2001; Davis et al., 2003].

\subsection{Speciation of water}

The FTIR measurements allow discrimination between water dissolved as hydroxyl groups and molecular water. Figure 4a shows molecular water concentrations vs. total water concentrations for most of the samples included in this study. Shown for comparison is a curve based on rapid-quench experiments on a MORB glass [Dixon et al., 1995]; the curve is a regular solution fit to samples with $\sim 0.5-2.5 \%$ total water, but most of the experimental data are for $>$ 
$0.8 \% \mathrm{H}_{2} \mathrm{O}$, and thus the curve represents an extrapolation for the water contents of most of the glasses in this study. Also shown for comparison are data for other Hawaiian glasses (Figure 4b) and back-arc basin glasses (Figure 4c). Although many of the HSDP2 glasses fall slightly below the curve based on the experiments, the variations in speciation with total water content are similar for the natural and experimental samples. The small but systematic difference between the HSDP2 samples and the curve based on the experiments could reflect extrapolation of the experimental results to lower total water contents, different cooling rates and therefore closure temperatures for the natural and experimental glasses [e.g., Dingwell and Webb, 1990; Zhang et al., 1995; Zhang et al., 2000], compositional dependence of the molar absorptivity of the 1630 $\mathrm{cm}^{-1}$ band (i.e., using a value of 20 1/mol-cm [Dixon et al., 1997; Dixon and Clague, 2001] rather than 25 1/mol-cm produces a closer match of our results to the model speciation curve for MORB), or compositional dependence of the speciation. Regardless of the ultimate explanation, the differences are small and do not affect our interpretations.

Two pillow-rim glasses (Figures $4 \mathrm{a}$ and $\mathrm{b}$ ) and three intrusive glasses (Figure 4c) plot significantly above the trend defined by the other HSDP2 glasses and the Dixon et al. [1995] curve. In addition to their high concentrations of molecular water, these glasses display other characteristics that distinguish them from experimental and natural glasses with more typical relative species concentrations: (1) Although they are clear and crystal-free, these glasses are sometimes darker than other glasses (i.e., they cannot be seen through under the microscope unless polished to $<70 \mu \mathrm{m}$, whereas lower molecular water content glasses are typically transparent at thicknesses up to 200-300 $\mu \mathrm{m}$ ). (2) The molecular water band at $1630 \mathrm{~cm}^{-1}$ in some of these samples has a shoulder at $\sim 1556 \mathrm{~cm}^{-1}$, and the intrusive sample with the highest molecular water content (SR0957-4.1 from $3020.3 \mathrm{mbsl}$ ) has a prominent shoulder on the 1630 $\mathrm{cm}^{-1}$ molecular water peak centered at $1595 \mathrm{~cm}^{-1}$ and minor absorptions at 1360, 1423, and 1495 $\mathrm{cm}^{-1}$, none of which have been observed in other HSDP2 glasses or experimentally produced hydrous basaltic glasses. These features suggest differences in the mode of incorporation of molecular water in these samples. (3) The three intrusive samples with elevated molecular water 
contents (SR944-11.6 at 2979.9 mbsl, SR957-4.1 at $3020.3 \mathrm{mbsl}$, and SR972-15.7 at 3086.4 mbsl) have detectable dissolved molecular $\mathrm{CO}_{2}$ based on the presence of an absorption at 2350 $\mathrm{cm}^{-1}$. Concentrations are low (on the order of $10 \mathrm{ppm}$ based on an extinction coefficient of 1000 1/mol-cm; [Fine and Stolper, 1985a]), but this feature is nevertheless unusual for basaltic glasses, which typically contain only carbonate [Fine and Stolper, 1985b]. (4) Molecular water concentrations in individual glass chips from these samples are highly variable (indicated by the large error bars on these analyses); variations in both total and molecular water contents between different glass chips from the same sample are even greater.

Dixon et al. [1995], Newman et al. [2000], and Davis et al. [2003] suggested that submarine basaltic glasses with molecular water contents elevated significantly above the experimentally determined curve shown in Figure 4 could be explained by absorption of molecular water during low-temperature alteration, and we propose that such processes are responsible for the enrichments in molecular water observed in some of the HSDP2 glasses and for the associated features described in the previous paragraph. Although experiments on basaltic glasses have not demonstrated such phenomena, experiments on other glass compositions have demonstrated that low-temperature hydration can produce elevated molecular water contents [Olbert and Doremus, 1983; Zhang et al., 1991; Pandya et al., 1994]. The preferential occurrence of elevated molecular water concentrations in samples related to intrusive units, either in intrusive units themselves or in pillows surrounding the intrusive units (although not all such samples have elevated molecular water contents; see Figure 4), is consistent with this hypothesis since alteration has been observed adjacent to intrusions in the HSDP2 core [Hawaii Scientific Drilling Project, 2000].

\subsection{Carbon dioxide contents}

$\mathrm{CO}_{2}$ concentrations for all glasses with concentrations greater than $20 \mathrm{ppm}$ are shown in Figure 2c. All dissolved $\mathrm{CO}_{2}$ is present as carbonate, except as described above (section 6.2) for the three high-molecular-water intrusive glasses that have small amounts of molecular $\mathrm{CO}_{2}$. 
Only three hyaloclastite glasses have detectable $\mathrm{CO}_{2}$ (SR0837-21.0, $2477.9 \mathrm{mbsl}, 61 \pm 9$ ppm and SR0837-21.1, 2477.9 mbsl, $58 \pm 7$ ppm; SR0921-14.10, 2860.9 mbsl, $29 \pm 5$ ppm); as described in section 6.1.1, these are also the only hyaloclastite glasses with undegassed $\mathrm{H}_{2} \mathrm{O}$ contents. None of the glasses from massive basalts have $\mathrm{CO}_{2}$ contents above the FTIR detection limit. $\mathrm{CO}_{2}$ concentrations both in pillow glasses and in intrusive glasses range from below the FTIR detection limit up to $\sim 120 \mathrm{ppm}$. $\mathrm{CO}_{2}$ concentrations in intrusive glasses are in all cases comparable to those of pillow basalts from similar depths.

It is important to emphasize that although the $\mathrm{CO}_{2}$ contents reported here are broadly systematic with depth (Figure 2c) and comparable to ion microprobe measurements on the same samples (Figure 1), they are at the low end of what is feasible with FTIR. In particular, the carbonate bands are small, broad, and superimposed on a background that is sensitive to the major element composition of the glass. Detailed interpretation will require more precise analytical techniques or the availability of samples erupted at greater depth.

\subsection{Cl contents}

Chlorine is a highly incompatible element with partitioning similar to $\mathrm{K}$ (or perhaps even as incompatible as Ba and Rb) [Schilling et al., 1980; Michael and Cornell, 1998; Saal et al., 2002]. When data on Hawaiian glasses are viewed as a whole, $\mathrm{Cl}$ behaves as anticipated for such an element. For example, as for $\mathrm{H}_{2} \mathrm{O}$ (see section 9.4.2 and Figure 14a), there is an overall negative correlation between $\mathrm{Cl}$ and $\mathrm{SiO}_{2}$ contents for Hawaiian magmas [Dixon and Clague, 2001], with alkalic lavas having significantly higher $\mathrm{Cl}$ contents, as expected for magmas generated by lower degrees of melting than tholeiites. $\mathrm{Cl}$ is also known to be a volatile element that degasses from basaltic magmas under subaerial and shallow submarine conditions [Swanson and Fabbi, 1973; Unni and Schilling, 1978; Davis et al., 2003]. However, interpretations of Cl contents of oceanic basalts in general [Michael and Schilling, 1989; Jambon et al., 1995; Michael and Cornell, 1998] and Hawaiian pillow-rim glasses and melt inclusions in particular [Kent et al., 1999a; Kent et al., 1999b; Dixon and Clague, 2001; Hauri, 2002; Davis et al., 2003] are complicated by the susceptibility of $\mathrm{Cl}$ contents to contamination from brines and sea water. 
$\mathrm{Cl}$ contents are shown versus depth in Figure 2d, versus $\mathrm{SiO}_{2}$ in Figure 3c, and versus other volatile components and $\mathrm{K}_{2} \mathrm{O}$ in Figure 5. Note that analyses of $\mathrm{Cl}$ (and $\mathrm{F}$ ) are all from samples deeper that $\sim 2000 \mathrm{mbsl}$, and most are from zones 3 and 4 . The range of $\mathrm{Cl}$ contents is 0.011-0.056\%, comparable to that observed by Davis et al. [2003] for Mauna Loa submarine samples and well within the compiled ranges for Hawaiian melt inclusions and submarine glasses [Kent et al., 1999a; Dixon and Clague, 2001; Hauri, 2002; Davis et al., 2003]. Although there are no systematics with respect $\mathrm{SiO}_{2}$ content, depth, or rock type, Figure 5 shows that the fractionated samples with the lowest $\mathrm{H}_{2} \mathrm{O}$ and $\mathrm{S}$ contents also tend to have the lowest $\mathrm{Cl}$ contents, and there may be a weak correlation between $\mathrm{H}_{2} \mathrm{O}$ and $\mathrm{Cl}$, suggesting that degassing of $\mathrm{Cl}$ accompanies that of $\mathrm{H}_{2} \mathrm{O}$ and $\mathrm{S}$. There are, however, several features of the $\mathrm{Cl}$ data set that suggest caution in interpreting the $\mathrm{Cl}$ concentrations. Swanson and Fabbi [1973] and Davis et al. [2003] showed that glasses quenched from subaerially erupted magmas from Kilauea and Mauna Loa degassed to $\mathrm{Cl}$ contents lower than $0.011-0.013 \%$. However, as shown in Figure 3 and Figure 5, few of the HSDP2 glasses have $\mathrm{Cl}$ contents this low, even among those samples known based on their $\mathrm{H}_{2} \mathrm{O}$ and $\mathrm{S}$ contents to have degassed extensively under subaerial conditions. Although it is possible that the HSDP2 glasses simply degassed to higher $\mathrm{Cl}$ contents than the Kilauea and Mauna Loa samples, perhaps reflecting different eruptive conditions or that $\mathrm{Cl}$ degassing depends strongly on melt composition, an alternative is that most of the glasses have been contaminated to some extent by $\mathrm{Cl}$-rich sea-water-derived components. The comparisons of Hawaiian melt inclusions and submarine glasses shown by Hauri [2002] and Davis et al. [2003] suggest that most submarine glasses, even many of those with low Cl contents, are indeed Cl-enriched relative to mantle-derived values. Hauri [2002] showed that Kilauea melt inclusions, which he considered similar to Mauna Kea, have $\mathrm{Cl} / \mathrm{K}$ ratios of $\sim 0.03$, and he chose to exclude as contaminated all Kilauea and Mauna Kea glasses with $\mathrm{Cl} / \mathrm{K}>0.06$. Figure $5 \mathrm{f}$ shows lines of $\mathrm{Cl} / \mathrm{K}=0.03$ and 0.06 ; none of the HSDP2 glasses have $\mathrm{Cl} / \mathrm{K} \leq 0.03$, and $\sim 45 \%$ of the samples have $\mathrm{Cl} / \mathrm{K}>0.06$. Thus, according to these criteria, a substantial fraction of the HSDP2 samples experienced some secondary $\mathrm{Cl}$ enrichment. 
Although some of the HSDP2 glasses might be unaffected by interaction with Cl-rich sea-water-derived components, we have no objective basis for distinguishing them. Consequently, we do not interpret in any detail the $\mathrm{Cl}$ contents of these glasses. We note, however, that there is no signature of this alteration in any other elements analyzed by us. For example, none of the samples with unusually high $\mathrm{Cl}$ contents (i.e., samples with $\mathrm{Cl}>0.03$ [Davis et al., 2003], distinguished by orange dots on all figures) have elevated $\mathrm{H}_{2} \mathrm{O}$ or molecular water contents, which we have taken as an indicator of secondary alteration (see section 6.2). Additionally, the only sample with elevated water content on which $\mathrm{Cl}$ was also determined (SR944-11.60; $1.27 \% \mathrm{H}_{2} \mathrm{O}, 0.024 \% \mathrm{Cl}$ ) has a $\mathrm{Cl} / \mathrm{K}$ ratio of 0.073 , only slightly above the limit for unaltered samples suggested by Hauri [2002]. Based on the results of Hauri [2002] and Davis et al. [2003], a study of melt inclusions in HSDP2 olivines might be the most fruitful approach to determining pristine $\mathrm{Cl}$ contents in these samples.

\section{5. $\underline{\text { F contents }}$}

Fluorine is an incompatible element with partitioning behavior somewhere between $\mathrm{Ti}$ or the heavy rare earths [Hauri, 2002] and Sr and P [Schilling et al., 1980; Saal et al., 2002], but there is uncertainty over its volatility during basaltic volcanism [see discussion in Davis et al., 2003]. F contents from this study are shown versus depth in Figure 2e, versus $\mathrm{SiO}_{2}$ in Figure 3d, and versus other volatile components in Figure 5. As emphasized above for the $\mathrm{Cl}$ analyses, $\mathrm{F}$ contents have only been determined for samples deeper than $\sim 2000 \mathrm{mbsl}$. The range of F contents, $0.025-0.051 \%$, is comparable to those reported for other Hawaiian volcanoes by Davis et al. [2003] and Hauri [2002], although not extending quite as high. There are no systematics with respect $\mathrm{SiO}_{2}$ content, depth, or rock type. $\mathrm{F}$ is uncorrelated with $\mathrm{S}$ or $\mathrm{H}_{2} \mathrm{O}$, suggesting that it is involatile during the magmatic processes influencing the HSDP2 magmas, in agreement with the results of Davis et al. [2003] for Mauna Loa. F is uncorrelated with Cl, and there is no evidence in our data of the enrichment of F seen in some submarine Mauna Loa samples by Davis et al. [2003] and attributed by them to assimilation of subaerial fumarole deposits. As described in section 7.2, $\mathrm{F}$ is enriched along with other involatile incompatible elements in 
glasses from the excursion at the top of zone 3 and its concentration in zone 4 pillows increases with progressive fractionation. These observations support the interpretations of Rowe and Schilling [1979] and Davis et al. [2003] that F generally behaves straightforwardly as an involatile incompatible element during petrogenesis of basic magmas, although there may be exceptions to this rule in the Azores and Iceland [e.g., Schilling et al., 1980; and see the discussion in Davis et al., 2003].

\section{Variations of volatiles with depth in the HSDP2 core}

\subsection{What do degassed glasses deep in the submarine section signify?}

Stolper et al. [2004] divided the submarine section of the core into the four zones shown in Figure 2 based largely on the silica contents of the samples. These zones provide a framework for discussion of the magmatic history recorded by the HSDP2 samples. With the exception of a single sample from the base of massive unit 191 (SR0508-8.00, $1283.5 \mathrm{mbsl}, 0.46 \% \mathrm{H}_{2} \mathrm{O}$; see section 6.1.2), all of the samples from zones 1 and 2 (i.e., from shallower than $2233 \mathrm{mbsl}$ ) are degassed, with undetectable $\mathrm{CO}_{2}$, and with $\mathrm{H}_{2} \mathrm{O}$ and $\mathrm{S}$ contents signifying that they quenched to glass from magmas degassed at near-atmospheric pressure. The boundary between zones 2 and 3 at $2233 \mathrm{mbsl}$ is an abrupt change from the high- $\mathrm{SiO}_{2}$, degassed hyaloclastites at the base of zone 2 to the low- $\mathrm{SiO}_{2}$, undegassed pillows at the top of zone 3, and with the exception of a thin zone of partially degassed samples near the base of zone 3 (2438-2481 mbsl), all glasses from zone 3 are undegassed with respect to $\mathrm{H}_{2} \mathrm{O}$ and $\mathrm{S}$. It is important to emphasize that with the exception of the single sample mentioned above, all of the undegassed glasses in the core are from deeper than $2233 \mathrm{mbsl}$ and most ( $\sim 75 \%$ of the undegassed samples) are pillow lavas; moreover, all partially degassed magmas occur deeper than 2438 mbsl (i.e., primarily in zone 4). The boundary between zones 3 and 4 at $2481 \mathrm{mbsl}$ is an abrupt change from the undegassed and partially degassed low- $\mathrm{SiO}_{2}$ glasses at the base of zone 3 to the degassed high- $\mathrm{SiO}_{2}$ samples at the top of zone 4 . Zone 4 is complex in terms of its volatiles contents, containing degassed and undegassed high- $\mathrm{SiO}_{2}$ pillows and hyaloclastites over most of its depth interval. $\mathrm{CO}_{2}$ contents are low throughout zone 3 , but nevertheless there is a trend of increasing $\mathrm{CO}_{2}$ with increasing 
depth in this interval; moreover, the trend of increasing $\mathrm{CO}_{2}$ with depth among the undegassed samples is continuous from zone 3 through the full depth range of zone 4 . All of the intrusive glasses from this study are from zone 4; two are partially degassed based on their S contents and the rest are undegassed. Their $\mathrm{CO}_{2}$ contents increase with depth and follow the trend defined by the undegassed pillows and hyaloclastites over the depth of zone 4.

The uniformly degassed character of glasses from the shallowest part of the submarine section (i.e., from near the top of zone 1) is not surprising since such samples must have been deposited near sea level, but the samples from near the base of zone 2 are from more than $1 \mathrm{~km}$ deeper in the core than the subaerial-submarine transition, and based on the age relations in the core [Sharp and DePaolo, 2004] and typical subsidence rates ( 2.5 mm/y; see section 9.2) they would have been deposited at water depths of $\sim 850-1000$ mbsl. Magmas saturated with waterrich vapor at these pressures would be expected to contain up to $\sim 1 \% \mathrm{H}_{2} \mathrm{O}$, and thus the presence of degassed magmas at these depths in the core require transport of liquids or glasses degassed at low pressures to these significant water depths. The problem is even more severe for the degassed samples occurring near the base of zone 4 at depths in the core of $>3000$ mbsl, which must have been deposited at water depths of $\sim 2500 \mathrm{~m}$ or greater, at which the water solubilities are even higher.

The degassed character of the hyaloclastites is likely a straightforward consequence of their mode of formation by slumping of oversteepened near-shore fragmental deposits formed by quenching and fragmentation of degassed subaerial magmas on reaching the shoreline.

Likewise, we attribute the degassed nature of the massive units to their formation from subaerial flows that penetrated the subaerial-submarine boundary at the shoreline and flowed, perhaps in tubes, some distance under water down the flank of the volcano [e.g., Moore et al., 1973; Tribble, 1991; Garcia and Davis, 2001; Davis et al., 2003]. The rarity of massive units of this sort deeper than zone 1 may simply reflect an upper limit to the distance such flows usually propagate on the underwater slopes of this volcano, although Garcia and Davis [2001] and Davis et al. [2003] inferred the propagation of such flows to much greater depths (i.e., up to $3.1 \mathrm{kmbsl}$ 
at distances of up to $\sim 20 \mathrm{~km}$ from the current shoreline) on the west side of Mauna Loa. Note that we have no explanation for why there are no pillows associated with the massive submarine flows, yet we would expect such an association [e.g., Moore et al., 1973; Tribble, 1991] if this process did indeed produce the massive units in the shallow submarine parts of the core.

The degassed pillows deep in the core present more of a problem than the degassed hyaloclastites and massive lavas. One possibility is that, like the massive flows, they formed from subaerial lava flows that penetrated the subaerial-submarine boundary at the shoreline and flowed some distance under water down the flank of the volcano; this is how Garcia and Davis [2001] and Davis et al. [2003] explained their discovery of significant quantities of degassed pillows deep on the submarine flank of Mauna Loa. This explanation seems most plausible for the distinctive group of shallow, degassed pillows in zone 2 since for these units the flows would not have had to propagate more than several kilometers past the shoreline, but it could also apply to the degassed and partially degassed pillows from zones 3 and 4, which, although from deep in the HSDP2 core, were emplaced at shallower water depths and therefore likely shorter distances from the shoreline than many of the degassed Mauna Loa pillows described by Garcia and Davis [2001] and Davis et al. [2003]. A simple test of this possibility is that lavas formed in this way would have $\mathrm{CO}_{2}$ contents below detection limits by FTIR analysis (i.e., because they would have degassed to near-atmospheric pressure prior to entering the sea), so this emplacement mechanism cannot apply to those pillows shown in Figure 3 from deeper than 2233 mbsl with detectable $\mathrm{CO}_{2}$ contents.

An alternative explanation of the degassed and partially degassed submarine pillows from deep in the core is that, as suggested by Dixon et al [1991] and Clague et al. [1991] for lavas from Kilauea's Puna ridge, they represent mixtures of undegassed magmas from depth in the magmatic system with magmas that degassed at high levels (e.g., in summit magma chamber(s) or conduits [Kazahaya et al., 1994] or perhaps by eruption followed by draining back into the magma chamber [Dixon et al., 1991; Wallace and Anderson, 1998]); these mixtures could then have flowed downslope within the volcanic edifice and finally reemerged as submarine pillow 
lavas. Although Dixon et al. [1991] found pillows with evidence of such high level degassing as deep as $\sim 3$ kmbsl on Kilauea’s Puna ridge, they pointed out that such samples are more common among shallower samples, and this is also the case for the HSDP2 pillow-rim glasses, of which most of the degassed examples occur in the 1984-2136 mbsl interval in zone 2 . This mode of formation of the degassed and partially degassed submarine magmas is discussed in more detail below (see section 9.1).

\subsection{Fine-scale variability in $\mathrm{H}_{2} \mathrm{O}$ and $\mathrm{S}$ contents}

\subsubsection{Zone 3}

Although to first order the samples from zone 3 (most of which are from pillows, the exceptions are from units 294 and 296, two thin hyaloclastite units from near the base of zone 3) can be characterized as a nearly uniform sequence of undegassed low- $\mathrm{SiO}_{2}$ magmas, in detail there is structure, with anomalous intervals at both the bottom and top of the zone.

Stolper et al. [2004] emphasized that samples from the top $\sim 50 \mathrm{~m}$ of zone 3 (2233-2280 mbsl) are systematically elevated in the concentrations of incompatible elements relative to samples from deeper in zone 3; e.g., $\mathrm{K}_{2} \mathrm{O}$ and $\mathrm{P}_{2} \mathrm{O}_{5}$ concentrations increase abruptly by $\sim 20 \%$ at $2280 \mathrm{mbsl}$, but vary little in samples from the underlying $200 \mathrm{~m}$. They proposed that this difference could be largely explained by a decrease near the top of zone 3 in the degree of partial melting of a source similar to those that produced the lower zone 3 magmas. Figure 7 shows an enlargement of the chemical variations over the depth interval of zone 3. Figure 7a shows that the $\mathrm{MgO}$ contents of the glasses decrease regularly with decreasing depth over most of zone 3 . In order to account for the effects of fractionation, the concentrations of other elements shown in Figure 7 were adjusted to $7 \% \mathrm{MgO}$ using the calculations described in section 8.2.2 (see also the caption to Figure 7). Although $\mathrm{Cl}$ contents adjusted to $7 \% \mathrm{MgO}$ show no systematic variation over the entire depth range of zone 3 (including the upper $50 \mathrm{~m}$; Figure 7d), F content decreases by $\sim 40 \%$ from the base of zone 3 to $\sim 2280 \mathrm{mbsl}$, then increases by $\sim 30 \%$ at $\sim 2280 \mathrm{mbsl}$, and then increase by an additional 5-10\% in the upper $50 \mathrm{~m}$ of zone 3 (Figure 7e). The increase in F at the top of zone 3 is comparable to that observed for other involatile incompatible elements 
(Figures 7f-i). Although the $\mathrm{H}_{2} \mathrm{O}$ contents of glasses in the 2280-2233 mbsl interval are higher than deeper zone 3 glasses, after correction to $7 \% \mathrm{MgO}$ the $\mathrm{H}_{2} \mathrm{O}$ and $\mathrm{S}$ contents are constant over most of zone 3, showing no systematic variations with depth in zone 3 as a whole, at $2280 \mathrm{mbsl}$, or over the 2233-2280 mbsl interval (Figures $7 \mathrm{~b}$ and c).

Based on volatile contents, we are also able to recognize an anomalous interval in the lower $\sim 40 \mathrm{~m}$ of zone 3 (2438-2481 mbsl; see Figure 7). $\mathrm{H}_{2} \mathrm{O}$ and $\mathrm{S}$ concentrations vary by more than a factor of 2 in this interval, in contrast to a total variability of $\sim \pm 10 \%$ at higher levels in zone 3 (after correction for fractionation), and $\mathrm{Cl}$ and $\mathrm{F}$ are both slightly lower in this interval than in immediately overlying samples. Although their correlations with depth in this interval are weak, $\mathrm{H}_{2} \mathrm{O}$ and $\mathrm{S}$ tend to decrease with decreasing depth. With the exception of the hyaloclastite glasses from unit 294 (i.e., samples SR835-11.2 and SR835-17.3 at 2462.3 and $2464.1 \mathrm{mbsl}$, with 9.5-9.6\% MgO), samples from this interval are more fractionated (i.e., have lower $\mathrm{MgO}$ contents) than overlying samples, and their $\mathrm{MgO}$ contents are roughly correlated with the degree of degassing based on S content.

\subsubsection{Zone 4}

Although the upper limits of the distributions of $\mathrm{H}_{2} \mathrm{O}$ and $\mathrm{S}$ contents of zone 4 pillows (all of which are high- $\mathrm{SiO}_{2}$ samples) are similar to most zone 3 pillows (all of which are low$\mathrm{SiO}_{2}$ samples), Figure 2 shows that zone 4 pillows extend to much lower $\mathrm{H}_{2} \mathrm{O}$ and $\mathrm{S}$ contents; $\mathrm{Cl}$ and $\mathrm{F}$ are not depleted in the low- $\mathrm{H}_{2} \mathrm{O}$, low-S zone 4 pillows. A number of pillows (particularly in the $\sim 2600-2750$ and $\sim 2900-3000$ mbsl intervals) are low in $\mathrm{H}_{2} \mathrm{O}$ without showing comparable depletions in S, a feature pointed out by Wallace and Anderson [1998] for some Kilauea glasses and attributed by them to the buffering of S contents by immiscible sulfide liquids; the absence of sulfides in all but the most S-rich high-SiO ${ }_{2}$ glasses (Figure 6b) rules out this explanation for the HSDP2 glasses. As for the interval of variably degassed glasses at the base of zone 3, these observations suggest variability in the processes leading to the occurrence of magmas degassed at low pressures in the relatively deep submarine section. Note that $\mathrm{H}_{2} \mathrm{O}$ and $\mathrm{S}$ (and $\mathrm{Cl}$, although weakly) are positively correlated with $\mathrm{MgO}$ for zone 4 pillows (Figures 9a-c), suggesting a 
connection between degassing and high level fractionation. In contrast, $\mathrm{F}$ is negatively correlated with $\mathrm{MgO}$ for these samples (Figure $9 \mathrm{~d}$ ) and positively correlated with $\mathrm{K}_{2} \mathrm{O}$ (not shown), as expected for an involatile incompatible element and consistent with its not having been lost in significant quantities from these samples by degassing.

Although most of the degassed and partially degassed pillows in zone 4 do not show any systematics with depth, there is a narrow interval (2763-2841 mbsl) over which $\mathrm{H}_{2} \mathrm{O}$ and $\mathrm{S}$ in pillow-rim glasses decrease significantly and systematically with decreasing depth, spanning nearly the entire range in $\mathrm{H}_{2} \mathrm{O}$ and $\mathrm{S}$ contents observed in high- $\mathrm{SiO}_{2}$ pillows throughout the entire core. Figure 8 shows an enlargement of the chemical variations over this depth interval. Because of the close spacing of S measurements (spaced on average $\sim 2 \mathrm{~m}$ ), the trend in this interval is most clearly defined by $\mathrm{S}$ contents, although water shows a similar trend. There are insufficient $\mathrm{Cl}$ and $\mathrm{F}$ data in this interval to determine if these elements show evidence of degassing. There are no indications from the description of the core of any systematic lithological or structural changes in this depth interval. However, the core in this interval is complex, with a hyaloclastite unit sandwiched between the two pillow intervals that define the $\mathrm{S}$ and $\mathrm{H}_{2} \mathrm{O}$ trend and several intrusive units cross-cutting the hyaloclastite and pillows in this interval. Variations in major elements are subtle if present, and the correlation of degassing with $\mathrm{MgO}$ (i.e., with fractionation) is weak in this interval. Nevertheless, the existence of such a coherent trend demonstrates that the factors leading to the eruption of degassed magmas at depth in the submarine section can vary systematically with time and are not random.

\section{The role of water in the fractionation of the high- and $\mathrm{low}_{-} \mathrm{SiO}_{2}$ magma series}

\subsection{Introduction to fractionation trends and MELTS calculations}

In this section, we model the liquid-lines-of-descent of the high- and low-SiO ${ }_{2} \mathrm{HSDP} 2$ magma series. The goals are to establish the conditions of fractionation of magmas from the HSDP2 core, to provide a framework for understanding those aspects of chemical variability in our sample suite related to crystallization, and in particular to understand how the degree of degassing (especially the water content) influences the crystallization sequences and liquid-lines- 
of-descent of the high- and low-SiO magma series. The most reliable approach to determining the liquid-lines-of-descent of the two magma series would be to do crystallization experiments on representative $\mathrm{MgO}$-rich liquids from each series, varying parameters such as $\mathrm{P}_{\text {total, }} \mathrm{p}_{\mathrm{H}_{2} \mathrm{O}}, f \mathrm{O}_{2}$, and cooling rate to simulate the differences between equilibrium and fractional crystallization. This would represent a substantial research program beyond the scope of our study, and in any case, interpolation between the experiments to examine all possible conditions would be problematic. We have chosen the alternative approach of using the MELTS programs and database to simulate the results of crystallization of the high- and low- $\mathrm{SiO}_{2}$ series. Although imperfect in that MELTS has oversimplifications related to the functional forms of its thermochemical models and in the calorimetric and phase equilibrium data used to calibrate it, this approach has been shown to reproduce successfully key features of the phase equilibria of basaltic and peridotitic systems [Ghiorso et al., 1994; Hirschmann et al., 1998], and it has the advantage of being able to explore easily and precisely the effects of changing variables.

Moreover, despite its limitations, it has the advantages of internal thermodynamic consistency, and although it was not calibrated with significant constraints from experiments on Hawaiian magma compositions, the results are based on a data base that applies more generally than to Hawaiian petrogenesis. There have been several previous studies in which MELTS was used to model fractionation of Hawaiian magmas [e.g., Johnson et al., 2002; Davis et al., 2003], but ours is the first for which such an extensive set of glasses has also been analyzed for water, thus allowing a detailed comparison between the calculations and the glass compositions and an evaluation of the influence of water on the observed fractionation trends.

The MELTS calculations were done on three compositions (Table 2), one from the low$\mathrm{SiO}_{2}$ series and two from the high- $\mathrm{SiO}_{2}$ series. The undegassed low- $\mathrm{SiO}_{2}$ composition is based on the average of six undegassed and partially degassed, $\mathrm{MgO}$-rich glasses. The starting composition for the calculations was then obtained by adding equilibrium olivine to this average composition at 1 bar at an $f \mathrm{O}_{2}$ of QFM (based on $\mathrm{Fe}_{2} \mathrm{O}_{3} / \mathrm{FeO}$ ratios of Kilauea glasses [Carmichael, 1991]) in increments of $0.01 \%$ until an $\mathrm{MgO}$ content of $10 \%$ was reached; this 
$\mathrm{MgO}$ content is arbitrary and was chosen simply so as to have the starting composition crystallize significant olivine before reaching saturation with other silicates. At each step, the equilibrium olivine was calculated using an olivine-liquid $\mathrm{K}_{\mathrm{D}, \mathrm{Mg}-\mathrm{Fe}}+2$ of 0.32 , olivine

stoichiometry, and a $\mathrm{Fe}^{+2} / \mathrm{Fe}^{+3}$ ratio in the liquid based on Kress and Carmichael [1991]. Further details of the olivine-addition calculation are given in Table 3 in Stolper et al. [2004]. For the high- $\mathrm{SiO}_{2}$ series, calculations were done on an undegassed composition based on the average of the 10 most magnesian undegassed high- $\mathrm{SiO}_{2}$ glasses (the composition was adjusted to $10 \%$ $\mathrm{MgO}$ by olivine addition as described above) and on the composition of SR0844-16.8, the most magnesian of the degassed high- $\mathrm{SiO}_{2}$ glasses (although to ensure vapor-saturation in the MELTS calculations described below, the water content was arbitrarily set to $0.5 \%$ ).

All calculations were done with MELTS (version 5). Equilibrium melting calculations were performed by going "up-temperature" in $1^{\circ} \mathrm{C}$ increments. Equilibrium melting is identical to equilibrium crystallization, so although crystallization calculations could in principle have been done by incrementing temperature in the "down-temperature" direction, in practice, the calculations are more stable in the up-temperature direction. Fractional crystallization was modeled by a series of $1^{\circ} \mathrm{C}$ down-temperature equilibrium crystallization steps followed by removal of the crystals from the bulk composition; however, the results of equilibrium melting and fractional crystallization are sufficiently similar that we restrict our discussion to the equilibrium results.

\subsection{Fractionation of the low-SiO 2 magma series}

\subsubsection{Degassed low- $\mathrm{SiO}_{2}$ glasses: crystallization at 10 bars}

We consider first the equilibrium liquid-line-of-descent of the model low- $\mathrm{SiO}_{2}$ parental liquid at 10 bars and an $f \mathrm{O}_{2}$ of QFM-2; although this is a relatively low $f \mathrm{O}_{2}$, MELTS calculations are known to require artificially low $\mathrm{fO}_{2} \mathrm{~s}$ to reproduce experimental MORB crystallization trends [Asimow, 2002]. The calculated crystallization sequence is olivine (Fo83.5, note that this is more Fe-rich than the Fo 84.5 calculated at QFM using the olivine-addition procedure described above), followed by plagioclase $\left(\mathrm{An}_{74.3}\right)$ at $7.1 \% \mathrm{MgO}$, and then augite 
$\left(\mathrm{Wo}_{42.1} \mathrm{En}_{47.1} \mathrm{Fs}_{10.9}\right)$ at $6.8 \% \mathrm{MgO}$. Calculations were continued down to a residual liquid with $5.5 \% \mathrm{MgO}$ (i.e., lower than the most evolved of the low- $\mathrm{SiO}_{2}$ degassed glasses), but no other solid phase joins the crystallizing assemblage after augite.

Figures 10a-e compare the liquid-line-of-descent for the 10 bar MELTS calculation to the low- $\mathrm{SiO}_{2}$ degassed glasses (i.e., zone 1 and 2 glasses with $<50 \% \mathrm{SiO}_{2}$ and the glasses from the 1765-1810 mbsl excursion) on $\mathrm{MgO}$ vs. $\mathrm{SiO}_{2}, \mathrm{Al}_{2} \mathrm{O}_{3}, \mathrm{FeO} * \mathrm{CaO}$, and $\mathrm{TiO}_{2}$ variation diagrams. Samples for which we have petrographic data are distinguished on Figure 10 by larger symbols, and their phenocryst/microphenocryst assemblages are indicated by different colors. The entry of each phase into the crystallization sequence is clearly manifested in the calculated liquid-lineof-descent, and the calculated assemblages and glass compositions are consistent with the observed phenocryst/microphenocryst assemblages in the degassed zone 1 and 2 glasses. The crystallization of plagioclase leads to significant decreases in $\mathrm{Al}_{2} \mathrm{O}_{3}$ and increases in $\mathrm{FeO}$ * with decreasing $\mathrm{MgO}$, and the crystallization of augite leads to decreasing $\mathrm{CaO}$ along with increasing $\mathrm{FeO}^{*}$ (the effect of plagioclase on $\mathrm{FeO}^{*}$ is much larger than that of pyroxene). Both pyroxene and plagioclase crystallization diminish the rate of decrease of $\mathrm{MgO}$ with progressive crystallization, so incompatible components such as $\mathrm{TiO}_{2}$ (Figure $10 \mathrm{e}$ ), $\mathrm{Na}_{2} \mathrm{O}$, and $\mathrm{K}_{2} \mathrm{O}$ (not shown) increase more sharply with decreasing $\mathrm{MgO}$ after these phases have joined the crystallization sequence.

Since the bulk composition used to calculate the liquid-line-of-descent has $0.60 \% \mathrm{H}_{2} \mathrm{O}$, (i.e., more than the solubility of water in basaltic liquids at 10 bars), all of the residual liquids are vapor saturated and contain $\sim 0.2 \mathrm{wt} \% \mathrm{H}_{2} \mathrm{O}$, comparable to but somewhat higher than the 0.09$0.15 \% \mathrm{H}_{2} \mathrm{O}$ in the degassed low- $\mathrm{SiO}_{2}$ glasses. Lowering the pressure to 5 bars provides a closer match to the observed water contents (calculated values are $\sim 0.15 \%$ ), but plagioclase appears when the residual liquid has $7.25 \% \mathrm{MgO}$, which is higher than the $\mathrm{MgO}$ content at which plagioclase appears as a microphenocryst and at which the $\mathrm{Al}_{2} \mathrm{O}_{3}$ contents of the glasses decrease with decreasing $\mathrm{MgO}$. Increasing the pressure to 20 bars increases the dissolved water content of the liquid to $\sim 0.3 \% \mathrm{H}_{2} \mathrm{O}$ and delays the crystallization of plagioclase so that it appears when the 
residual liquid has $\sim 7.0 \% \mathrm{MgO}$, which is low relative to that required to satisfy the phenocryst assemblages and the observed trends of the degassed glass compositions. As described below (section 8.2.3), such fine tuning of the free parameters in the MELTS calculations produces slightly better or worse fits, but the key point is that the liquid-line-of-descent and crystallization sequence predicted by MELTS for $\mathrm{p}_{\mathrm{H}_{2} \mathrm{O}} \sim 10$ bars are reasonable matches to the glass compositions and phenocryst/microphenocryst assemblages of the degassed low-SiO 2 HSDP2 glasses.

Note that the glasses from the 1765-1810 mbsl excursion (shown as diamonds in Figures 10a-e) are poorly matched by the calculated 10 bar liquid-line-of-descent of the low-SiO${ }_{2}$ model parental liquid. In particular, as a result of their higher $\mathrm{CaO}$ contents, they define a liquid-lineof-descent that is cpx-saturated at significantly higher $\mathrm{MgO}$ contents than the other HSPD2 samples. This observation that these glass compositions cannot be related by low pressure fractionation to the more abundant low- $\mathrm{SiO}_{2}$ glasses in the core is the basis of the conclusion of Stolper et al. [2004] that they were derived from distinct parental liquids with higher $\mathrm{CaO}$ and $\mathrm{K}_{2} \mathrm{O}$ and lower $\mathrm{FeO} *$ and $\mathrm{Al}_{2} \mathrm{O}_{3}$ than those from which the more typical HSDP2 low-SiO 2 magmas were derived.

\subsubsection{Undegassed and partially degassed low- $\mathrm{SiO}_{2}$ glasses: crystallization at 50 bars}

For comparison with the undegassed low-SiO 2 HSDP2 glasses (all from zones 3 and 4), we calculated the crystallization sequence and liquid-line-of-descent of the model low-SiO 2 parental liquid composition at 50 bars (at an $\mathrm{fO}_{2}$ of QFM-2). Results are shown in Figures 10f-j. The calculated crystallization sequence is olivine (Fo83.6 ; again, Fe-rich relative to the Fo ${ }_{84.5}$ calculated at QFM using the olivine-addition procedure described above), followed by plagioclase $\left(\mathrm{An}_{76.5}\right)$ at $6.7 \% \mathrm{MgO}$, and then augite $\left(\mathrm{Wo}_{43.2} \mathrm{En}_{46.3} \mathrm{Fs}_{10.5}\right)$ at $6.6 \% \mathrm{MgO}$.

Calculations were continued down to a residual liquid with $5.5 \% \mathrm{MgO}$ (i.e., lower than the most evolved of the low-SiO 2 undegassed and partially degassed glasses), but no other solid phase joins the crystallizing assemblage after augite. The water contents of the calculated vaporsaturated residual liquids are $0.47-0.51 \%$ (vs. $0.67 \pm 0.06 \% \mathrm{H}_{2} \mathrm{O}$ for the undegassed low- $\mathrm{SiO}_{2}$ 
glasses with $\geq 7 \% \mathrm{MgO}$ ). Note that the appearance of plagioclase in the 50 bar calculation is delayed relative to that observed in the 5-20 bar calculations both in terms of temperature $\left(1148^{\circ} \mathrm{C}\right.$ at 50 bars vs. $1170^{\circ} \mathrm{C}$ and $1160^{\circ} \mathrm{C}$ at 5 and 20 bars) and the $\mathrm{MgO}$ content of the coexisting liquid (6.7\% $\mathrm{MgO}$ at 50 bars vs. $7.0 \%$ at 20 bars and $7.2 \%$ at 5 bars) as a result of the higher water content. The calculated appearance of augite is also delayed slightly at the higher water contents in the liquids at 50 bars relative to the temperatures and liquid $\mathrm{MgO}$ contents at 520 bars $\left(1146^{\circ} \mathrm{C}\right.$ and $6.6 \% \mathrm{MgO}$ at 50 bars vs. $1153^{\circ} \mathrm{C}$ and $6.8 \% \mathrm{MgO}$ at 20 bars and $1160^{\circ} \mathrm{C}$ and $6.9 \% \mathrm{MgO}$ at 5 bars).

The model liquid-line-of-descent at 50 bars matches well the $\mathrm{MgO}$ vs. $\mathrm{Al}_{2} \mathrm{O}_{3}, \mathrm{FeO}^{*}$, $\mathrm{CaO}$, and $\mathrm{TiO}_{2}$ trends displayed by the low- $\mathrm{SiO}_{2}$ undegassed and partially degassed glasses from zones 3 and 4 (Figures 10f-j). With the exception of the most magnesian of the two olivine+plagioclase-bearing samples, the MELTS trend is also consistent with the observed phenocryst/microphenocryst assemblages. Although the calculations would not predict the more MgO-rich of these two glasses (SR0831-2.3) to be plagioclase-saturated, this sample defines the top of the variably degassed excursion at the base of zone 3 , and its $\mathrm{H}_{2} \mathrm{O}(0.38 \%)$ and $\mathrm{S}(0.06 \%)$ contents are much lower than the typical undegassed samples. Consequently, the liquid-line-ofdescent for this sample would be expected to be intermediate between the 10 and 50 bar calculations shown in Figure 10, and thus the early appearance of plagioclase in this sample (which is in any case rare and close to the lower-size limit for microphenocrysts) relative to the 50 bar calculation is not surprising.

Increasing the pressure to 100 bars increases the water contents of the calculated residual liquids (i.e., up to $\sim 0.76 \%$ ) such that plagioclase crystallization is suppressed to a sufficient extent (i.e., plag-in occurs when the liquid has $6.4 \% \mathrm{MgO}$ ) that the calculated liquid-line-ofdescent is a poor match to the undegassed low- $\mathrm{SiO}_{2}$ glass compositions.

Note that the glasses from the 2233-2280 mbsl excursion (shown as diamonds in Figures 10f-j) do not lie on the model liquid-line-of-descent. In particular, at 7-7.5\% MgO, these glasses have higher $\mathrm{TiO}_{2}$ (Figure 10j) and $\mathrm{Na}_{2} \mathrm{O}$ and $\mathrm{K}_{2} \mathrm{O}$ (not shown) and lower $\mathrm{CaO}$ contents than the 
most abundant zone 3 and zone 4 glasses. Although not shown on Figures 10f-j, a MELTS calculation at 50 bars and QFM-2 on the average composition of the seven glasses from 2260$2280 \mathrm{mbsl}$ with 7-7.5\% $\mathrm{MgO}\left(\sim 0.7 \% \mathrm{H}_{2} \mathrm{O}\right)$ defines a liquid-line-of-descent that passes through the group of $\sim 2233 \mathrm{mbsl}$ glasses at $6.0-6.3 \% \mathrm{MgO}$ for most elements.

\subsubsection{Effects of pressure, $f \mathrm{O}_{2}$, and water content}

Pressure, $\mathrm{fO}_{2}$, and water content all affect the MELTS-calculated liquid-line-of-descent for the low- $\mathrm{SiO}_{2}$ model composition. For example, increasing $f \mathrm{O}_{2}$ to QFM-1 or QFM at 10 bars leads to earlier crystallization of pyroxene (due to enhanced stability of $\mathrm{Fe}^{3+}$-bearing pyroxene components), resulting in decreasing $\mathrm{CaO}$ and increasing $\mathrm{FeO}$ at higher $\mathrm{MgO}(7.12 \% \mathrm{MgO}$ at QFM-1 and 7.52\% MgO at QFM) than for crystallization at QFM-2 (6.86\% MgO). Likewise, as described above, increasing pressure under water-vapor-saturated conditions increases the dissolved water content, strongly suppressing the crystallization of plagioclase [see also Johnson et al., 2002] and slightly suppressing the crystallization of pyroxene. Although these effects are not large, they are systematic and by varying them we can produce better or worse matches to the observed compositional trends of the HSDP2 glasses. We have not mapped out the combinations of parameters that produce a reasonable match to the observed phenocryst/microphenocryst assemblages and glass compositions, primarily because at this level of detail, we do not regard MELTS as sufficiently accurate to provide useful constraints on actual fractionation processes.

One thing that must be emphasized is the importance of vapor-composition in this discussion. In the calculations described above, we assumed $\mathrm{H}_{2} \mathrm{O}$ was the only component in the vapor, and thus under vapor-saturated conditions, total pressure and the partial pressure of water are equal. However, at the range of pressures of these calculations, the effect of pressure is actually quite small (i.e., if we compared the liquid-lines-of-descent of two identical compositions at 10 and 50 bars under vapor-undersaturated conditions, the calculated differences would be unimportant at the level we are considering), so the large effects we observe in our calculations are due to effects of the varying partial pressure of water. Consequently, the 
comparison between the 10 and 50 bar calculations is in essence a comparison between these two partial pressures of water rather than necessarily indicating a difference in total pressure. $\mathrm{CO}_{2}$ is a significant component of the vapor calculated to be in equilibrium with the HSDP2 submarine glasses on eruption; for example, based on their $\mathrm{CO}_{2}$ and $\mathrm{H}_{2} \mathrm{O}$ contents and Newman and Lowenstern [2002], low-SiO 2 HSDP2 pillows would be saturated with vapors containing $~ 30-90$ volume percent $\mathrm{CO}_{2}$, comparable to the range calculated for Loihi and North Arch lavas [Dixon et al., 1997; Dixon and Clague, 2001]. Thus, variations in the partial pressure of water can be readily envisioned in terms of variable $\mathrm{CO}_{2} / \mathrm{H}_{2} \mathrm{O}$ ratios in the coexisting vapor at constant total pressure. On the other hand, if the vapor were $\mathrm{H}_{2} \mathrm{O}$-rich, the differences in partial pressure of water implied by our calculations would signify variable total pressures.

Despite the many degrees of freedom in these calculations of liquid-lines-of-descent of low- $\mathrm{SiO}_{2}$ parent liquids, we conclude that the degassed low- $\mathrm{SiO}_{2}$ glasses are compatible with crystallization at low total pressures and low, roughly constant partial pressures of water $(\sim 10$ bars), such that the water contents of the residual melts are low, and the undegassed low-SiO 2 glasses are compatible with crystallization at higher partial pressures of water ( $\sim 50$ bars $)$, consistent with their relatively high dissolved water contents and the resulting effects on crystallization sequences and liquid-lines-of-descent.

\subsection{Fractionation of the high-SiO ${ }_{2}$ magma series}

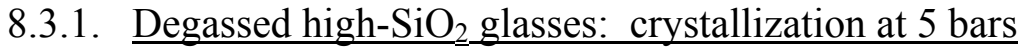

For comparison with the degassed high-SiO $2 \mathrm{HSDP} 2$ glasses, we calculated the crystallization sequence and liquid-line-of-descent of the degassed model high- $\mathrm{SiO}_{2}$ liquid composition at 5 bars and QFM-1. The resulting calculated liquids contain $\sim 0.15 \% \mathrm{H}_{2} \mathrm{O}$, consistent with the water contents measured in the degassed high- $\mathrm{SiO}_{2}$ glasses $(\sim 0.06-0.2 \mathrm{wt}$. \% $\mathrm{H}_{2} \mathrm{O}$ ). Olivine is the liquidus phase $\left(\mathrm{Fo}_{85.0}\right)$, followed by the essentially simultaneous appearance of plagioclase $\left(\mathrm{An}_{72.9}\right)$ and augite $\left(\mathrm{Wo}_{38.1} \mathrm{En}_{49.9} \mathrm{Fs}_{12.0}\right)$ when the residual liquid has $7.0 \% \mathrm{MgO}$ and finally pigeonite $\left(\mathrm{Wo}_{15.4} \mathrm{En}_{70.0} \mathrm{Fs}_{14.7}\right)$ when the liquid has $6.4 \% \mathrm{MgO}$. Calculations were also 
done at QFM-2, but augite crystallization is delayed until the residual liquid has $6.8 \% \mathrm{MgO}$, resulting in a poorer match to the petrographic relationships shown in Figures 10k-o.

Figures 10k-o demonstrate that the calculated liquid-line-of-descent at 5 bars total pressure corresponds well to the observed trends in $\mathrm{Al}_{2} \mathrm{O}_{3}, \mathrm{FeO}^{*}, \mathrm{CaO}$, and $\mathrm{TiO}_{2}$ vs. $\mathrm{MgO}$ of the degassed high- $\mathrm{SiO}_{2}$ glasses and that the near-simultaneous appearance of plagioclase and augite in the MELTS calculation when the liquid has $\sim 7 \% \mathrm{MgO}$ is consistent with most of the phenocryst and microphenocryst assemblages in these glasses. Although the predicted appearance of pigeonite in the calculated liquid-line-of-descent is inconsistent with our petrographic observations, this does not appear to have a significant influence on the model liquid-line-of-descent. Two HSDP2 samples have orthopyroxene phenocrysts [Stolper et al., 2004], but based on its rarity petrographically and its absence in the calculated crystallization sequences, we conclude that orthopyroxene fractionation is not significant in the HSDP2 sample suite.

\subsubsection{Undegassed high- $\mathrm{SiO}_{2}$ glasses: polybaric crystallization}

Isobaric MELTS calculations cannot reproduce the compositional variations observed in the undegassed and partially degassed high- $\mathrm{SiO}_{2}$ glasses. At pressures $<50$ bars, calculated vapor-saturated water contents are lower than the $0.5-0.6 \% \mathrm{H}_{2} \mathrm{O}$ observed in the magnesian glasses with $\geq 7$ wt. $\% \mathrm{MgO}$, but at pressures $\geq 50$ bars, calculated residual liquids contain sufficient water to delay the appearance of plagioclase to such an extent that the liquid-lines-ofdescent (filled small gray circles in Figures 10p-t show such a calculation at 70 bars) match neither the observed trends in glass composition nor the observed phenocryst/microphenocryst assemblages.

It is not surprising that an isobaric vapor-saturated liquid-line-of-descent does not capture the details of the oxide- $\mathrm{MgO}$ trends since, as shown in Figure $9 \mathrm{a}$ for zone 4 pillows, $\mathrm{H}_{2} \mathrm{O}$ contents of high- $\mathrm{SiO}_{2}$ glasses decrease systematically with progressive fractionation for the undegassed and partially degassed high- $\mathrm{SiO}_{2}$ glasses, suggesting that crystallization and degassing occurred concurrently in liquids from which these high- $\mathrm{SiO}_{2}$ glasses formed. In the 
context of our modeling, degassing implies depressurization: for example, if the liquids are assumed to be saturated with pure $\mathrm{H}_{2} \mathrm{O}$ vapor, the observed decrease from $0.5-0.6 \% \mathrm{H}_{2} \mathrm{O}$ to $0.2 \%$ $\mathrm{H}_{2} \mathrm{O}$ as the $\mathrm{MgO}$ content of the liquid decreases from $\sim 7 \%$ to $6 \%$ (Figure $9 \mathrm{a}$ ) implies a pressure decrease from $\sim 70$ bars to $\sim 10$ bars. We have not explored polybaric crystallization paths in detail, but the following T-P path at QFM produces a liquid-line-of-descent that roughly fits the $\mathrm{MgO}-$ oxide trends: $1240 \rightarrow 1170^{\circ} \mathrm{C}(10.0-7.7 \% \mathrm{MgO})$ at 70 bars, followed by $1170 \rightarrow 1150^{\circ} \mathrm{C}$ (7.7-7.3\% MgO) with pressure decreasing at $3 \mathrm{bar} /{ }^{\circ} \mathrm{C}$, and then $1150 \rightarrow 1130^{\circ} \mathrm{C}$ at 10 bars $(7.3-$ $5.8 \% \mathrm{MgO}$ ). This polybaric liquid-line-of-descent is plotted in Figures 10p-t and Figures 9a and d. In this calculation, olivine is the liquidus phase (Fo85.7), followed by augite $\left(\mathrm{Wo}_{39.8} \mathrm{En}_{49.2} \mathrm{Fs}_{11.0}\right)$ when the liquid has $\sim 7.35 \% \mathrm{MgO}\left(1160^{\circ} \mathrm{C}, 40\right.$ bars $)$. With further polybaric cooling, plagioclase $\left(\mathrm{An}_{72.6}\right)$ joins the crystallizing assemblage when the liquid has $\sim 6.8 \% \mathrm{MgO}$ $\left(1152^{\circ} \mathrm{C}, 16\right.$ bars) followed by pigeonite $\left(\mathrm{Wo}_{13.0} \mathrm{En}_{66.2} \mathrm{Fs}_{20.8}\right)$ when the liquid has $\sim 6.5 \% \mathrm{MgO}$ $\left(1148^{\circ} \mathrm{C}, 10 \mathrm{bars}\right)$. This path is only one of a family of possibilities, but it demonstrates that crystallization accompanying progressive depressurization/volatile loss can account in high- $\mathrm{SiO}_{2}$ glasses for the phenocryst/microphenocryst assemblages and the variations in glass composition (including $\mathrm{H}_{2} \mathrm{O}$ content) with fractionation. Moreover, this calculation and the others presented in this section demonstrate clearly that understanding the details of glass composition and phenocryst/microphenocryst assemblages requires understanding of the water contents of magmas and the interplay between crystallization, initial water content, and depressurization and degassing.

\section{Discussion}

\subsection{The connection between degassing, mixing, and fractionation}

A key result is the apparent connection between degassing, fractionation, and mixing in the magmas from which the HSDP2 glasses formed. The connection between degassing and fractionation is emphasized by the following statistics: for the high- $\mathrm{SiO}_{2}$ samples, $\sim 80 \%$ of the glasses with $>7 \% \mathrm{MgO}$ are undegassed, while $\sim 90 \%$ of the glasses with $<7 \% \mathrm{MgO}$ are degassed or partially degassed; for low- $\mathrm{SiO}_{2}$ pillows and hyaloclastites (excluding the excursions 
at $2233-2280$ and $1765-1810 \mathrm{mbsl}$ ), $85 \%$ of the samples with $>7 \% \mathrm{MgO}$ are undegassed, while $67 \%$ of the samples with $<7 \% \mathrm{MgO}$ are degassed. The correlation between degassing and fractionation is well-illustrated by the high- $\mathrm{SiO}_{2}$ pillows from zone 4, in which $\mathrm{MgO}$ contents are positively correlated with $\mathrm{H}_{2} \mathrm{O}$ contents (Figure 9a); likewise, all but 3 of the 18 partially degassed and undegassed glasses from the lower $40 \mathrm{~m}$ of zone 3 define an excellent correlation between $\mathrm{MgO}$ and $\mathrm{S}$ contents. The case for mixing is based largely on the patterns shown in Figures $3 \mathrm{a}$ and $\mathrm{b}$, which demonstrate the complete absence of undegassed glasses with intermediate $\mathrm{SiO}_{2}$ contents but show that all samples with intermediate $\mathrm{SiO}_{2}$ contents are degassed.

Although these three magmatic processes can occur independently, their connection in the petrogenesis of HSDP2 samples may be a natural consequence of processes in high-level magma chambers such as those thought to exist at depths of several kilometers beneath the summits of Hawaiian volcanoes [Ryan et al., 1981; Clague, 1987; Klein et al., 1987]. Undegassed magmas are less dense than degassed magmas at the same degree of fractionation (e.g., at $1255^{\circ} \mathrm{C}$ and 50 bars, the olivine-adjusted low- $\mathrm{SiO}_{2}$ composition in Table 2 has a MELTS-calculated density of $2.68 \mathrm{~g} / \mathrm{cm}^{3}$, but the same composition with $0 \% \mathrm{H}_{2} \mathrm{O}$ a calculated density of $2.73 \mathrm{~g} / \mathrm{cm}^{3}$ under these conditions), so such magmas will tend to rise to the top of a magma chamber after being introduced at its base [Sparks and Huppert, 1984; Clague et al., 1995]. The cool, low-pressure roofs of magma chambers are environments in which magmas can both degas and begin to crystallize; alternatively, magmas from the top of the magma chamber could actually erupt, degas and partially crystallize, and then drain back into the magmatic system [Dixon et al., 1991; Wallace and Anderson, 1998]. In addition to the heat loss that occurs near the top of the magma chamber, degassing raises the liquidus, which would result in crystallization even in the absence of cooling, although MELTS calculations such as those described in section 8 show that this effect is small (e.g., at $1246^{\circ} \mathrm{C}$, the liquidus of the olivineadjusted low- $\mathrm{SiO}_{2}$ composition at 50 bars, decreasing the pressure to 1 bar results in the crystallization of only $0.69 \%$ olivine). The degassed, partially crystallized magmas would be 
denser than the underlying magma (crystallization can either raise or lower the density of the residual liquid, depending on whether pyroxene and/or plagioclase co-crystallize with olivine, but in any case, the effects of volatiles are so great that they dominate the density balance), and thus they would descend back into the magma chamber, mixing with the deeper magmas. When viewed in this way, degassing, fractionation, and mixing are closely related magma chamber processes, driven by the behavior of volatiles (particularly $\mathrm{H}_{2} \mathrm{O}$ ). Similar themes have been developed in several studies of submarine glasses from Kilauea [Clague et al., 1991; Dixon et al., 1991; Clague et al., 1995]. Note, however, that partially degassed low- $\mathrm{SiO}_{2}$ magmas are rare in the HSDP2 section (indeed, they appear to be restricted to the bottom $\sim 40 \mathrm{~m}$ of zone 3 ), consistent with the suggestion of Stolper et al. [2004] that low- $\mathrm{SiO}_{2}$ magmas from the HSDP2 core may have typically bypassed the shallow magma chambers in which these processes would occur. Moreover, as emphasized by Dixon et al. [1991], these processes are only possible in magma chambers within subaerial volcanoes, since otherwise, pressures even at the very tops of the magma chambers would be typically be too high to permit significant degassing of $\mathrm{H}_{2} \mathrm{O}$ and $\mathrm{S}$; this is consistent with our results since the presence of degassed hyaloclastites throughout the core demonstrates that the summit of Mauna Kea was above sea level throughout the time interval sampled by the HSDP2 core.

Another aspect of our data that provides insight into these processes is the presence of $\mathrm{CO}_{2}$ in the partially degassed glasses from zone 4 and the overall correlation between depth and $\mathrm{CO}_{2}$ content in zones 3 and 4 (Figure $2 \mathrm{~b}$ ). The dependence of $\mathrm{CO}_{2}$ content on depth strongly suggests control by solubility; that is, lavas with high enough dissolved volatile components to be supersaturated with respect to vapor upon eruption vesiculate, and the volatile content of the vapor-saturated liquid (now quenched to glass) is a function of the pressure at which this occurs, which is in turn a linear function of the water depth. Because of the much lower solubility of $\mathrm{CO}_{2}$ in basaltic melts relative to water and sulfur at the eruption pressures of the HSDP pillows, the water and sulfur contents of the liquids are usually less affected by this vesiculation compared to the $\mathrm{CO}_{2}$ contents, which will vary roughly linearly with water depth [Dixon and 
Stolper, 1995]. This is illustrated in Figure 11 by the nearly vertical model degassing paths; for example, a liquid such as $\boldsymbol{a}$, with $240 \mathrm{ppm} \mathrm{CO}_{2}$ and $0.6 \% \mathrm{H}_{2} \mathrm{O}$ erupted on the sea floor at 2000 mbsl (200 bars) degasses to $\boldsymbol{b}$; in this process, the dissolved $\mathrm{CO}_{2}$ content decreases to about 80 ppm, but the water content is essentially unchanged; if the same sample erupted at $1000 \mathrm{mbsl}$, it would degas to $c$, and would have a final $\mathrm{CO}_{2}$ content of $\sim 30 \mathrm{ppm}$, but still with $0.6 \%$ water. Only after the sample is brought to pressures less than 40-50 bars do significant amounts of water begin to degas from the sample for this example, at which point the $\mathrm{CO}_{2}$ content would be well below the detection limit. This simple example shows how the dissolved $\mathrm{CO}_{2}$ and $\mathrm{H}_{2} \mathrm{O}$ contents of submarine glasses can provide a quantitative estimate of the depth of eruption, but for the present purpose, there are two apparently contradictory points: If a basaltic liquid degassed at sufficiently low pressure to lose $\mathrm{H}_{2} \mathrm{O}$ and $\mathrm{S}$ (as the degassed and partially degassed samples from zones 3 and 4 have clearly done), their $\mathrm{CO}_{2}$ contents should be effectively zero; yet, the pillows from zones 3 and 4 not only contain $\mathrm{CO}_{2}$, but the dependence of their $\mathrm{CO}_{2}$ contents on depth suggests a solubility control, such that the liquids from which they quenched must have had even higher $\mathrm{CO}_{2}$ contents prior to eruption. So the paradox is how can the degassed and partially degassed samples from deep in the submarine section be depleted in $\mathrm{H}_{2} \mathrm{O}$ and $\mathrm{S}$ yet still have so much dissolved $\mathrm{CO}_{2}$.

Dixon et al. [1991] explained this paradox for submarine glasses from the Puna Ridge on Kilauea as a consequence of mixing of degassed and undegassed magmas in near-surface magma chambers. This is illustrated schematically in Figure 11, where mixing of a degassed magma such as $\boldsymbol{d}$ with undegassed magma such as $\boldsymbol{a}$ can produce magmas such as $\boldsymbol{e}$ with low (i.e., "partially degassed") $\mathrm{H}_{2} \mathrm{O}$ contents, but with $\mathrm{CO}_{2}$ contents high enough such that on eruption at $<200$ bars, they can still be vapor-saturated, leading to $\mathrm{CO}_{2}$ contents in glasses dependent on water depth and controlled by the pressure dependence of $\mathrm{CO}_{2}$ solubility. Note that this resolution of the paradox predicts high $\mathrm{CO}_{2} / \mathrm{H}_{2} \mathrm{O}$ ratios in mixtures of degassed and undegassed magmas, and as shown in Figure 11, most of the partially degassed (and degassed) and fractionated high- $\mathrm{SiO}_{2}$ glasses from zone 4 do indeed have elevated $\mathrm{CO}_{2} / \mathrm{H}_{2} \mathrm{O}$ ratios. 
Other explanations for the presence of $\mathrm{CO}_{2}$ in $\mathrm{H}_{2} \mathrm{O}$ - and $\mathrm{S}$-depleted glasses envision interaction between $\mathrm{CO}_{2}$-rich bubbles and degassed or partially degassed magmas. For example, following a discussion by Anderson et al. [1989] of similar possible phenomena in rhyolitic magma chambers, Dixon et al. [1991] noted that bubbles exsolved from magmas deep within (or even beneath) magma chambers will be rich in $\mathrm{CO}_{2}$, and that if rising bubbles encounter degassed and fractionated magma descended from shallow parts of the magma chamber, they will tend to dissolve; the resulting magmas will typically be fractionated, low in $\mathrm{H}_{2} \mathrm{O}$ and $\mathrm{S}$, but with high $\mathrm{CO}_{2} / \mathrm{H}_{2} \mathrm{O}$ ratios, and depending on the pressure at which the bubbles dissolve, they can have sufficient $\mathrm{CO}_{2}$ to exsolve bubbles on subsequent eruption on the sea floor. A related hypothesis was offered by Hauri [2002] for low $\mathrm{S}$ and high $\mathrm{CO}_{2}$ in melt inclusions in olivines from Hawaiian volcanoes; he proposed that descending degassed magmas in a convecting magma chamber encounter and dissolve $\mathrm{CO}_{2}$-rich bubbles rising from depth, thereby reenriching degassed magmas with $\mathrm{CO}_{2}$ at depths up to $4.5 \mathrm{~km}$. We note that distinguishing the mixing of degassed and undegassed magmas as proposed by Dixon et al. [1991] and illustrated in Figure 11 from hypotheses that involve dissolution of $\mathrm{CO}_{2}$-rich bubbles at depth by degassed magmas [Anderson et al., 1989; Dixon et al., 1991; Hauri, 2002] would be difficult in practice, requiring, for example, distinguishing a steep mixing path such as the one shown in orange in Figure 11 from a near-vertical path for bubble dissolution such as the one shown in red.

\subsection{The potential of $\mathrm{CO}_{2}$ contents of submarine lavas for quantifying subsidence and/or} estimating ages

The increasing $\mathrm{CO}_{2}$ contents of the HSDP2 glasses with depth in zones 3 and 4 are consistent with increasing eruption depth. The pressures at which vapor-saturated liquids quenched to glass and thus their eruption depths can be quantified using the isobars shown in Figure 11 (calculated using Newman and Lowenstern [2002] based on the solubility model of Dixon et al. [1995]). Although there is considerable uncertainty in calculated depths of eruption because of the low $\mathrm{CO}_{2}$ contents of these samples, measurements of this type have potential for addressing significant issues in volcano evolution. For example, the difference between the 
eruption depth calculated from the dissolved volatile contents and the depth of the sample in the core gives the total amount of subsidence of the volcano at the drill site since eruption; with precise age constraints on the samples, the total subsidence vs. age relationship could be differentiated to give the subsidence rate. An alternative application of the model eruption depths based on volatile contents is to calculate ages assuming a constant subsidence rate of $\sim 2.5$ $\mathrm{mm} / \mathrm{y}$. This subsidence rate appears to be a surprisingly robust value based on dateable sediments from the shallowest parts of the HSDP1 core [summarized in DePaolo et al., 1996; Moore et al., 1996], current subsidence rates in Hilo from tide gauge records [Moore et al., 1996], ages of subsided coral reefs around Hawaii [Moore and Campbell, 1987; Ludwig et al., 1991], and the depth of the subaerial-submarine transition in the HSDP2 core (i.e., combining its depth of $1079 \mathrm{mbsl}$ and an age of $410 \mathrm{ka}$ [Sharp and DePaolo, 2004] gives an average subsidence rate of $\sim 2.6 \mathrm{~mm} / \mathrm{y}$ ). Although no substitute for radiometric age determinations, such age estimates are nevertheless useful where, as for the HSDP2 samples, radiometric age determinations are few. Figure 12 shows the average ages of undegassed samples from zone 3 $(502 \pm 80\{1 \sigma\} \mathrm{ka})$ and zone $4(501 \pm 105\{1 \sigma\} \mathrm{ka})$ based on an assumed subsidence rate of 2.5 $\mathrm{mm} / \mathrm{y}$. These estimates agree with the Ar-Ar dates of Sharp and DePaolo [2004] and with the age-depth model of DePaolo and Stolper [1996], which predicts high growth rates and a steep age vs. depth curve in the interval over which our age estimates are calculated (Figure 12). Likewise, the correspondence with the radiometric ages supports the assumed long-term average subsidence rate for the drill site of $\sim 2.5 \mathrm{~mm} / \mathrm{y}$.

\section{3. $\mathrm{CO}_{2}$ in intrusive rocks}

Figure $2 \mathrm{c}$ shows that the maximum $\mathrm{CO}_{2}$ contents of the intrusive glasses are comparable to those of the pillows at similar depths. As a result, pressures of intrusion (i.e., pressures based on the assumption of vapor saturation; see section 9.2) are comparable to the rocks into which they intrude. This suggests that the intrusive units were emplaced near the sea floor since otherwise the pressures and hence the $\mathrm{CO}_{2}$ contents of the intrusive units would have been higher than those of the associated pillows. The maximum excess pressure of the intrusive units relative 
to undegassed pillows and hyaloclastites occurring within $\sim 50 \mathrm{~m}$ of the intrusive is $\sim 100$ bars, corresponding to intrusion at depths of up to $\sim 300 \mathrm{~m}$ beneath the sea floor. Note that this is the maximum excess pressure; most of the intrusive units have calculated pressures of vapor saturation with a few tens of bars of the surrounding pillows, well within the uncertainty of this calculation. These results are consistent with the lobate boundaries of intrusive units into hyaloclastites [Hawaii Scientific Drilling Project, 2001], which suggest intrusion into shallow soft, unconsolidated sediment. Assuming an average growth rate of $\sim 0.01 \mathrm{~m} / \mathrm{y}$ for the volcano at the drill site in zones 3 and 4 [Sharp and DePaolo, 2004], this suggests that the intrusive units were emplaced $<30 \mathrm{ka}$ after the pillows and hyaloclastites they intrude.

We have no explanation for why the intrusive units (nearly all of which are low- $\mathrm{SiO}_{2}$ magmas) should all have been emplaced so shortly after eruption of adjacent pillows (all of which are high- $\mathrm{SiO}_{2}$ magmas). One possibility is that they actually represent "burrowing" flows [Beresford and Cas, 2001]; i.e., surface flows that descend into underlying sediments and fractured pillows due to their higher density, but it is unclear why this process should be limited to low- $\mathrm{SiO}_{2}$ flows. However, regardless of the origin of these intrusive units, it is clear that no deep intrusive units are present among those we have analyzed from the HSDP2 core since magmas intruded at depths of 1-2 km within the volcanic edifice would have $\mathrm{CO}_{2}$ contents hundreds of ppm higher than adjacent pillows, and we can confidently rule out the presence of such $\mathrm{CO}_{2}$-rich glasses among the HSDP2 samples.

\subsection{Volatiles in the sources of HSDP magmas}

\subsubsection{Average volatile contents of HSDP2 glasses}

Limiting ourselves to relatively primitive samples (i.e., $\mathrm{MgO} \geq 7 \%$ ) and excluding samples with high molecular water contents or $\mathrm{Cl}$ contents suggesting hydration or assimilation, we calculated average $\mathrm{H}_{2} \mathrm{O}, \mathrm{S}, \mathrm{Cl}$, and $\mathrm{F}$ contents of the high and low $\mathrm{SiO}_{2} \mathrm{HSDP} 2$ magma types. For the low- $\mathrm{SiO}_{2}$ glasses, the average volatile contents $( \pm 1 \sigma)$ are $0.67 \pm 0.06 \% \mathrm{H}_{2} \mathrm{O}$, $0.104 \pm 0.006 \% \mathrm{~S}, 0.024 \pm 0.002 \% \mathrm{Cl}$, and $0.038 \pm 0.004 \% \mathrm{~F}$; for the high-SiO 2 glasses, the averages are $0.52 \pm 0.05 \% \mathrm{H}_{2} \mathrm{O}, 0.114 \pm 0.012 \% \mathrm{~S}, 0.017 \pm 0.003 \% \mathrm{Cl}$, and $0.032 \pm 0.008 \% \mathrm{~F}$. We 
calculated candidate primary magmas for each suite by incremental addition of equilibrium olivine to the average glass composition until the model olivine-enriched liquid could coexist with Fo90.5 olivine [details of these calculations are given in Stolper et al., 2004]. Volatile contents of the reconstructed parent liquids for the high- and low- $\mathrm{SiO}_{2}$ glasses are listed in Table 3 along with estimates of the volatile contents of primitive magmas from other Hawaiian volcanoes. Note that we cannot rule out the possibility of some $\mathrm{H}_{2} \mathrm{O}$ having been lost by partial degassing from the liquids from which the "undegassed" HSDP2 glasses were quenched and thus that these estimates represent lower limits to the water contents of primitive magmas. We also emphasize that $\mathrm{CO}_{2}$ contents of undegassed HSDP2 magmas cannot be estimated from our results, because the positive correlation of $\mathrm{CO}_{2}$ contents with depth in the core provides strong evidence for loss of $\mathrm{CO}_{2}$ from some unknown higher value during eruption on the sea floor. Finally, given the susceptibility of these glasses to $\mathrm{Cl}$ contamination, the estimated $\mathrm{Cl}$ contents of the primitive magmas should be regarded as upper limits.

\subsubsection{Comparisons to other Hawaiian volcanoes}

Several recent papers have examined covariations of $\mathrm{H}_{2} \mathrm{O}$ with other incompatible elements and with radiogenic isotope ratios in undegassed magmas from mid-ocean ridges and ocean islands [Dixon and Clague, 2001; Dixon et al., 2002; Hauri, 2002; Michael and Kamenetsky, 2002; Wallace, 2002 ]. The principal objectives have been to establish the water contents of their mantle sources and of the various identifiable global mantle components (e.g, DMM, FOZO, HIMU, EM components), and in the case of Hawaiian magmas to characterize the specific source components that have been identified for Hawaii (e.g., KEA, KOO, LOIHI). Important results of these studies have been the inference that the $\mathrm{H}_{2} \mathrm{O} / \mathrm{Ce}$ ratios of mantle components that have been associated with recycled crustal materials (e.g., the Koolau component in Hawaii and the EM components) are low, suggesting the efficient removal of water and perhaps sulfur during the dehydration that accompanies subduction [Dixon and Clague, 2001; Dixon et al., 2002; Hauri, 2002] and the suggestion of a concentric zonation in volatile contents in the Hawaiian plume [Dixon and Clague, 2001]. 
Figure 13 shows NMORB- and primitive-mantle-normalized "spidergrams" for the average high- and low- $\mathrm{SiO}_{2}$ glasses. The strong similarities of minor and trace elements of the two magma series is clear from this comparison [Baker et al., 2004]. The main point in the current context, however, is that the behaviors of $\mathrm{H}_{2} \mathrm{O}, \mathrm{F}$, and $\mathrm{S}$ in the HSDP2 samples are consistent with their known partitioning behavior. For example, $\mathrm{H}_{2} \mathrm{O}$ is elevated $(\sim 4-5 \mathrm{X})$ in the HSDP2 glasses relative to MORB, but its enrichment is comparable to that of Ce, La, and $\mathrm{K}$, which are known to have similar partition coefficients. Likewise, $\mathrm{F}$ is enriched by $\sim 2-3 \mathrm{X}$ relative to $\mathrm{MORB}$, but elements such as $\mathrm{Nd}$ are similarly enriched. $\mathrm{S}$ is a relatively compatible element, and although its behavior depends strongly on $f \mathrm{O}_{2}$, the presence or absence of sulfide, and melt composition, its concentration in the HSDP2 samples is comparable to that of MORBs, consistent with its compatible behavior. The significant elevation in $\mathrm{Cl}$ in the HSDP2 samples relative to MORB contrasts with all other incompatible elements (i.e., not just relative to neighboring elements such as $\mathrm{K}$ on the spider diagram) and strongly supports our previous inference (see section 6.4) that the $\mathrm{Cl}$ contents of HSDP2 glasses are systematically contaminated with sea-water-derived components.

Figures $14 \mathrm{a}-\mathrm{c}$ show $\mathrm{H}_{2} \mathrm{O}$ contents, $\mathrm{H}_{2} \mathrm{O} / \mathrm{K}_{2} \mathrm{O}$ ratios, and $\mathrm{H}_{2} \mathrm{O} / \mathrm{Ce}$ ratios of undegassed HSDP2 glasses as functions of $\mathrm{SiO}_{2}$ content; shown for comparison are data for undegassed glasses from other Hawaiian volcanoes. In order to avoid effects of degassing, only glasses with $\geq 0.09 \% \mathrm{~S}$ are shown. Although it has little impact (especially for the $\mathrm{H}_{2} \mathrm{O} / \mathrm{K}_{2} \mathrm{O}$ and $\mathrm{H}_{2} \mathrm{O} / \mathrm{Ce}$ diagrams), we only show glasses with $\geq 7 \% \mathrm{MgO}$, to avoid possible complexities associated with fractionation.

Figure 14a shows that there is an overall negative correlation between $\mathrm{SiO}_{2}$ and $\mathrm{H}_{2} \mathrm{O}$ contents of Hawaiian magmas; Dixon and Clague [2001] show a similar relationship for Cl. Although dominated by the high $\mathrm{H}_{2} \mathrm{O}$ contents of low- $\mathrm{SiO}_{2}$ alkalic glasses, the HSDP2 glasses extend this same trend to higher $\mathrm{SiO}_{2}$ contents; e.g., the $\mathrm{H}_{2} \mathrm{O}$ contents of the low- $\mathrm{SiO}_{2} \mathrm{HSDP} 2$ glasses are higher than those of the high- $\mathrm{SiO}_{2} \mathrm{HSDP} 2$ glasses. The $\mathrm{H}_{2} \mathrm{O}$ and $\mathrm{SiO}_{2}$ contents of Mauna Loa and Kilauea glasses are similar to those of the high-SiO $2 \mathrm{HSDP}_{2}$ samples and are 
thus compatible with the overall trend. Loihi tholeiitic glasses are an important exception to this pattern: their $\mathrm{H}_{2} \mathrm{O}$ contents are lower than those of the low- $\mathrm{SiO}_{2} \mathrm{HSDP} 2$ glasses at the same $\mathrm{SiO}_{2}$ content.

The anti-correlation between $\mathrm{H}_{2} \mathrm{O}$ and $\mathrm{SiO}_{2}$ in relatively unfractionated Hawaiian glasses probably reflects primarily the lower degrees of melting and higher pressures of melting of alkalic relative to tholeiitic Hawaiian magmas [e.g., Frey et al., 1991; Yang et al., 1996; Feigenson et al., 2003; Huang and Frey, 2003]. It is significant that except for the South Arch samples, the $\mathrm{H}_{2} \mathrm{O} / \mathrm{Ce}$ and $\mathrm{H}_{2} \mathrm{O} / \mathrm{K}_{2} \mathrm{O}$ ratios of the alkalic glasses are in the range of the tholeiitic glasses, suggesting that the sources of alkalic magmas are not generally enriched in water relative to similarly incompatible components. This argues against a significant role for metasomatism by a water-rich melt or vapor in the petrogenesis of these magmas, although a $\mathrm{CO}_{2}$-rich metasomatic agent could account both for their alkalic nature and the lack of waterenrichment [Wyllie, 1988]. Dixon and Clague [2001] emphasized that the South Arch magmas are the exception to this trend in that they have significantly elevated $\mathrm{H}_{2} \mathrm{O} / \mathrm{Ce}$ ratios, and thus enrichment of water relative to similarly incompatible elements in their sources is plausible, perhaps related to metasomatism by water-rich fluids or by mobility of low-degree melts upstream of the Hawaiian plume [Wyllie, 1988; Dixon and Clague, 2001].

Focusing on the $\mathrm{H}_{2} \mathrm{O} / \mathrm{K}_{2} \mathrm{O}$ (Figure 14b) and $\mathrm{H}_{2} \mathrm{O} / \mathrm{Ce}$ (Figure 14c) ratios, there are several points:

- Although the individual samples cover a significant range, the average low-SiO $\mathrm{HSDP}_{2}$ glass is water-enriched relative to elements of similar compatibility (i.e., $\mathrm{K}$ and $\mathrm{Ce}$ ) compared to the average high- $\mathrm{SiO}_{2}$ glass. Although subdued because of the scale, this is also apparent in Figure 13. Note also that the range of the high-SiO${ }_{2} \mathrm{HSDP} 2$ glasses is smaller than that of the low- $\mathrm{SiO}_{2}$ glasses.

- The high-SiO 2 HSDP2 glasses and the low-SiO 2 glasses from the 2233-2280 mbsl excursion are essentially indistinguishable from Kilauea and Mauna Loa glasses in terms of their $\mathrm{H}_{2} \mathrm{O} / \mathrm{K}_{2} \mathrm{O}$ and $\mathrm{H}_{2} \mathrm{O} / \mathrm{Ce}$ ratios. These samples are also comparable to normal Pacific MORB 
[Michael, 1995; Danyushevsky et al., 2000; Dixon et al., 2002] in terms of these ratios. The high-SiO $\mathrm{SHSDP}_{2}$ glasses are also comparable in their $\mathrm{Pb}$ and $\mathrm{Sr}$ isotopes to Kilauea magmas and correspond well to the KEA component defined by Dixon et al. [2001]; according to them, this component dominates among samples produced by high degrees of melting of the plume core.

- The low-SiO $\mathrm{SiSDP}_{2}$ glasses have elevated $\mathrm{H}_{2} \mathrm{O} / \mathrm{K}_{2} \mathrm{O}$ and $\mathrm{H}_{2} \mathrm{O} / \mathrm{Ce}$ ratios relative to tholeiites from other Hawaiian volcanoes. Indeed, only one sample from Loihi [KK16-1 - see Dixon and Clague, 2001] is comparable to the middle-to-upper reaches of the range of ratios in the low-SiO 2 HSDP2 glasses. The upper end of the distribution of $\mathrm{H}_{2} \mathrm{O} / \mathrm{K}_{2} \mathrm{O}$ and $\mathrm{H}_{2} \mathrm{O} / \mathrm{Ce}$ ratios in the low-SiO 2 HSDP2 glasses is comparable to the high ratios observed by Simons et al. [2002] for the Easter-Salas y Gomez seamount chain and Easter microplate in the Pacific and by Dixon et al. [2002] for the Azores platform in the Atlantic. Dixon et al. [2001; 2002] identified this water-rich component with "PHEM" [Farley et al., 1992] or "FOZO" [Hart et al., 1992], a globally consistent end member in ocean island basalt isotopic arrays that is widely interpreted as an entrained lower mantle component. High ${ }^{3} \mathrm{He} /{ }^{4} \mathrm{He}$ ratios are a distinctive feature of the FOZO/PHEM mantle component, and the fact that the low-SiO 2 HSDP 2 magmas generally have elevated ${ }^{3} \mathrm{He} /{ }^{4} \mathrm{He}$ ratios [Kurz et al., 2004] is consistent with the identification of this water-rich component in the HSDP2 samples with a FOZO/PHEM reservoir. Other isotopic characteristics of the low-SiO${ }_{2} \mathrm{HSDP}$ magmas are also consistent with this interpretation [Dixon and Clague, 2001; Dixon et al., 2002].

Several recent publications have emphasized the presence of a water-poor (i.e., relative to Ce and K) and S-poor component in the "enriched" sources of Hawaii and hot spots more generally [Dixon and Clague, 2001; Dixon et al., 2002; Hauri, 2002]. The simplest interpretation of the presence of this component ("KOO" in Hawaii, named for its strong expression in some Koolau samples), with its isotopic evidence of recycled sediment [Eiler et al., 1996; Lassiter and Hauri, 1998; Blichert-Toft et al., 1999], is that it represents subducted material that lost a significant fraction of its volatiles during dehydration associated with 
subduction. Although our data on the HSDP2 samples does not contribute to this debate, since the high- $\mathrm{SiO}_{2}$ glasses have the canonical $\mathrm{H}_{2} \mathrm{O} / \mathrm{Ce}$ and $\mathrm{H}_{2} \mathrm{O} / \mathrm{K}$ ratios and the low- $\mathrm{SiO}_{2}$ glasses are water-rich, the compilation shown in Figure 14 summarizes the data leading to the identification of this volatile-poor component. In particular, the reconstructed primitive Koolau magma based on melt inclusions [Hauri, 2002] has low $\mathrm{H}_{2} \mathrm{O} / \mathrm{K}_{2} \mathrm{O}$ (Figure $14 \mathrm{~b}$ ), $\mathrm{S} / \mathrm{K}_{2} \mathrm{O}$ (Figure $14 \mathrm{e}$ ), and $\mathrm{Cl} / \mathrm{K}$ ratios relative to other Hawaiian magmas. This interpretation is plausible, but we note (as also pointed out by Davis et al. [2003]) that although the depletion in S in the Koolau parent melt reconstructed by Hauri [2002] is very clear in Figure 14e, the lack of such a depletion is equally clear in submarine glasses thought to come from Koolau (i.e., the yellow square in Figure 14d and the yellow triangles in Figures 14d and e [Clague et al., 2002; Shinozaki et al., 2002; Davis et al., 2003]), calling into question the inferred S-depletion of Koolau magmas. Moreover, the depletion in $\mathrm{H}_{2} \mathrm{O}$ of Hauri's [2002] reconstructed Koolau parent melt relative to $\mathrm{K}_{2} \mathrm{O}$ (Figure $14 b)$ is small relative to the significant range observed in undegassed Hawaiian pillow rim glasses (and indeed Loihi pillow glasses extend to greater depletions in $\mathrm{H}_{2} \mathrm{O}$; see below) and in MORB glasses [e.g., Michael, 1995; Dixon et al., 2002; Saal et al., 2002].

It is clear from Figures 14a-c that Loihi tholeiitic glasses are low in $\mathrm{H}_{2} \mathrm{O}$ relative to most other Hawaiian tholeiitic glasses (and even relative to the reconstructed Koolau parent liquid from Hauri [2002]); this is what led Dixon et al. [2001] to propose that these samples contain a significant fraction of dehydrated KOO component. However, the reconstructed parental Loihi tholeiitic magma based on melt inclusions shown in Figure 14b from Hauri [2002] does not show this feature, and indeed, this composition is similar to the average water-rich low-SiO $2 \mathrm{HSDP}_{2}$ glass. Complicating matters further, the reconstructed parental Loihi alkalic magma from Hauri [2002] is water-poor, in agreement with results based on pillow-rim glasses. Finally, the Loihi pillow rim glasses all have elevated S contents compared to other Hawaiian glasses (Figure 14d); i.e., they do not have the low $\mathrm{S}$ contents (or $\mathrm{S} / \mathrm{K}_{2} \mathrm{O}$ ratios; see Figure $14 \mathrm{e}$ ) associated by Hauri [2002] with the effects of subduction on volatile contents of recycled materials. It may be significant that the compositions based on melt inclusions shown in Figure 14 are generally 
higher in $\mathrm{H}_{2} \mathrm{O}$ and $\mathrm{S}$ than the measurements on pillow glasses, but this is not the case for $\mathrm{H}_{2} \mathrm{O}$ in Kilauea glasses or S in Koolau glasses. Although it is tempting to suggest that Loihi pillow glasses could have lost significant volatiles on eruption, Dixon and Clague [2001] make a strong case that this has not occurred at Loihi. We cannot resolve these discrepancies with currently available data, and more work will be required to determine whether the patterns of volatile abundances based on studies of pillow glasses or those based on studies of melt inclusions are more representative.

\section{Conclusions}

(1) $\mathrm{H}_{2} \mathrm{O}, \mathrm{CO}_{2}, \mathrm{~S}, \mathrm{Cl}$, and $\mathrm{F}$ concentrations are reported for 556 glasses from the submarine section of the 1999 phase of HSDP core drilling in Hilo, Hawaii. Samples spanning the highand low-SiO 2 compositional groups and all rock types (pillows, hyaloclastites, massive lavas, intrusive rocks) are included. These samples represent a detailed time sequence spanning $\sim 200 \mathrm{Ky}$, providing the opportunity to study the variation of volatiles in lavas over a considerable fraction of the lifetime of a Hawaiian volcano.

(2) Glasses have been subdivided based on whether they are undegassed $\left(\geq 0.45\right.$ wt. $\% \mathrm{H}_{2} \mathrm{O}, \geq$ 0.09 wt. \% S) or have lost significant volatiles at near-atmospheric pressure. All glasses with intermediate $\mathrm{SiO}_{2}$ contents are degassed, and more extensively degassed glasses tend to be more fractionated, suggesting that most magmas with intermediate $\mathrm{SiO}_{2}$ contents are mixtures of magmas from the high- and $\mathrm{low}-\mathrm{SiO}_{2}$ groups and that mixing occurred in shallow magma chambers in which degassing and crystallization occurred. The connection between mixing, degassing, and fractionation in the glasses could reflect the increase in melt density that accompanies degassing, which could induce overturn and mixing in magma chambers.

(3) Nearly all hyaloclastite glasses are degassed, consistent with their formation from subaerially erupted magmas that fragmented on entering the ocean and were then transported by gravity flows down the flanks of the volcano. Massive lavas are also nearly all degassed, consistent with formation from subaerial flows that penetrated the shoreline and flowed some distance under water. Most pillows are undegassed, suggesting they avoided degassing in low- 
pressure environments, but the shallowest pillows are highly degassed, consistent with subaerial flows that penetrated the shoreline and were emplaced at shallow submarine depths. Some pillow glasses have $\mathrm{H}_{2} \mathrm{O}$ and $\mathrm{S}$ contents indicating degassing but elevated $\mathrm{CO}_{2}$ contents that correlate with depth in the core; these tend to be more fractionated and could have formed by mixing of degassed and undegassed magmas during overturn in high-level magma chambers or by resorption of rising $\mathrm{CO}_{2}$-rich bubbles by degassed magmas. Intrusive glasses are all undegassed and have $\mathrm{CO}_{2}$ contents similar to adjacent pillows, indicating intrusion at shallow levels in the volcanic edifice.

(4) $\mathrm{Cl}$ is weakly correlated with $\mathrm{H}_{2} \mathrm{O}$ and $\mathrm{S}$, suggesting $\mathrm{Cl}$ is lost during low-pressure degassing. However, the data also indicate that most samples have experienced some contamination by sea-water-derived components. F behaves as an involatile incompatible element in these samples.

(5) Fractionation trends can be modeled using the MELTS program, but only if $\mathrm{H}_{2} \mathrm{O}$ contents are included. Degassed glasses require fractionation at $\mathrm{p}_{\mathrm{H}_{2} \mathrm{O}} \approx 5-10$ bars. Undegassed low- $\mathrm{SiO}_{2}$ glasses require fractionation at $\mathrm{p}_{\mathrm{H}_{2} \mathrm{O}} \approx 50$ bars. The liquid-line-of-descent of undegassed and partially degassed high-SiO 2 glasses can be explained by coupled crystallization and degassing (e.g, cooling by $\sim 40^{\circ} \mathrm{C}$ as pressure decreases from 70 bars to 10 bars).

(6) The water depths at which undegassed pillows were erupted can be calculated from their $\mathrm{CO}_{2}$ and $\mathrm{H}_{2} \mathrm{O}$ contents assuming vapor saturation; the difference between this calculated depth and the depth of a sample in the core provides an estimate of the amount of subsidence since eruption. Assuming a subsidence rate of $2.5 \mathrm{~mm} / \mathrm{y}$, the amount of subsidence is consistent with ages of $\sim 500 \mathrm{kyr}$ for samples from the lower $750 \mathrm{~m}$ of the core, in agreement with radiometric ages.

(7) $\mathrm{H}_{2} \mathrm{O}$ contents of undegassed low- $\mathrm{SiO}_{2}$ glasses are systematically higher than those of high$\mathrm{SiO}_{2}$ glasses, and their $\mathrm{H}_{2} \mathrm{O} / \mathrm{K}_{2} \mathrm{O}$ and $\mathrm{H}_{2} \mathrm{O} / \mathrm{Ce}$ ratios are higher than typical for tholeiitic pillow glasses from other Hawaiian volcanoes. However, there are discrepancies in these 
ratios for other volcanoes between results based on studies of pillow glasses and melt inclusions. More work will be required to resolve these discrepancies.

\section{Acknowledgments}

We thank the entire Hawaii Scientific Drilling Project team for their assistance, but in particular Don DePaolo and Don Thomas for their roles in the leadership of the project. Jackie Dixon, Erik Hauri, Peter Michael, and Sally Newman all helped with our compilation of volatile data from other submarine glasses. Ian Hutcheon and Doug Phinney provided assistance with the ion microprobe measurements at Livermore. This work was supported by NSF grants EAR9528594 (Caltech) and EAR-9528534 (University of Hawaii) and by The International

Continental Scientific Drilling Program (ICDP). SOEST contribution number 6354 and Caltech

Division of Geological and Planetary Sciences contribution number 8960.

\section{References}

Anderson, A.T., Jr., S. Newman, S.N. Williams, T.H. Druitt, C. Skirius, and E. Stolper, $\mathrm{H}_{2} \mathrm{O}$, $\mathrm{CO}_{2}, \mathrm{Cl}$ and gas in Plinian and ash-flow Bishop rhyolite, Geology, 17, 221-225, 1989.

Asimow, P.D., Problems with MELTS oxygen fugacity calibration, 2002.

Baker, M.B., E.M. Stolper, C. Seaman, and T. Plank, Trace elements in submarine glasses from the HSDP2 core, $G G G$, (in preparation), 2004.

Beeson, M.H., D.A. Clague, and J.P. Lockwood, Origin and depositional environment of clastic deposits in the Hilo drill hole, Hawaii, J. Geophys. Res., 101, 11,617-11,629, 1996.

Beresford, S.W., and R.A.F. Cas, Komatiitic invasive lava flows, Kambalda, Western Australia, Canad. Mineral., 39, 525-535, 2001.

Blichert-Toft, J., F.A. Frey, and F. Albarède, Hf isotope evidence for pelagic sediments in the source of Hawaiian basalts, Science, 285, 879-882, 1999.

Byers, C., M. Garcia, and D. Muenow, Volatiles in pillow rim glasses from Loihi and Kilauea volcanoes, Geochim. Cosmochim. Acta, 49, 1,887-1,896, 1985.

Carmichael, I.S.E., The redox state of basic and silicic magmas: a reflection of their source regions?, Contrib. Mineral. Petrol., 106, 129-141, 1991.

Clague, D.A., Hawaiian xenolith populations, magma supply rates, and development of magma chambers, Bull. Volcanol., 49, 577-587, 1987.

Clague, D.A., and J.G. Moore, Geology and petrology of Mahukona volcano, Hawaii, Bull. Volcanol., 53, 159-172, 1991.

Clague, D.A., W.S. Weber, and J.E. Dixon, Picritic glasses from Hawaii, Nature, 353, 553-556, 1991.

Clague, D.A., J.G. Moore, J.E. Dixon, and W.B. Friesen, Petrology of submarine lavas from Kilauea's Puna ridge, Hawaii, J. Petrol., 36, 299-349, 1995.

Clague, D.A., A.S. Davis, J.L. Bischoff, J.E. Dixon, and R. Geyer, Lava bubble-wall fragments formed by submarine hydrovolcanic: Explosions on Loihi seamount and Kilauea volcano, Bull. Volcanol., 61, 437-449, 2000a.

Clague, D.A., J.G. Moore, and J.R. Reynolds, Formation of submarine flat-topped volcanic cones in Hawaii, Bull. Volcanol., 62, 214-233, 2000b.

Clague, D.A., J.G. Moore, and A.S. Davis, Volcanic breccia and hyaloclastite in blocks from the Nuuanu and Wailau landslides, Hawaii, in Hawaiian Volcanoes: Deep Underwater 
Perspectives, edited by E. Takahashi, P. Lipman, M. Garcia, J. Naka, and S. Aramaki, pp. 279-296, American Geophysical Union, Washington, D.C., 2002.

Danyushevsky, L.V., S.M. Eggins, T.J. Falloon, and D.M. Christie, $\mathrm{H}_{2} \mathrm{O}$ abundance in depleted to moderately enriched mid-ocean ridge magmas; Part I: Incompatible behaviour, implications for mantle storage, and origin of regional variations, J. Petrol., 41, 1,329$1,364,2000$.

Davis, M.G., M.O. Garcia, and P. Wallace, Volatiles in glasses from Mauna Loa volcano, Hawai'i: Implications for magma degassing and contamination, and growth of Hawaiian volcanoes, Contrib. Mineral. Petrol., 570-591, 2003.

DePaolo, D.J., E. Stolper, and D. Thomas, The Hawaii Scientific Drilling Project: Summary of preliminary results, GSA Today, 6, 1-8, 1996.

DePaolo, D.J., and E.M. Stolper, Models of Hawaiian volcano growth and plume structure: Implications of results from the Hawaii Scientific Drilling Project, J. Geophys. Res., 101, 11,643-11,654, 1996.

Dingwell, D.B., and S.L. Webb, Relaxation in silicate melts, Eur. J. Mineral., 2, 427-449, 1990.

Dixon, J.E., E. Stolper, and J.R. Delaney, Infrared spectroscopic measurements of $\mathrm{CO}_{2}$ and $\mathrm{H}_{2} \mathrm{O}$ in Juan de Fuca ridge basaltic glasses, Earth Planet. Sci. Lett., 63, 4,469-4,475, 1988.

Dixon, J.E., D.A. Clague, and E.M. Stolper, Degassing history of water, sulfur, and carbon in submarine lavas from Kilauea volcano, Hawaii, J. Geol., 99, 371-394, 1991.

Dixon, J.E., and V. Pan, Determination of the molar absorptivity of dissolved carbonate in basanitic glass, Amer. Mineral., 80, 1,339-1,342, 1995.

Dixon, J.E., and E.M. Stolper, An experimental study of water and carbon dioxide solubilities in mid-ocean ridge basaltic liquids. Part II: Applications to degassing, J. Petrol., 36, 1,6331,646, 1995.

Dixon, J.E., E.M. Stolper, and J.R. Holloway, An experimental study of water and carbon dioxide solubilities in mid-ocean ridge basaltic liquids. Part I: Calibration and solubility models, J. Petrol., 36, 1,607-1,631, 1995.

Dixon, J.E., Degassing of alkalic basalts, Amer. Mineral., 82, 368-378, 1997.

Dixon, J.E., D.A. Clague, P. Wallace, and R. Poreda, Volatiles in alkalic basalts from the North Arch volcanic field, Hawaii: Extensive degassing of deep submarine-erupted alkalic series lavas, J. Petrol., 38, 911-939, 1997.

Dixon, J.E., and D.A. Clague, Volatiles in basaltic glasses from Loihi seamount, Hawaii: Evidence for a relatively dry plume component, J. Petrol., 42, 627-654, 2001.

Dixon, J.E., L. Leist, C. Langmuir, and J.-G. Schilling, Recycled dehydrated lithosphere observed in plume-influenced mid-ocean-ridge basalt, Nature, 420, 385-389, 2002.

Eiler, J.M., K.A. Farley, J.W. Valley, A.W. Hofmann, and E.M. Stolper, Oxygen isotope constraints on the sources of Hawaiian volcanism, Earth Planet. Sci. Lett., 144, 453-468, 1996.

Farley, K.A., J.H. Natland, and H. Craig, Binary mixing of enriched and undegassed (primitive?) mantle components (He, Sr, Nd, Pb) in Samoan lavas, Earth Planet. Sci. Lett., 111, 183$199,1992$.

Feigenson, M.D., L.L. Bolge, M.J. Carr, and C.T. Herzberg, REE inverse modeling of HSDP2 basalts: Evidence for multiple sources in the Hawaiian plume, $G G G, 4$, Paper No. 10.1029/2001GC000271, 2003.

Fine, G., and E. Stolper, The speciation of carbon dioxide in sodium aluminosilicate glasses, Contrib. Mineral. Petrol., 91, 105-121, 1985a.

Fine, G.J., and E.M. Stolper, Dissolved carbon dioxide in basaltic glasses: Concentrations and speciation, Earth Planet. Sci. Lett., 76, 263-278, 1985 b.

Frey, F.A., M.O. Garcia, W.S. Wise, A. Kennedy, P. Gurriet, and F. Albarède, The evolution of Mauna Kea volcano, Hawaii: Petrogenesis of tholeiitic and alkalic basalts, J. Geophys. Res., 96, 14,347-14,375, 1991.

Garcia, M.O., D. Muenow, K.E. Aggrey, and J.R. O'Neil, Major element, volatile, and stable isotopic geochemistry of Hawaiian submarine tholeiitic glasses, J. Geophys. Res., 94, 10,525-10,538, 1989. 
Garcia, M.O., B.A. Jorgenson, J.J. Mahoney, E. Ito, and A.J. Irving, An evaluation of temporal geochemical evolution of Loihi summit lavas: Results from Alvin submersible dives, $J$. Geophys. Res., 98, 537-550, 1993.

Garcia, M.O., T.P. Hulsebosch, and J.M. Rhodes, Olivine-rich submarine basalts from the southwest rift zone of Mauna Loa volcano: Implications for magmatic processes and geochemical evolution, in Mauna Loa Revealed: Structure, Composition, History, and Hazards, edited by J.M. Rhodes, and J.P. Lockwood, pp. 219-239, American Geophysical Union, Washington, D.C., 1995.

Garcia, M.O., and M.G. Davis, Submarine growth and internal structure of ocean island volcanoes based on submarine observations of Mauna Loa volcano, Hawaii, Geology, 29, 163-166, 2001.

Ghiorso, M.S., M.M. Hirschmann, and R.O. Sack, New software models thermodynamics of magmatic systems, EOS, 75, 571-576, 1994.

Hart, S.R., E.H. Hauri, L.A. Oschmann, and J.A. Whitehead, Mantle plumes and entrainment: Isotopic evidence, Science, 256, 517-520, 1992.

Hauri, E.H., SIMS analysis of volatiles in silicate glasses, 2: isotopes and abundances in Hawaiian melt inclusions, Chem. Geol., 183, 115-141, 2002.

Hawaii Scientific Drilling Project, Core logs and summarizing data, edited by C. Seaman, M.O. Garcia, and E. Stolper, California Institute of Technology, Pasadena, 2000.

Hawaii Scientific Drilling Project, Deep drilling into a Hawaiian volcano, EOS, 82, 154-155, 2001.

Head, J.W., III, and L. Wilson, Deep submarine pyroclastic eruptions: theory and predicted landforms and deposits, J. Volc. Geotherm. Res., 121, 155-193, 2003.

Hirschmann, M.M., M.S. Ghiorso, P.D. Asimow, L.E. Wasylenki, and E.M. Stolper, Calculation of peridotite melting from thermodynamic models of minerals and melts. I. Methods and comparison to experiments, J. Petrol., 39, 1,091-1,115, 1998.

Hofmann, A.W., Chemical differentiation of the Earth: The relationship between mantle, continental crust, and oceanic crust, Earth Planet. Sci. Lett., 90, 297-314, 1988.

Huang, S., and F.A. Frey, Trace element abundances of Mauna Kea basalt from phase 2 of the Hawaii Scientific Drilling Project: Petrogenetic implications of correlations with major element content and isotopic ratios, GGG, 4, Paper No. 10.1029/2002GC000322, 2003.

Hutcheon, I.D., Description of ion microprobe procedures, 2001.

Jambon, A., B. Deruelle, G. Dreibus, and F. Pineau, Chlorine and bromine abundance in MORB: the contrasting behaviour of the Mid-Atlantic Ridge and East Pacific Rise and implications for chlorine geodynamic cycle, Chem. Geol., 126, 101-117, 1995.

Johnson, K.T.M., J.R. Reynolds, D. Vonderhaar, D.K. Smith, and L.S.L. Kong, Petrological systematics of submarine basalt glasses from the Puna ridge, Hawai' $\mathrm{i}$ : Implications for rift zone plumbing and magmatic processes, in Hawaiian Volcanoes: Deep Underwater Perspectives, edited by E. Takahashi, P. Lipman, M. Garcia, J. Naka, and S. Aramaki, pp. 143-159, American Geophysical Union, Washington, D.C., 2002.

Kazahaya, K., H. Shinohara, and G. Saito, Excessive degassing of Izu-Oshima volcano: magma convection in a conduit, Bull. Volcanol., 56, 207-216, 1994.

Kent, A.J.R., D.A. Clague, M. Honda, E.M. Stolper, I.D. Hutcheon, and M.D. Norman, Widespread assimilation of a seawater-derived component at Loihi seamount, Hawaii, Geochim. Cosmochim. Acta, 63, 2,749-2,761, 1999a.

Kent, A.J.R., M.D. Norman, I.D. Hutcheon, and E.M. Stolper, Assimilation of seawater-derived components in an oceanic volcano: evidence from matrix glasses and glass inclusions from Loihi seamount, Hawaii., Chem. Geol., 156, 299-319, 1999b.

Killingley, J.S., and D.W. Muenow, Volatiles from Hawaiian submarine basalts determined by dynamic high-temperature mass-spectrometry, Geochim. Cosmochim. Acta, 39, 1,4671,473, 1975.

Klein, F.W., R.Y. Koyanagi, J.S. Nakata, and W.R. Tanigawa, The seismicity of Kilauea's magma system, U.S.G.S. Prof. Pap., 1350, 1,019-1,185, 1987. 
Kress, V.C., and I.S.E. Carmichael, The compressibility of silicate liquids containing $\mathrm{Fe}_{2} \mathrm{O}_{3}$ and the effect of composition, temperature, oxygen fugacity and pressure on their redox states, Contrib. Mineral. Petrol., 108, 82-92, 1991.

Kurz, M.D., J. Curtice, and D.E. Lott, III, Rapid helium isotopic variability in Mauna Kea shield lavas from the Hawaiian Scientific Drilling Project, $G G G$, (in press), 2004.

Lassiter, J.C., and E.H. Hauri, Osmium-isotope variations in Hawaiian lavas: Evidence for recycled oceanic lithosphere in the Hawaiian plume, Earth Planet. Sci. Lett., 164, 483496, 1998.

Ludwig, K.R., B.J. Szabo, J.G. Moore, and K.R. Simmons, Crustal subsidence rate off Hawaii determined from ${ }^{234} \mathrm{U} /{ }^{238} \mathrm{U}$ ages of drowned coral reefs, Geology, 19, 171-174, 1991.

Maicher, D., J.D.L. White, and R. Batiza, Sheet hyaloclastite: density-current deposits of quench and bubble-burst fragments from thin, glassy sheet lava flows, Seamount Six, Eastern Pacific Ocean, Mar. Geol., 171, 75-94, 2000.

Mathez, E.A., Sulfur solubility and magmatic sulfides in submarine basalt glass, J. Geophys. Res., 81, 4,269-4,276, 1976.

McDonough, W.F., and S.-S. Sun, The composition of the Earth, Chem. Geol., 120, 223-253, 1995.

Michael, P., Regionally distinctive sources of depleted MORB: Evidence from trace elements and $\mathrm{H}_{2} \mathrm{O}$, Earth Planet. Sci. Lett., 131, 301-320, 1995.

Michael, P.J., The concentration, behavior and storage of $\mathrm{H}_{2} \mathrm{O}$ in the suboceanic upper mantle: Implications for mantle metasomatism, Geochim. Cosmochim. Acta, 52, 555-566, 1988.

Michael, P.J., and J.G. Schilling, Chlorine in mid-ocean ridge magmas: Evidence for assimilation of seawater-influenced components, Geochim. Cosmochim. Acta, 53, 3,1313,143, 1989.

Michael, P.J., and W.C. Cornell, Influence of spreading rate and magma supply on crystallization and assimilation beneath mid-ocean ridges: Evidence from chlorine and major element chemistry of mid-ocean ridge basalts, J. Geophys. Res., 103, 18,325-18,356, 1998.

Michael, P.J., and V.S. Kamenetsky, Low $\mathrm{H}_{2} \mathrm{O}$ in the LOMU source of oceanic magmas: inferences from a South Atlantic glass, Geochim. Cosmochim. Acta, 66, A511, 2002.

Moore, J.G., and B.P. Fabbi, Estimate of juvenile sulfur content of basalt, Contrib. Mineral. Petrol., 33, 118-127, 1971.

Moore, J.G., R.L. Phillips, R.W. Grigg, D.W. Peterson, and D.A. Swanson, Flow of lava into sea, 1969-1971, Kilauea volcano, Hawaii, Bull., Geol. Soc. Am., 84, 537-546, 1973.

Moore, J.G., and J.G. Schilling, Vesicles, water, and sulfur in Reykjanes ridge basalts, Contrib. Mineral. Petrol., 41, 105-118, 1973.

Moore, J.G., D.A. Clague, and W.R. Normark, Diverse basalt types from Loihi seamount, Hawaii, Geology, 10, 88-92, 1982.

Moore, J.G., and J.F. Campbell, Age of tilted reefs, Hawaii, J. Geophys. Res., 92, 2,641-2,646, 1987.

Moore, J.G., D.A. Clague, K.R. Ludwig, and R.K. Mark, Subsidence and volcanism of the Haleakala ridge, Hawaii, J. Volc. Geotherm. Res., 42, 273-284, 1990.

Moore, J.G., and D.A. Clague, Volcano growth and evolution of the island of Hawaii, Bull., Geol. Soc. Am., 104, 1,471-1,484, 1992.

Moore, J.G., B.L. Ingram, K.R. Ludwig, and D.A. Clague, Coral ages and island subsidence, Hilo drill hole, J. Geophys. Res., 101, 11,599-11,605, 1996.

Newman, S., E. Stolper, and R. Stern, $\mathrm{H}_{2} \mathrm{O}$ and $\mathrm{CO}_{2}$ in magmas from the Mariana arc and backarc systems, GGG, 1, Paper No. 1999GC000027, 2000.

Newman, S., and J.B. Lowenstern, VOLATILECALC: A silicate melt- $\mathrm{H}_{2} \mathrm{O}-\mathrm{CO}_{2}$ solution model written in Visual Basic for Excel, Comput. Geosci., 28, 597-604, 2002.

Newman, S., Unpublished back-arc basin glass analyses, 2003.

Olbert, B.H., and R.H. Doremus, Infrared study of soda-lime glass during hydration and dehydration, J. Amer. Ceram. Soc., 66, 163-166, 1983.

Pandya, N., D.W. Muenow, S.K. Sharma, and B.L. Sherriff, The speciation of water in hydrated alkali silicate-glasses, J. Non-Cryst. Solids, 176, 140-146, 1994. 
Pearce, J.A., and I.J. Parkinson, Trace element models for mantle melting: Application to volcanic arc petrogenesis, in Magmatic Processes and Plate Tectonics, edited by H.M. Prichard, T. Alabaster, N.B.W. Harris, and C.R. Neary, pp. 373-403, Geological Society of London, London, 1993.

Reed, B.C., Linear least-squares fits with errors in both coordinates. II: Comments on parameter variances, Amer. J. Phys., 60, 59-62, 1992.

Rhodes, M., and M.J. Vollinger, Composition of basaltic lavas sampled by phase-2 of the Hawaiian Scientific Drilling Project: Geochemical stratigraphy and magma types, $G G G$, (in press), 2004.

Rowe, E.C., and J.-G. Schilling, Fluorine in Iceland and Reykjanes ridge basalts, Nature, 279, 33-37, 1979.

Ryan, M.P., R.Y. Koyanagi, and R.S. Fiske, Modelling the three-dimensional structure of macroscopic magma transport systems: Application to Kilauea volcano, Hawaii, $J$. Geophys. Res., 86, 7,111-7,129, 1981.

Saal, A.E., E.H. Hauri, C.H. Langmuir, and M.R. Perfit, Vapour undersaturation in primitive mid-ocean-ridge basalt and the volatile content of Earth's upper mantle, Nature, 419, 451455, 2002.

Schilling, J.G., M.B. Bergeron, and R. Evans, Halogens in the mantle beneath the North Atlantic, Philos. Trans. R. Soc. London, Ser. A, 297, 147-178, 1980.

Sharp, W.D., B.D. Turrin, P.R. Renne, and M.A. Lanphere, The ${ }^{40} \mathrm{Ar} /{ }^{39} \mathrm{Ar}$ and K/Ar dating of lavas from the Hilo 1-km core hole, Hawaii Scientific Drilling Project, J. Geophys. Res., 101, 11,607-11,616, 1996.

Sharp, W.D., and D.J. DePaolo, Dating of the HSDP2 core, $G G G$, (in preparation), 2004.

Sherman, S.B., M.O. Garcia, and E. Takahashi, Major element geochemistry of glasses in turbidites as source indicators: Implications for the $\mathrm{Nu}$ 'uanu and Wailau giant submarine landslides, in Hawaiian Volcanoes: Deep Underwater Perspectives, edited by E. Takahashi, P. Lipman, M. Garcia, J. Naka, and S. Aramaki, pp. 263-277, American Geophysical Union, Washington, D.C., 2002.

Shinozaki, K., Z.-Y. Ren, and E. Takahashi, Geochemical and petrological characteristics of Nuuanu and Walilau landslide blocks, in Hawaiian Volcanoes: Deep Underwater Perspectives, edited by E. Takahashi, P. Lipman, M. Garcia, J. Naka, and S. Aramaki, pp. 297-310, American Geophysical Union, Washington, D.C., 2002.

Simons, K., J. Dixon, J.G. Schilling, R. Kingsley, and R. Poreda, Volatiles in basaltic glasses from the Easter-Salas y Gomez seamount chain and Easter microplate: Implications for geochemical cycling of volatile elements, $G G G, 3$, Paper No. 10.1029/2002GC000374, 2002.

Smith, T.L., and R. Batiza, New field and laboratory evidence for the origin of hyaloclastite flows on seamount summits, Bull. Volcanol., 51, 96-114, 1989.

Sparks, R.S.J., and H.E. Huppert, Density changes during the fractional crystallization of basaltic magmas: fluid dynamic implications, Contrib. Mineral. Petrol., 85, 300-309, 1984.

Stolper, E., and S. Newman, The role of water in the petrogenesis of Mariana trough magmas, Earth Planet. Sci. Lett., 121, 293-326, 1994.

Stolper, E., M. Garcia, C. Seaman, M.B. Baker, and S. Sherman, Glass in the submarine section of the HSDP2 drill core, Hilo, Hawaii, GGG, (in press), 2004.

Stolper, E.M., and J.R. Holloway, Experimental determination of the solubility of carbon dioxide in molten basalt at low pressure, Earth Planet. Sci. Lett., 87, 397-408, 1988.

Sun, S.-S., and W.F. McDonough, Chemical and isotopic systematics of oceanic basalts: Implications for mantle composition and processes, in Magmatism in the Ocean Basins, edited by A.D. Saunders, and M.J. Norry, pp. 313-345, Geological Society Special Publication No. 42, 1989.

Swanson, D.A., and B.P. Fabbi, Loss of volatiles during fountaining and flowage of basaltic lava at Kilauea volcano, Hawaii, J. Res., U.S.G.S., 1, 649-658, 1973.

Tribble, G.W., Underwater observations of active lava flows from Kilauea volcano, Hawaii, Geology, 19, 633-636, 1991. 
Unni, C.K., and J.G. Schilling, $\mathrm{Cl}$ and $\mathrm{Br}$ degassing by volcanism along Reykjanes ridge and Iceland, Nature, 272, 19-23, 1978.

Viereck, L.G., M.F.J. Flower, J. Hertogen, H.-U. Schmincke, and G.A. Jenner, The genesis and significance of N-MORB sub-types, Contrib. Mineral. Petrol., 102, 112-126, 1989.

Wallace, P.J., and A.T. Anderson, Effects of eruption and lava drainback on the $\mathrm{H}_{2} \mathrm{O}$ contents of basaltic magmas at Kilauea Volcano, Bull. Volcanol., 59, 327-344, 1998.

Wallace, P.J., Volatiles in submarine basaltic glasses from the Northern Kerguelen Plateau (ODP Site 1140): Implications for source region compositions, magmatic processes, and plateau subsidence, J. Petrol., 43, 1,311-1,326, 2002.

Wyllie, P.J., Solidus curves, mantle plumes, and magma generation beneath Hawaii, J. Geophys. Res., 93, 4,171-4,181, 1988.

Yang, H.-J., F.A. Frey, J.M. Rhodes, and M.O. Garcia, Evolution of Mauna Kea volcano: Inferences from lava compositions recovered in the Hawaii Scientific Drilling Project, $J$. Geophys. Res., 101, 11,747-11,767, 1996.

Zhang, Y., E.M. Stolper, and G.J. Wasserburg, Diffusion of water in rhyolitic glasses, Geochim. Cosmochim. Acta, 55, 441-456, 1991.

Zhang, Y., E.M. Stolper, and P.D. Ihinger, Kinetics of the reaction $\mathrm{H}_{2} \mathrm{O}+\mathrm{O}=2 \mathrm{OH}$ in rhyolitic and albitic glasses: Preliminary results, Amer. Mineral., 80, 593-612, 1995.

Zhang, Y.X., Z.J. Xu, and H. Behrens, Hydrous species geospeedometer in rhyolite: Improved calibration and application, Geochim. Cosmochim. Acta, 64, 3,347-3,355, 2000. 


\section{Figure captions}

Figure 1 Comparison of $\mathrm{CO}_{2}$ concentrations in basaltic glasses measured by FTIR and ion microprobe. Open circles are HSDP2 glasses, filled circles are experimentally produced glasses quenched from $\mathrm{CO}_{2}$-saturated basaltic melts, red diamonds are natural Kilauea basaltic glasses; the two Kilauea glasses were analyzed as secondary standards. Error bars represent $1 \sigma$ uncertainties based on replicate FTIR and ion probe measurements and where not shown are smaller than the size of the symbols. The weighted least-squares fit (dashed line) has the equation: FTIR $\mathrm{CO}_{2}=1.136(49)$ (ion probe $\mathrm{CO}_{2}$ ) $-30.742(6.196)$ and was determined using the formulation of Reed [1992] that incorporates errors on both the $\mathrm{x}$ and $\mathrm{y}$ coordinates. Parentheses enclose $1 \sigma$ uncertainties on the slope and y-intercept in terms of the least units cited. The two samples with zero $\mathrm{CO}_{2}$ as determined by FTIR were not included in the fit.

Figure 2 (a) $\mathrm{H}_{2} \mathrm{O}$, (b) $\mathrm{S}$, (c) $\mathrm{CO}_{2}$, (d) $\mathrm{Cl}$, and (e) $\mathrm{F}$ concentrations vs. depth for HSDP2 glasses. Blue symbols are samples with $\mathrm{SiO}_{2}<50 \%$ ("low-SiO ${ }_{2}$ "); pink samples have $\mathrm{SiO}_{2} \geq 50 \%$ ("high- $\mathrm{SiO}_{2}$ "); green symbols are glasses from the 2233-2280 mbsl excursion at the top of zone 3 [Stolper et al., 2004]; cyan symbols are high-CaO- $\mathrm{K}_{2} \mathrm{O}$ glasses from zone 1 [Stolper et al., 2004]. Symbols with orange dots indicate samples designated as altered (see text and Table 1 in Stolper et al. [2004]). Zone boundaries [Stolper et al., 2004] are marked with solid lines and excursion boundaries (see text and Stolper et al. [2004]) are shown with dashed lines except when they coincide with zone boundaries. Error bars in (a) and (c) are $1 \sigma$ based on replicate analyses of each sample. Note that two intrusive glasses (SR944-11.6, SR957-4.1) with $>1.2 \% \mathrm{H}_{2} \mathrm{O}$ are not shown in (a).

Figure 3 (a) $\mathrm{H}_{2} \mathrm{O}$, (b) $\mathrm{S}$, (c) $\mathrm{Cl}$, and (d) $\mathrm{F}$ vs. $\mathrm{SiO}_{2}$ contents for HSDP2 glasses. Symbols as in Figure 2. Red horizontal lines divide undegassed, partially degassed, and degassed samples [see text and Moore and Clague, 1992; Garcia and Davis, 2001; Stolper et al., 2004]. The dashed, black horizontal line in (c) arbitrarily distinguishes "contaminated" samples (> $0.03 \% \mathrm{Cl}$ ). Note that one intrusive glass (SR957-4.1) with $3.85 \% \mathrm{H}_{2} \mathrm{O}$ is not shown in (a).

Figure 4 (a) Speciation of water in HSDP2 glasses based on FTIR measurements. The black curve in all panels is based on experiments on a MORB composition [Dixon et al., 1995]. (a) HSDP2 glasses only. Symbols and error bars as in Figure 2, except all samples (regardless of $\mathrm{MgO}$ content) are filled, and symbols enclosed in red circles are glasses from within $1 \mathrm{~m}$ of an intrusion. Labeled samples with excess molecular water are discussed in the text. (b) Same as (a) but at an expanded scale and other Hawaiian glasses are shown for comparison [Dixon et al., 1997; Dixon and Clague, 2001; Davis et al., 2003]. Where shown, error bars on data points from the literature are from the original sources. (c) Same as (b) but with the scale expanded even further and with water-rich back-arc basin glasses shown for comparison [Stolper and Newman, 1994; Newman et al., 2000; Newman, 2003].

Figure 5 (a) $\mathrm{H}_{2} \mathrm{O}$ vs. $\mathrm{S}$, (b) $\mathrm{H}_{2} \mathrm{O}$ vs. $\mathrm{Cl}$, (c) $\mathrm{H}_{2} \mathrm{O}$ vs, $\mathrm{F}$, (d) $\mathrm{S}$ vs. $\mathrm{Cl}$, (e) F vs. $\mathrm{Cl}$, and (f) $\mathrm{K}_{2} \mathrm{O}$ vs. $\mathrm{Cl}$ for HSDP2 glasses. Symbols as in Figure 2. Dashed, black horizontal lines on figures with $\mathrm{Cl}$ arbitrarily distinguish "contaminated" samples $(>0.03 \% \mathrm{Cl})$. The red lines defining "degassed" samples in (a), (b), and (d) are based on Stolper et al. [2004], Moore and Clague [1992], and Garcia and Davis [2001].

Figure 6 (a) FeO* vs. S in HSDP2 glasses. Symbols as in Figure 2. (b) FeO* vs. S in HSDP2 glasses distinguishing samples without immiscible sulfide bleb (open symbols) from samples with sulfide blebs in matrix glass or in olivine-hosted melt inclusions. The line in each panel is the best fit for sulfide-saturated MORB glasses from Mathez [1976]. 
Figure 7 (a) $\mathrm{MgO}$, (b) $\mathrm{H}_{2} \mathrm{O}$, (c) $\mathrm{S}$, (d) $\mathrm{Cl}$, (e) F, (f) $\mathrm{Na}_{2} \mathrm{O}$, (g) $\mathrm{P}_{2} \mathrm{O}_{5}$, (h) $\mathrm{TiO}_{2}$, and (i) $\mathrm{K}_{2} \mathrm{O}$ vs. depth for zone 3 glasses. Solid vertical lines indicate the upper and lower limits to zone 3 ; dashed vertical lines indicate the limits of the "excursions" at the top and bottom of this zone. Symbols as in Figure 2 except all samples (regardless of $\mathrm{MgO}$ content) are filled. For zone-3 glasses from deeper than $2280 \mathrm{mbsl}$, concentrations in (b)-(i) have been adjusted to $7 \% \mathrm{MgO}$ using the MELTS-calculated liquid-line-of-descent at 50 bars shown in Figures 10f-j. For glasses from the 2233-2280 mbsl excursion, these concentrations were adjusted to $7 \% \mathrm{MgO}$ using a similar calculation for the average glass composition from 2260-2280 mbsl (the two glasses in the 2233-2280 mbsl interval more MgO-rich than this average were projected to $7 \% \mathrm{MgO}$ parallel to the most magnesian portion of the MELTS trend).

Figure 8 (a) $\mathrm{MgO}$, (b) $\mathrm{H}_{2} \mathrm{O}$, (c) $\mathrm{S}$, (d) $\mathrm{Cl}$, and (e) $\mathrm{F}$ vs. depth for zone 4 glasses in the vicinity of the excursion at 2763-2841 mbsl. Dashed vertical lines indicate the limits of the excursion. Symbols as in Figure 2 except all samples (regardless of $\mathrm{MgO}$ content) are filled.

Figure $9 \mathrm{MgO}$ vs. (a) $\mathrm{H}_{2} \mathrm{O}$, (b) $\mathrm{S}$, (c) $\mathrm{Cl}$, and (d) $\mathrm{F}$ for high- $\mathrm{SiO}_{2}$ zone 4 pillows. Panels (a) and (d) also show MELTS-calculated liquid-lines-of-descent for parental high-SiO $\mathrm{S}_{2}$ melt at 70 bars and following a polybaric path from 70 to 10 bars; details of these calculations are described in the text. Other oxides on these liquid-lines-of-descent are shown in Figure 10pt. Note that the calculated liquids are initially (i.e., at 70 bars total pressure, $10 \% \mathrm{MgO}$, $0.563 \% \mathrm{H}_{2} \mathrm{O}$ ) vapor-undersaturated. For the isobaric calculations, the residual liquids become vapor-saturated at $\sim 7.28 \% \mathrm{MgO}$; for the polybaric calculations, the residual liquids become vapor-saturated at $\sim 7.67 \% \mathrm{MgO}$ at a pressure of 67 bars.

Figure 10 (a-e) $\mathrm{MgO}$ vs. $\mathrm{SiO}_{2}, \mathrm{Al}_{2} \mathrm{O}_{3}, \mathrm{FeO} *, \mathrm{CaO}$, and $\mathrm{TiO}_{2}$ for degassed low-SiO $2 \mathrm{HSDP} 2$ glasses compared to a 10 bar, QFM-2 MELTS calculation; (f-j) $\mathrm{MgO}$ vs. $\mathrm{SiO}_{2}, \mathrm{Al}_{2} \mathrm{O}_{3}, \mathrm{FeO}^{*}$, $\mathrm{CaO}$, and $\mathrm{TiO}_{2}$ for undegassed and partially degassed low-SiO $2 \mathrm{HSDP} 2$ glasses compared to a 50 bar, QFM-2 MELTS calculation; (k-o) MgO vs. $\mathrm{SiO}_{2}, \mathrm{Al}_{2} \mathrm{O}_{3}, \mathrm{FeO} *, \mathrm{CaO}$, and $\mathrm{TiO}_{2}$ for degassed high-SiO $\mathrm{SiSD}_{2} \mathrm{HS}$ glasses compared to a 5 bar, QFM-1 MELTS calculation; ( $\mathrm{p}-\mathrm{t}$ ) $\mathrm{MgO}$ vs. $\mathrm{SiO}_{2}, \mathrm{Al}_{2} \mathrm{O}_{3}, \mathrm{FeO} *, \mathrm{CaO}$, and $\mathrm{TiO}_{2}$ for undegassed and partially degassed high- $\mathrm{SiO}_{2}$ HSDP2 glasses compared to a 70 bar MELTS calculation and a polybaric MELTS calculation (both at QFM). The starting compositions for each of the MELTS calculations are described in the text and listed in Table 2. Small symbols (open circles and light blue or light green diamonds) are University of Hawaii glass data [see Stolper et al., 2004]; those open circles in panels (a-e) and (k-o) that contain filled, light-brown circles indicate high CaAl glasses [see Stolper et al., 2004]. The larger, colored symbols are Caltech glass data [see Stolper et al., 2004], where the color indicates the phenocryst/microphenocryst assemblage (see the figure legend and Table 1). Vertical black lines labeled pl-in (plagioclase-in), aug-in (augite-in), pl- \& aug-in, and pig-in (pigeonite-in) indicate the appearances of these phases in the MELTS calculations. In panels (p-t), the phase appearances apply only to the polybaric calculation. MELTS calculations in panels (a-o) are all $\mathrm{H}_{2} \mathrm{O}$-saturated; water contents in the calculated liquid-lines-of-descent are $\sim 0.21 \%$ at 10 bars (a-e), $\sim 0.49 \%$ at 50 bars ( $\mathrm{f}-\mathrm{j}$ ), and $\sim 0.15 \%$ at 5 bars (k-o). The polybaric calculation shown in (p-t) is initially $\mathrm{H}_{2} \mathrm{O}-$ undersaturated, reaching $\mathrm{H}_{2} \mathrm{O}$-saturation at $7.67 \% \mathrm{MgO}$ and $0.59 \% \mathrm{H}_{2} \mathrm{O}$ (at 67 bars).

Figure $11 \mathrm{H}_{2} \mathrm{O}$ (wt. \%) versus $\mathrm{CO}_{2}(\mathrm{ppm})$ in HSDP2 glasses. Symbols as in Figure 2. Solid black curves show solubility of $\mathrm{CO}_{2}+\mathrm{H}_{2} \mathrm{O}$ in basaltic melts at 50, 100, 200, and 300 bars [Newman and Lowenstern, 2002]. Nearly vertical curves are representative open system degassing paths from various initial melt compositions calculated using Newman and Lowenstern [2002]. The orange arrows illustrate how mixing of undegassed melt (a) and degassed melt $(\underline{\mathbf{d}})$ can produce a relatively $\mathrm{H}_{2} \mathrm{O}$-poor mixed liquid (e) with elevated $\mathrm{CO}_{2}$ content. The vertical red arrow illustrates the alternative whereby dissolution of $\mathrm{CO}_{2}$-rich bubbles by convecting degassed liquid can produce $\mathrm{H}_{2} \mathrm{O}$-poor, $\mathrm{CO}_{2}$-rich liquids [Hauri, 2002]. Note that low-MgO, high- $\mathrm{SiO}_{2}$ pillows (open pink symbols) have systematically low 
$\mathrm{H}_{2} \mathrm{O}$ contents and high $\mathrm{CO}_{2} / \mathrm{H}_{2} \mathrm{O}$ ratios, consistent with a connection between degassing, fractionation, and mixing.

Figure 12 Depth vs. age for HSDP samples compared to average "ages" of undegassed zone 3 and zone 4 pillows based on an assumed subsidence rate of $2.5 \mathrm{~mm} / \mathrm{y}$ (see text; uncertainties are $1 \sigma$ of the distributions of calculated ages in each zone). Data for HSDP1 samples are from Moore et al. [1996], Beeson et al. [1996], and Sharp et al. [1996]. HSDP2 data and the dashed best-fit line are from Sharp and DePaolo [2004]. Uncertainties on the literature data are from the original sources. The model curve (solid) is from DePaolo and Stolper [1996]. Zone boundaries are from Stolper et al. [2004].

Figure 13 Spidergrams for average undegassed high- and low-SiO $2 \mathrm{HSDP} 2$ glasses relative to (a) NMORB and (b) primitive mantle. Uncertainties are $1 \sigma$ of the distributions of analyses for the high- and low- $\mathrm{SiO}_{2}$ groups. For the HSDP2 glasses, the $\mathrm{H}_{2} \mathrm{O}, \mathrm{Cl}, \mathrm{F}$, and $\mathrm{S}$ concentrations are from this paper; the $\mathrm{Na}_{2} \mathrm{O}, \mathrm{K}_{2} \mathrm{O}$, and $\mathrm{P}_{2} \mathrm{O}_{5}$ concentrations are from Stolper et al. [2004]; all other concentrations are from Baker et al. [2004]. NMORB normalizing concentrations are from Sun and McDonough [1989], except Cl, F, and S (based on $\mathrm{Cl} / \mathrm{K}=0.01, \mathrm{~F} / \mathrm{P}=0.27$, and $\mathrm{S} / \mathrm{Dy}=225$ from Saal et al. [2002]), $\mathrm{Na}_{2} \mathrm{O}$ (based on Hofmann [1988] and a correction factor of 1.3 between elements with compatibility similar to $\mathrm{Na}$ between the Hofmann and Sun and McDonough compilations), $\mathrm{H}_{2} \mathrm{O}$ (based on the Ce content and assuming $\mathrm{H}_{2} \mathrm{O} / \mathrm{Ce}=180$ [Michael, 1995]), Sc [Pearce and Parkinson, 1993], $\mathrm{Cu}$ [Hofmann, 1988], and Zn [Viereck, 1989]. Primitive mantle normalizing concentrations are from $\mathrm{McD}$ Donough and Sun [1995], except for $\mathrm{H}_{2} \mathrm{O}, \mathrm{Cl}$, and $\mathrm{F}$, which were calculated from $\mathrm{H}_{2} \mathrm{O} / \mathrm{Ce}, \mathrm{Cl} / \mathrm{K}$, and $\mathrm{F} / \mathrm{P}$ ratios as described for $\mathrm{NMORB}$.

Figure $14 \mathrm{SiO}_{2}$ vs. (a) $\mathrm{H}_{2} \mathrm{O}$, (b) $\mathrm{H}_{2} \mathrm{O} / \mathrm{K}_{2} \mathrm{O}$, (c) $\mathrm{H}_{2} \mathrm{O} / \mathrm{Ce}$, (d) $\mathrm{S}$, and (e) $\mathrm{S} / \mathrm{K}_{2} \mathrm{O}$ for HSDP2 glasses and glasses from other Hawaiian volcanoes. Tholeiitic glasses are shown as circles; alkalic glasses are shown as squares with crosses. HSDP2 glass data are from this work. Data for glasses from other volcanoes are from the literature [Moore et al., 1982; Byers et al., 1985; Garcia et al., 1989; Moore et al., 1990; Clague and Moore, 1991; Clague et al., 1991; Moore and Clague, 1992; Garcia et al., 1993; Garcia et al., 1995; Dixon et al., 1997; Clague et al., 2000a; Dixon and Clague, 2001; Clague et al., 2002; Johnson et al., 2002; Shinozaki et al., 2002; Davis et al., 2003]. All samples shown (except from Kohala) have $\mathrm{MgO} \geq 7 \%$.

Glasses shown in (a)-(c) are undegassed based on their sulfur contents (i.e., $\mathrm{S} \geq 0.09 \%$ ); for North Arch samples, only those that experienced $<20 \%$ degassing are shown [Dixon et al., 1997]. All glasses with $\mathrm{MgO} \geq 7 \%$ are shown in (d) and (e), regardless of the extent of degassing. Averages and $1 \sigma$ error bars for the HSDP2 glasses are based on all undegassed glasses with $\mathrm{MgO} \geq 7 \%$. Averages or typical undegassed values for several volcanoes are shown as large, filled squares [Clague et al., 1995; Hauri, 2002; Davis et al., 2003]. The Hauri [2002] averages are labeled with an " $H$ ", and the Davis et al. [2003] typical undegassed values are labeled with a "D". The $\mathrm{SiO}_{2}$ contents and ranges (indicated by the error bars) plotted for these averages or typical values are based on the data compilation in Stolper et al. [2004]. The error bars in the "y direction" on the typical undegassed values from Davis et al. [2003] indicate the range of values given by them. The red horizontal lines in (d) divide undegassed, partially degassed, and degassed samples [see text and Moore and Clague, 1992; Garcia and Davis, 2001; Stolper et al., 2004]. The typical $\mathrm{H}_{2} \mathrm{O} / \mathrm{K}_{2} \mathrm{O}$ ratio of 1.3 for Kilauea [Wallace and Anderson, 1998] is shown in (b) for reference. Ranges $( \pm 1 \sigma)$ of $\mathrm{H}_{2} \mathrm{O} / \mathrm{K}_{2} \mathrm{O}$ and $\mathrm{H}_{2} \mathrm{O} / \mathrm{Ce}$ of for Pacific MORB based on Michael [1995] and Danyushevsky et al. [2000] are shown in (b) and (c) for reference (the $\mathrm{SiO}_{2}$ contents of these ranges are arbitrary). 
Table 1 Phenocrysts and microphenocrysts in glasses from the Caltech reference suite.

\begin{tabular}{|c|c|c|c|c|c|c|c|c|}
\hline \multirow{2}{*}{$\begin{array}{c}\text { Sample \# } \\
\text { SR471-1.1 }\end{array}$} & \multirow{2}{*}{$\frac{\text { type }}{\mathrm{h}}$} & \multirow{2}{*}{$\frac{\text { depth (mbsl) }}{1119.8}$} & \multirow[t]{2}{*}{$\begin{array}{l}\text { Phenocrysts } \\
(>0.5 \mathrm{~mm})\end{array}$} & \multicolumn{3}{|c|}{$\begin{array}{c}\text { Microphenocrysts } \\
(0.05-0.5 \mathrm{~mm})\end{array}$} & & \multirow{2}{*}{$\begin{array}{c}\begin{array}{c}\text { Vesicles } \\
\text { volume \% }\end{array} \\
\text { Š2 }\end{array}$} \\
\hline & & & & ol [sp] & plag & $\mathrm{cpx}$ & & \\
\hline SR485-0.9 & $\mathrm{h}$ & 1138.7 & ol [sp] & ol [sp] & plag & $\mathrm{cpx}$ & & Š2 \\
\hline SR495-0.9 & $\mathrm{h}$ & 1234.5 & ol [sp] & ol [sp] & plag & $\operatorname{cpx}$ & & $2-5$ \\
\hline SR508-8.6 & $\mathrm{h}$ & 1283.7 & & ol [sp] & r plag & & $\mathrm{sp}$ & Š2 \\
\hline SR523 & $\mathrm{h}$ & 1328.3 & & ol [sp] & plag & $\mathrm{cpx}$ & & Š2 \\
\hline SR544-5.3 & $\mathrm{h}$ & 1391.2 & & ol [sp] & vr plag & & & $2-5$ \\
\hline SR561-3.3 & $\mathrm{h}$ & 1436.9 & & ol [sp] & plag & & & Š2 \\
\hline SR595-6.4 & $\mathrm{h}$ & 1523.5 & & ol [sp] & plag & $\mathrm{rcpx}$ & & Š2 \\
\hline SR646/647 & $\mathrm{h}$ & 1653.2 & & ol [sp] & plag & $\mathrm{cpx}$ & & Š2 \\
\hline SR658-0.9 & $\mathrm{h}$ & 1685.8 & ol [sp] & ol [sp] & r plag & $\mathrm{rcpx}$ & & Š2 \\
\hline SR675-8.8 & $\mathrm{h}$ & 1739.4 & & ol [sp] & plag & $\mathrm{cpx}$ & & Š2 \\
\hline SR684-8.95 & $\mathrm{h}$ & 1766.5 & & ol & & $\mathrm{cpx}$ & & - \\
\hline SR686-5.1 & $\mathrm{h}$ & 1771.5 & & ol & & $\mathrm{cpx}$ & & $2-5$ \\
\hline SR689-2.2 & $\mathrm{h}$ & 1779.4 & & ol [sp] & & $\mathrm{cpx}$ & $\mathrm{sp}$ & $2-5$ \\
\hline SR694-4.9 & $\mathrm{m}$ & 1793 & ol [sp] & ol [sp] & plag & $\mathrm{cpx}$ & & Š2 \\
\hline SR696-8.4 & $\mathrm{h}$ & 1797.3 & & & & & & - \\
\hline SR697-8.1 & $\mathrm{h}$ & 1800.1 & ol [sp] & ol & r plag & $\operatorname{cpx}$ & & $2-5$ \\
\hline SR707-11.4 & $\mathrm{h}$ & 1837.7 & & ol [sp] & plag & $\operatorname{cpx}$ & & Š2 \\
\hline SR716-2.9 & $\mathrm{h}$ & 1890.7 & & ol & plag & $\mathrm{cpx}$ & & Š2 \\
\hline SR724-9.6 & $\mathrm{h}$ & 1938.3 & & ol & plag & $\mathrm{cpx}$ & & Š2 \\
\hline SR734-6.3 & $\mathrm{p}$ & 1987.8 & ol & ol [sp] & plag & $\mathrm{cpx}$ & & Š2 \\
\hline SR740-8.6 & $p$ & 2003 & & ol [sp] & plag & $\mathrm{rcpx}$ & & Š2 \\
\hline SR747-14.2 & $p$ & 2045.7 & & ol [sp] & plag & $r \mathrm{cpx}$ & & Š2 \\
\hline SR754-9.9 & $p$ & 2087 & & ol [sp] & & & $\mathrm{sp}$ & Š2 \\
\hline SR763-14.9 & $p$ & 2131.4 & & ol [sp] & vr plag & & & Š2 \\
\hline SR770-2.2 & $\mathrm{h}$ & 2167.1 & & ol [sp] & plag & $\mathrm{cpx}$ & & Š2 \\
\hline SR771-7.5 & $\mathrm{h}$ & 2175.3 & & ol & plag & $\mathrm{cpx}$ & & Š2 \\
\hline SR774-0.6 & $\mathrm{h}$ & 2190.6 & ol [sp] & ol [sp] & plag & $\mathrm{cpx}$ & & Š2 \\
\hline SR780-20.8 & $\mathrm{p}$ & 2236 & & ol [sp] & plag & $\operatorname{cpx}$ & & Š2 \\
\hline SR792-6.2 & $p$ & 2285.1 & & ol [sp] & & & & Š2 \\
\hline SR807-3.7 & $\mathrm{p}$ & 2340.5 & & ol [sp] & & & & Š2 \\
\hline SR822-3.4 & $p$ & 2382.5 & & ol [sp] & & & & $5-10$ \\
\hline SR831-2.3 & $p$ & 2438.4 & & ol [sp] & r plag & & & Š2 \\
\hline SR837-21.1 & $p$ & 2477.8 & & ol [sp] & & & & Š2 \\
\hline SR839-5.5 & $\mathrm{h}$ & 2486.2 & & ol & plag & $\mathrm{cpx}$ & & Š2 \\
\hline SR848-12.0 & $\mathrm{h}$ & 2540.4 & & ol [sp] & plag & $\mathrm{cpx}$ & & $5-10$ \\
\hline SR855-0.6 & $\mathrm{h}$ & 2581.1 & & ol & plag & $\mathrm{cpx}$ & $\mathrm{sp}$ & Š2 \\
\hline SR858-4.1 & i & 2600.5 & & ol [sp] & vr plag** & & & $5-10$ \\
\hline SR859-0.8 & i & 2605.3 & & ol [sp] & & & & $5-10$ \\
\hline SR859-1.0 & $p$ & 2605.3 & & ol & plag & $\mathrm{cpx}$ & & Š2 \\
\hline SR866-5.3 & $p$ & 2639.6 & & ol [sp] & & $r \operatorname{cpx}$ & & Š2 \\
\hline SR883-0.3 & $\mathrm{p}$ & 2685.4 & & ol [sp] & r plag & $\mathrm{cpx}$ & & Š2 \\
\hline SR892-13.8 & $\mathrm{h}$ & 2735.7 & & ol [sp] & & & & Š2 \\
\hline SR907-2.8 & $\mathrm{p}$ & 2789.4 & & ol & plag & $\mathrm{cpx}$ & & Š2 \\
\hline SR916-7.2 & $p$ & 2838.6 & & ol [sp] & plag* $^{*}$ & $\mathrm{cpx}^{*}$ & & $2-5$ \\
\hline SR926-2.3 & $\mathrm{h}$ & 2888.3 & & ol [sp] & vr plag & $\mathrm{rcpx}$ & & $2-5$ \\
\hline SR933-4.9 & $\mathrm{p}$ & 2930.5 & ol [sp] & ol [sp] & plag & $\mathrm{cpx}$ & & Š2 \\
\hline SR944-11.3 & $\mathrm{i}$ & 2979.7 & ol [sp] & ol [sp] & & & & $2-5$ \\
\hline SR947-6.1 & $p$ & 2987.3 & ol [sp] & ol [sp] & plag & $\mathrm{cpx}$ & $\mathrm{sp}$ & Š2 \\
\hline SR949-8.2 & $\mathrm{i}$ & 2993.7 & ol [sp] & ol [sp] & vr plag & & & Š2 \\
\hline SR961-4.1 & $p$ & 3037.5 & ol [sp] & ol [sp] & & & $\mathrm{sp}$ & $2-5$ \\
\hline SR970-3.0 & $p$ & 3078.1 & ol [sp] & ol [sp] & & vr cpx & & $2-5$ \\
\hline SR970-6.2 & $\mathrm{i}$ & 3079 & & ol [sp] & & & & Š2 \\
\hline SR975-0.5 & $p$ & 3088.3 & & ol [sp] & & & & Š2 \\
\hline SR975-2.6 & $p$ & 3088.9 & ol [sp] & ol [sp] & & $\mathrm{cpx}$ & & Š2 \\
\hline SR979-1.3 & $p$ & 3095.2 & & ol [sp] & plag* & $\mathrm{cpx}^{*}$ & & Š2 \\
\hline
\end{tabular}

Abbreviations: ol = olivine, $\mathrm{plag}=$ plagioclase, $\mathrm{cpx}=$ clinopyroxene, $\mathrm{sp}=$ spinel, $[\mathrm{sp}]=$ spinel present as an inclusion, $\mathrm{r}=\mathrm{rare}, \mathrm{vr}=\mathrm{very}$ rare, $\mathrm{h}=$ hyaloclastite, $\mathrm{i}=$ intrusive, $\mathrm{m}=$ massive, $\mathrm{p}=$ pillow

${ }^{*}=$ only present in one chip (out of the five in mount SR916-7.2 and out of the six in mount SR979-1.3); the composition of the glass in the ol+plag+cpx-bearing chip in SR979-1.3 is more evolved than the glasses in the other chips in the same mount [see Table 1,

2004]; the ol+plag+cpx-bearing chip in SR916-7.2 was not analyzed.

${ }^{* *}=$ located in one small circular area at the edge of one chip

Vesicle volume \% estimated visually; three ranges: Š2\%, $>2 \%$ and Š $5 \%$, and $>5 \%$ and Š $10 \%$.

Note that the presence/absence of phases is based on examination of small glass chips; small surface areas precluded point counting. Immiscible sulfide blebs were not observed in any of the CIT glass samples; sulfide blebs were observed in the matrix glass in UH samples SR0913-11.8, SR0914-10.5, SR0916-7.4, SR0967-2.0; UH samples SR0969-11.3 and SR0965-1.4 had sulfide blebs in olivine-hosted melt inclusions. 
Table 2 Compositions used in MELTS calculations.

\begin{tabular}{|c|c|c|c|c|c|c|c|c|c|c|c|}
\hline & $\mathrm{SiO}_{2}$ & $\mathrm{TiO}_{2}$ & $\mathrm{Al}_{2} \mathrm{O}_{3}$ & $\mathrm{FeO}^{*}$ & $\mathrm{MnO}$ & $\mathrm{MgO}$ & $\mathrm{CaO}$ & $\mathrm{Na}_{2} \mathrm{O}$ & $\mathrm{K}_{2} \mathrm{O}$ & $\mathrm{P}_{2} \mathrm{O}_{5}$ & $\mathrm{H}_{2} \mathrm{O}$ \\
\hline Low-SiO ${ }^{1}$ & 48.47 & 2.52 & 13.48 & 11.79 & 0.17 & 9.06 & $\overline{10.98}$ & 2.34 & 0.368 & 0.202 & $0 . \overline{620}$ \\
\hline oliv-corrected ${ }^{2}$ & 48.24 & 2.45 & 13.12 & 11.88 & 0.17 & 10.00 & 10.70 & 2.28 & 0.358 & 0.197 & 0.604 \\
\hline High-SiO $_{2}$ degassed $^{3}$ & 50.42 & 2.12 & 12.34 & 11.44 & 0.17 & 10.84 & 10.16 & 1.99 & 0.310 & 0.180 & 0.500 \\
\hline High-SiO, undegassed ${ }^{4}$ & 51.30 & 2.34 & 13.07 & 10.24 & 0.18 & 8.01 & 11.24 & 2.14 & 0.373 & 0.197 & 0.595 \\
\hline oliv-corrected ${ }^{5}$ & 50.69 & 2.22 & 12.37 & 10.45 & 0.17 & 10.00 & 10.65 & 2.02 & 0.353 & 0.186 & 0.563 \\
\hline
\end{tabular}

'The low-SiO ${ }_{2}$ composition represents the mean of SR0818-3.4, SR0823-17.5, SR0828-3.0, SR0828-13.9, SR0835-11.2, SR0835-17.3; MnO had not been measured on any of these samples (Univ. of Hawaii probe data) - the MnO value is the mean of the 13 undegassed and partially degassed low-SiO samples (the Caltech probe analyses); the $\mathrm{H}_{2} \mathrm{O}$ content is from sample SR0828-13.9, the only one of the six samples with a measured water content.

${ }^{2}$ The olivine-corrected composition was calculated by repeatedly adding $0.01 \%$ equilibrium olivine to the low-SiO ${ }_{2}$ liquid composition until the $\mathrm{MgO}$ content reached 10.00 wt. \%; the final ratio of initial liquid mass to initial liquid plus added olivine is 0.9736 . More details of the olivine-addition calculations are given in Stolper et al. [2003].

${ }^{3}$ The high- $\mathrm{SiO}_{2}$ composition used to model the degassed liquid line of descent is SR0844-16.8; the composition was not olivine-corrected since its MgO content is $>10$ wt. $\%$

${ }^{4}$ The high-SiO composition used to model the undegassed liquid line of descent is the mean of 10 samples from zone 4 [Stolper et al. , 2003]: SR0957-5.0, SR0958-5.6, SR0959-4.2, SR0959-7.9, SR0959-14.9, SR0960-4.4, SR0961-4.1, SR0961-4.2, SR0963-10.1, SR0963-17.0; MnO was only measured on SR0961-4.1; the mean water content is based on values from SR0959-14.9, SR0961-4.1, SR0961-4.2, SR0963-17.0.

${ }^{5}$ The olivine-corrected high-SiO${ }_{2}$ composition was calculated as described in footnote 2 ; the ratio of initial liquid to initial liquid plus added olivine is 0.9466 . 
Table 3 Estimates of volatile contents (wt. \%) of primitive Hawaiian magmas.

\begin{tabular}{|c|c|c|c|c|c|}
\hline source & $\mathrm{H}_{2} \mathrm{O}$ & $\bar{S}$ & $\mathrm{Cl}$ & $\bar{F}$ & notes \\
\hline \multicolumn{6}{|c|}{ Mauna Kea } \\
\hline high- $\mathrm{SiO}_{2}$ parent (this work) & $0.40(0.04)$ & $0.088(0.009)$ & $0.013(0.003)$ & $0.025(0.006)$ & \multirow{3}{*}{$\begin{array}{l}\text { average of } 33 \text { glasses, corrected to equilibrium with Fo } 90.5 \text { olivine } \\
\text { average of } 70 \text { glasses, corrected to equilibrium with Fo } 90.5 \text { olivine } \\
\text { corrected to } \mathrm{mg} \#=0.72\end{array}$} \\
\hline low- $\mathrm{SiO}_{2}$ parent (this work) & $0.51(0.05)$ & $0.079(0.005)$ & $0.018(0.002)$ & $0.029(0.003)$ & \\
\hline Hauri [2002] & 0.36 & 0.12 & 0.009 & 0.045 & \\
\hline \multicolumn{6}{|r|}{ 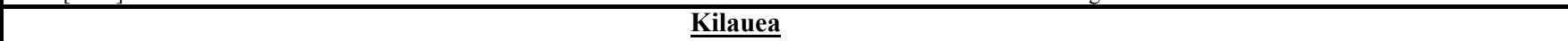 } \\
\hline Clague et al. [1995] & 0.37 & 0.1 & 0.01 & & corrected to equilibrium with Fo90.7 olivine \\
\hline Davis et al. [2003] & $0.43-0.58$ & $0.09-0.10$ & $\sim 0.01$ & $\sim 0.03$ & corrected to $16 \% \mathrm{MgO}$ \\
\hline Hauri [2002] & 0.40 & 0.12 & 0.009 & 0.043 & corrected to $\mathrm{mg} \#=0.72$ \\
\hline \multicolumn{6}{|c|}{$\underline{\underline{\text { Koolau }}}$} \\
\hline Hauri [2002] & 0.40 & 0.040 & 0.003 & 0.050 & corrected to $\mathrm{mg} \#=0.72$ \\
\hline \multicolumn{6}{|c|}{ Loihi } \\
\hline Davis et al. [2003] & $0.33-0.38$ & $0.062-0.132$ & $0 . \overline{013-0.022}$ & $0.03-0.04$ & corrected to $16 \% \mathrm{MgO}$ \\
\hline Hauri [2002] -- tholeiitic & 0.48 & 0.13 & 0.018 & 0.045 & corrected to $\mathrm{mg} \#=0.72$ \\
\hline Hauri [2002] -- alkalic & 0.60 & 0.16 & 0.030 & 0.054 & corrected to $\mathrm{mg} \#=0.72$ \\
\hline \multicolumn{6}{|c|}{ Mauna Loa } \\
\hline Davis et al. [2003] & $0.30-0.37$ & $0.086-0.116$ & $0.0095-0.0105$ & $0.027-0.033$ & corrected to $16 \% \mathrm{MgO}$ \\
\hline Hauri [2002] & 0.36 & 0.12 & 0.008 & 0.038 & corrected to $\mathrm{mg} \#=0.72$ \\
\hline \multicolumn{6}{|c|}{ North Arch } \\
\hline Dixon et al. [1997] -- alkali olivine basalt & $0.51-0.78$ & & $0.03-0.04$ & & corrected to equilibrium with Fo91 olivine \\
\hline Dixon et al. [1997] -- nephelinite & $1.4-2.0$ & & $0.08-0.11$ & & corrected to equilibrium with Fo91 olivine \\
\hline
\end{tabular}




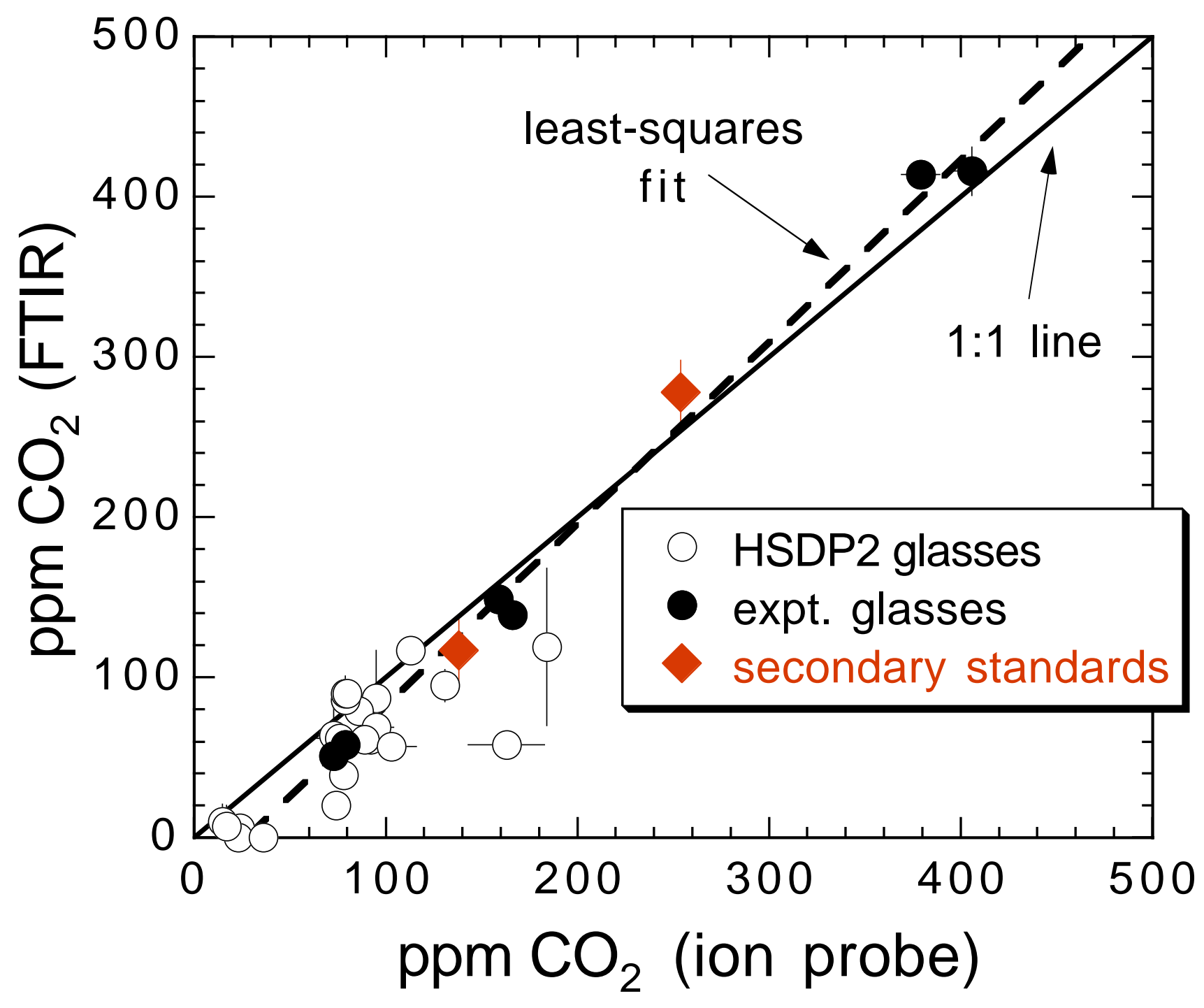

Figure 1 


\begin{tabular}{|c|}
\hline HSDP2 glasses \\
\hline $\begin{array}{ll}\Delta \text { hyaloclastite } & \text { pink - high } \mathrm{SiO}_{2} \\
\square \text { intrusive } & \text { blue }- \text { low } \mathrm{SiO}_{2} \\
\diamond \text { massive } & \text { cyan }-1800 \mathrm{mbsl} \text { excursion } \\
\text { O pillow } & \text { green }-2233 \mathrm{mbsl} \text { excursion } \\
\text { solid symbols }-\mathrm{MgO} \geq 7 \% \quad \text { grey infill - no major } \\
\text { open symbols }-\mathrm{MgO}<7 \% \quad \text { element analysis available } \\
\ldots\end{array}$ \\
\hline
\end{tabular}

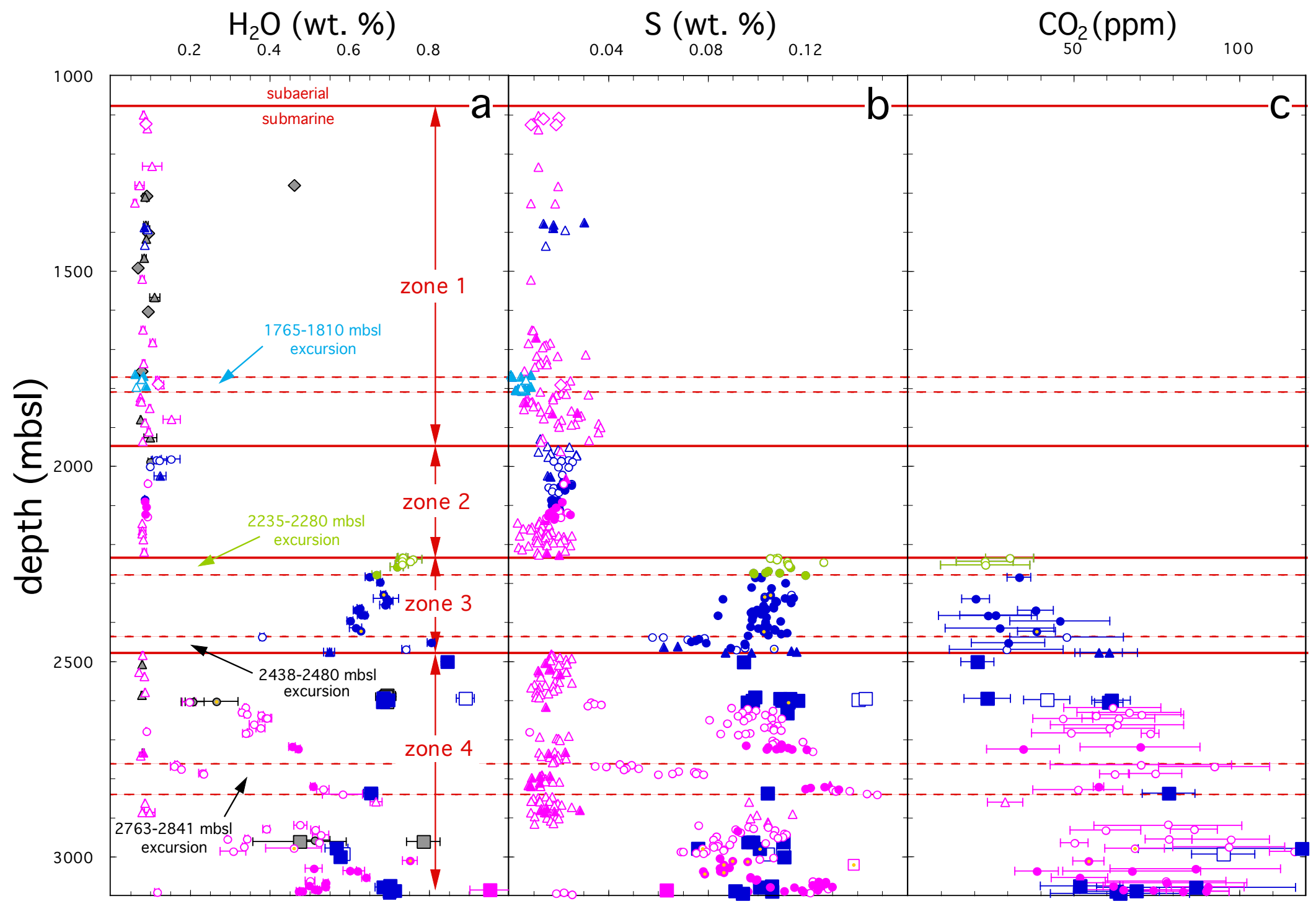

Figure $2 \mathrm{a}-\mathrm{c}$ 


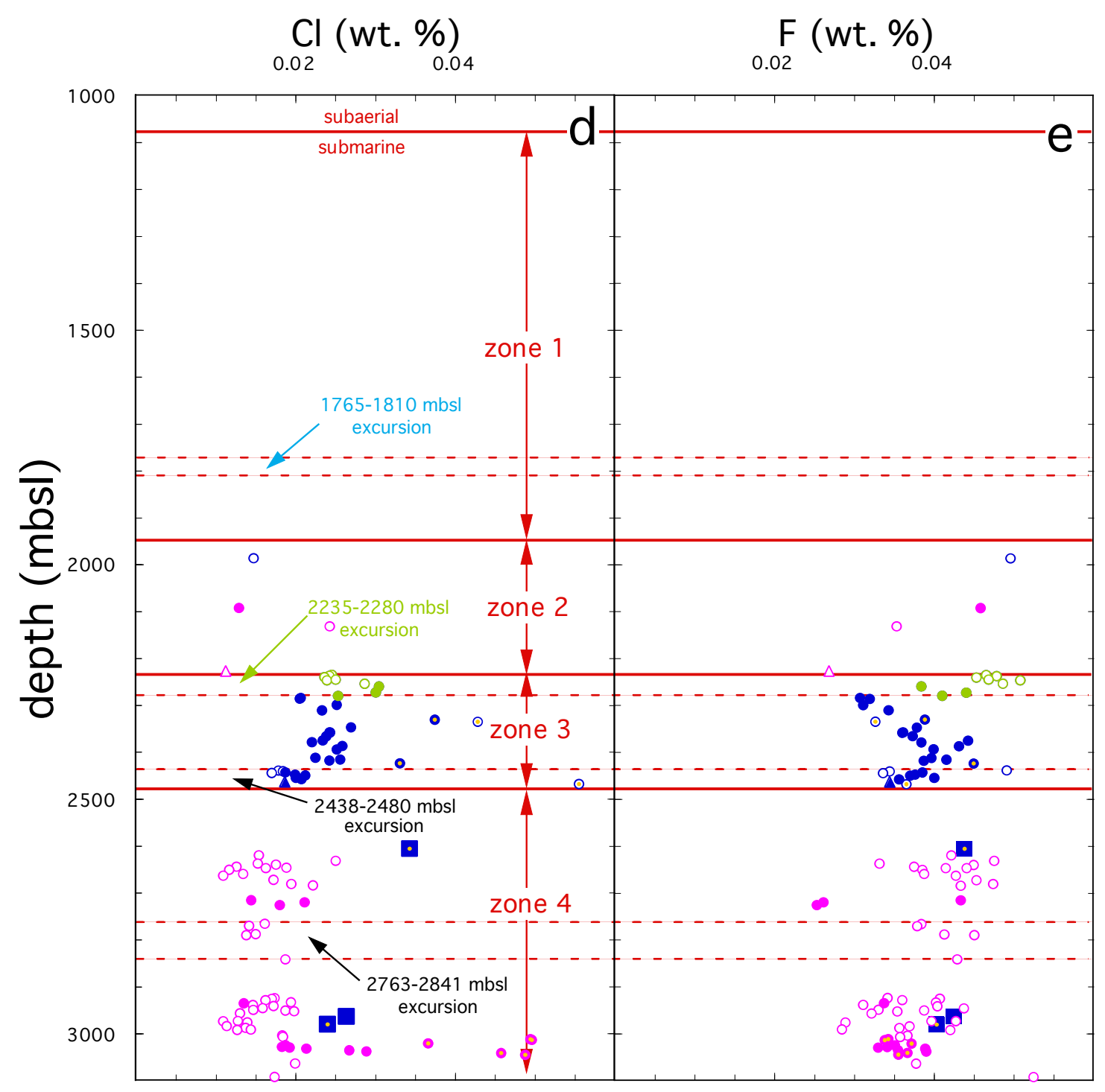

Figure $2 d-e$ 


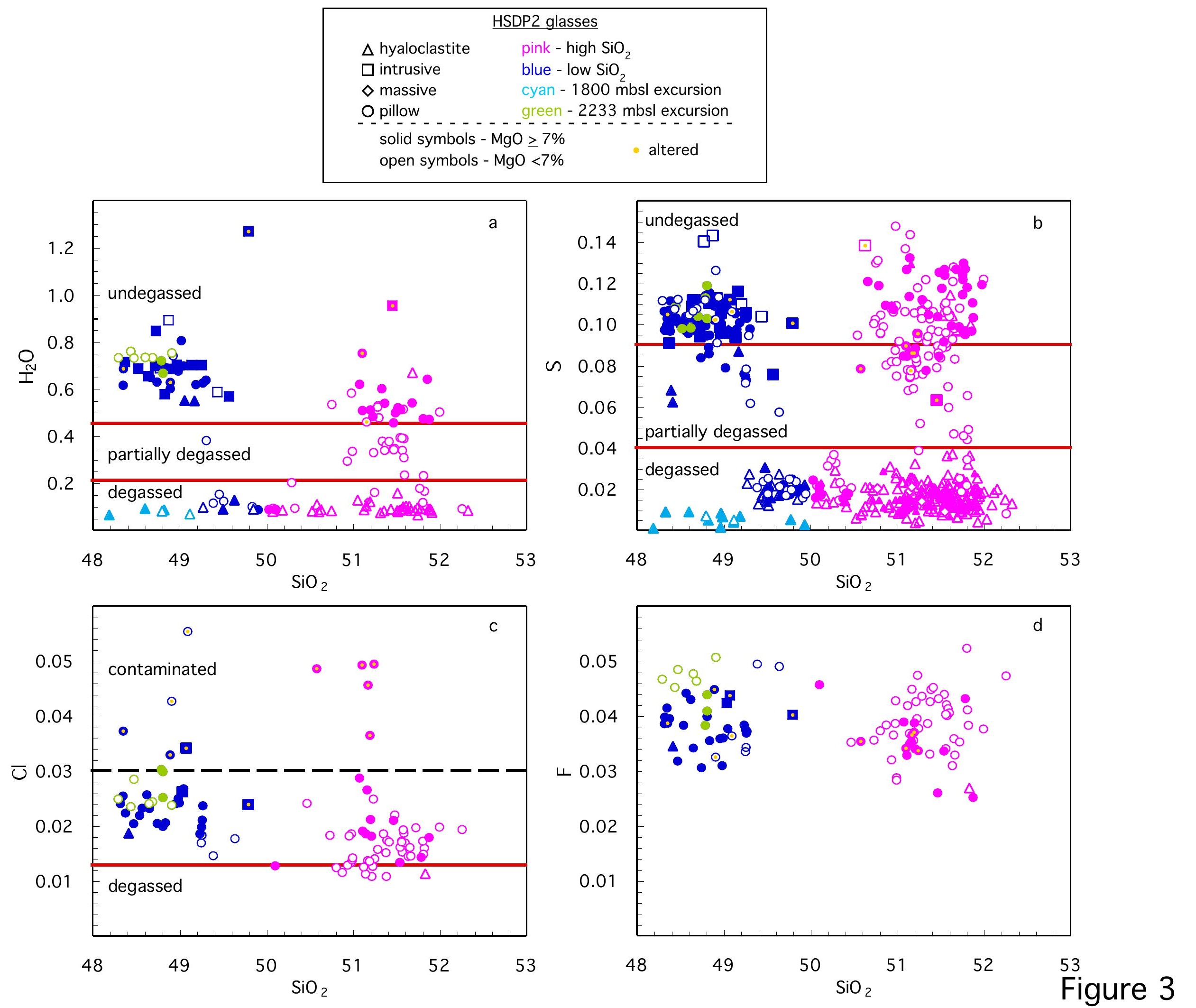




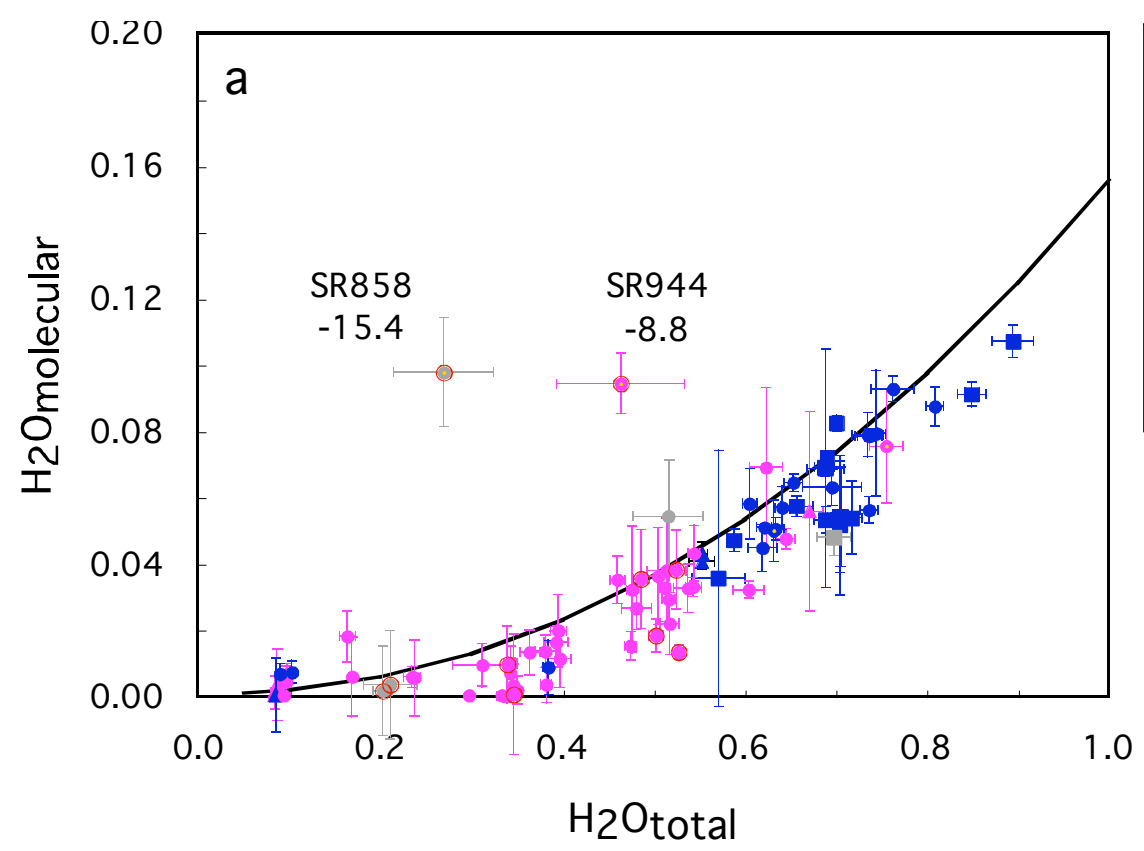

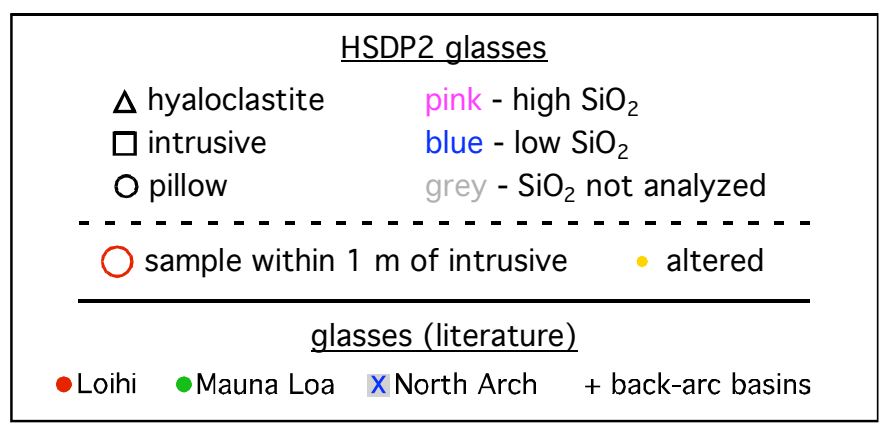
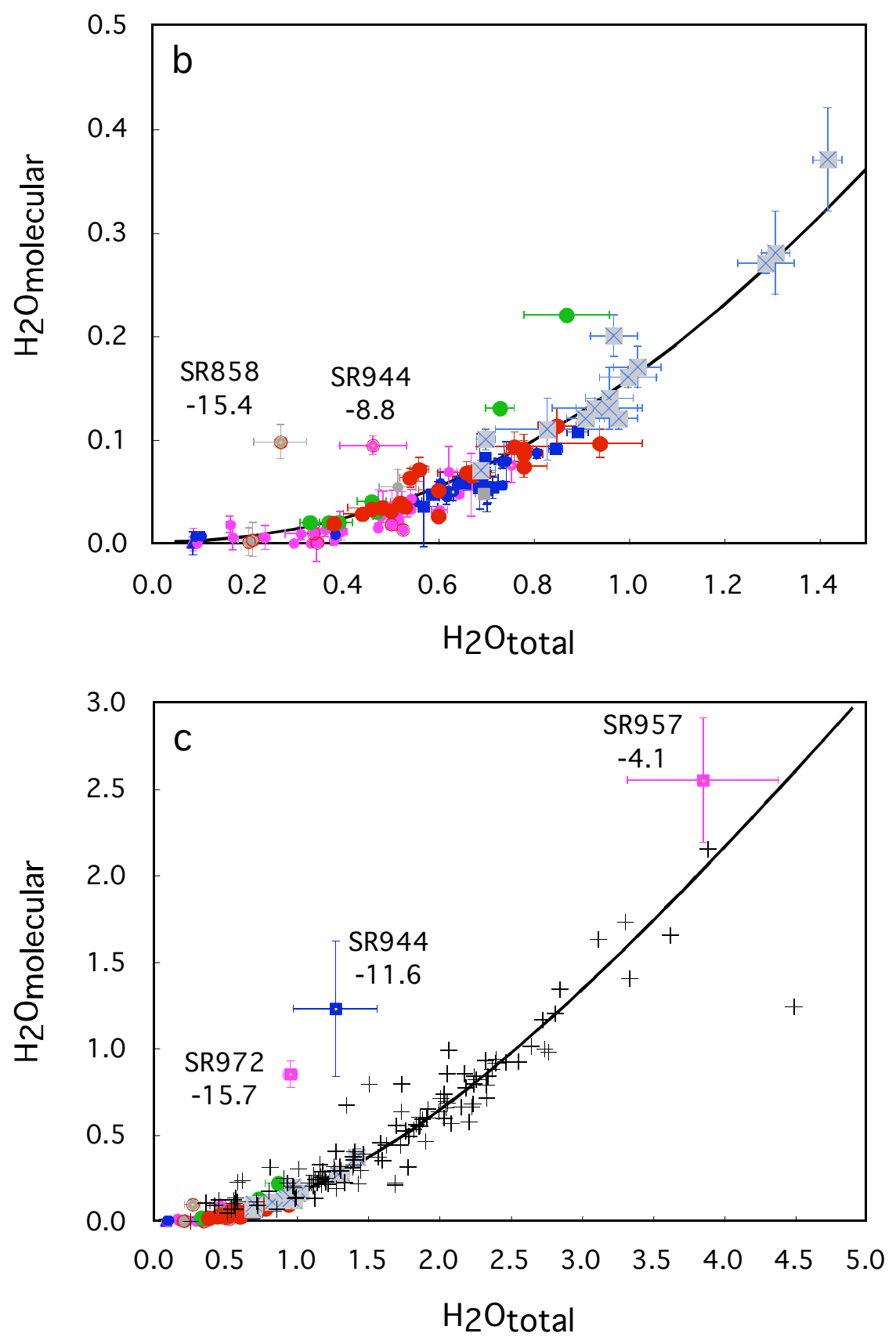


\begin{tabular}{|c|}
\hline HSDP2 glasses \\
\hline$\Delta$ hyaloclastite $\quad$ pink - high $\mathrm{SiO}_{2}$ \\
\hline$\square$ intrusive $\quad$ blue - low $\mathrm{SiO}_{2}$ \\
\hline cyan - 1800 mbsl excursion \\
\hline O pillow \\
\hline $\begin{array}{l}\text { solid symbols - } \mathrm{MgO} \geq 1 \% \\
\text { open symbols - } \mathrm{MgO}<7 \%\end{array}$ \\
\hline
\end{tabular}
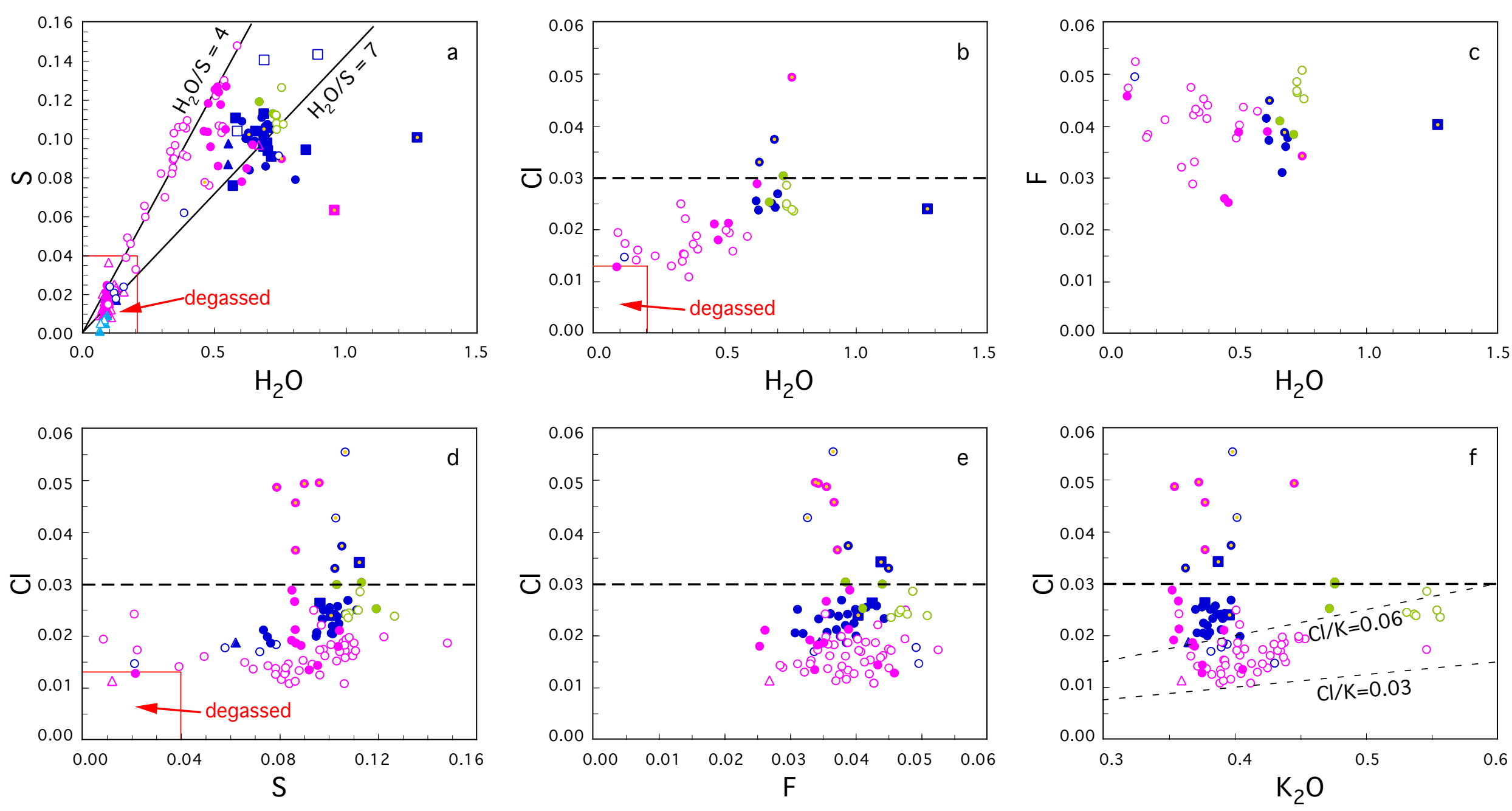

Figure 5 


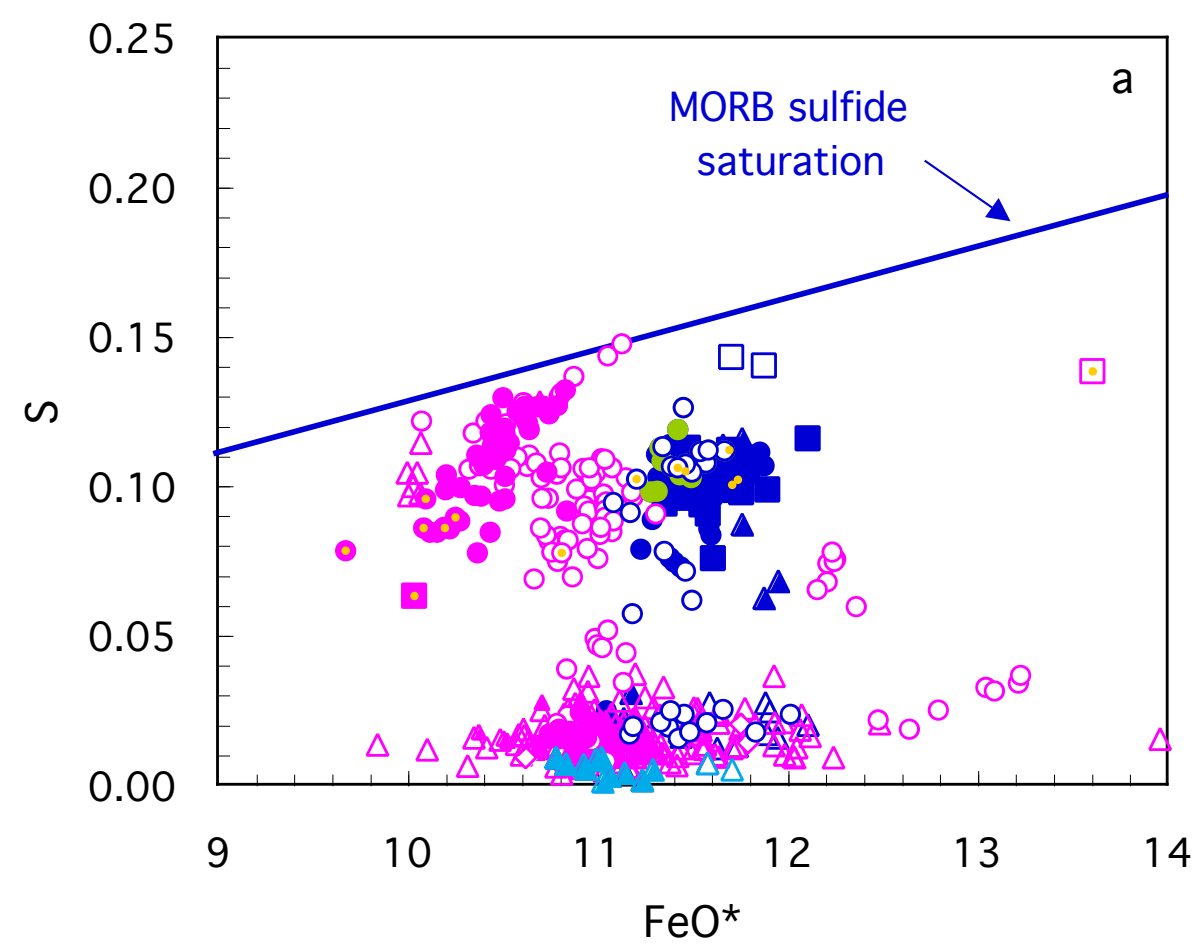

\begin{tabular}{|lc|}
\hline & HSDP2 glasses \\
$\Delta$ hyaloclastite & pink - high $\mathrm{SiO}_{2}$ \\
$\square$ intrusive & blue - low $\mathrm{SiO}_{2}$ \\
$\diamond$ massive & cyan -1800 mbsl excursion \\
O pillow & green -2233 mbsl excursion \\
\hdashline- solid symbols $-\mathrm{MgO} \geq 7 \%$ & \\
open symbols $-\mathrm{MgO}<7 \%$ & altered
\end{tabular}

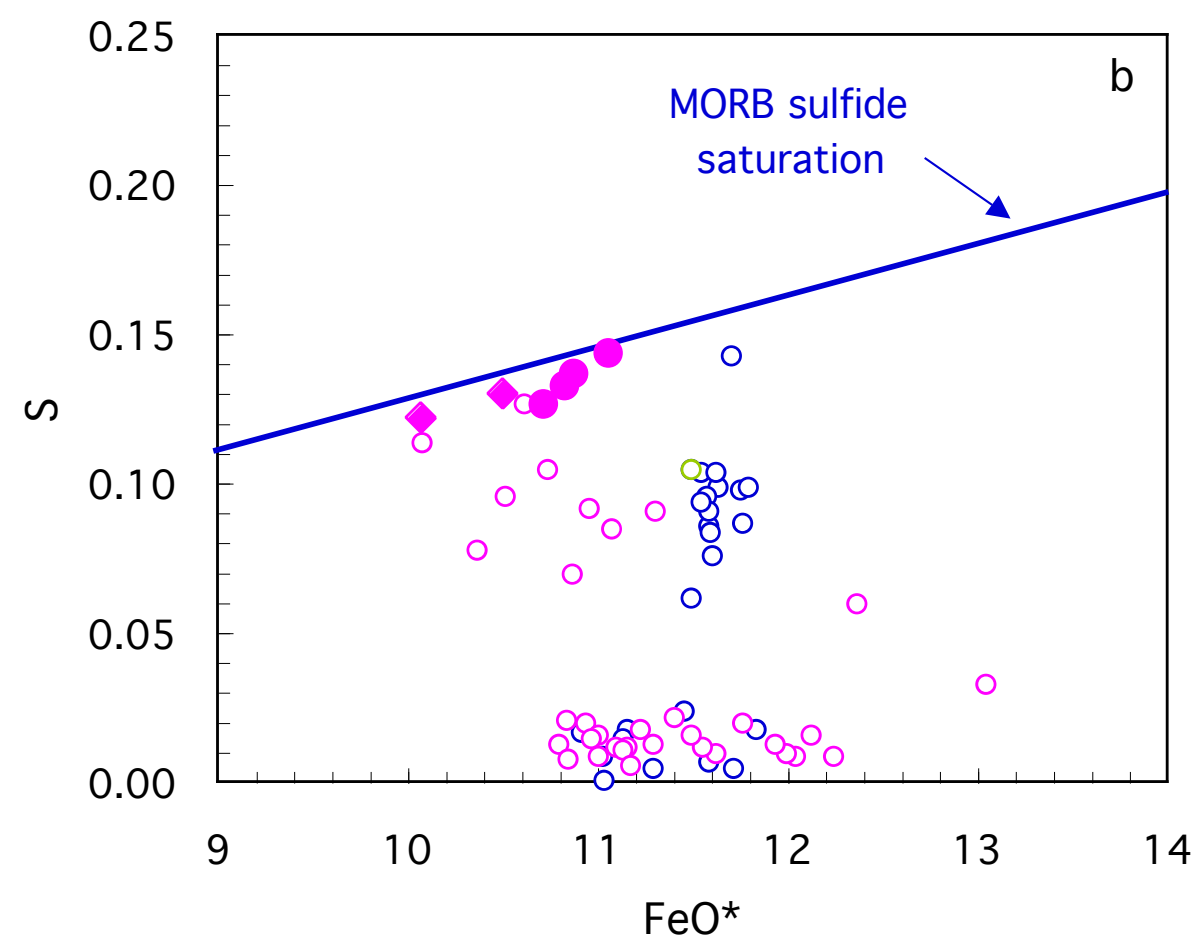

petrographic observations

O low- $\mathrm{SiO}_{2}$ glass; no sulfide blebs

$\mathrm{O}$ high- $\mathrm{SiO}_{2}$ glass; no sulfide blebs

○ 2233 mbsl excursion; no sulfide blebs

- high-SiO ${ }_{2}$ glass; sulfide blebs in matrix glass

$\checkmark$ high- $\mathrm{SiO}_{2}$ glass; sulfide blebs in olivine 

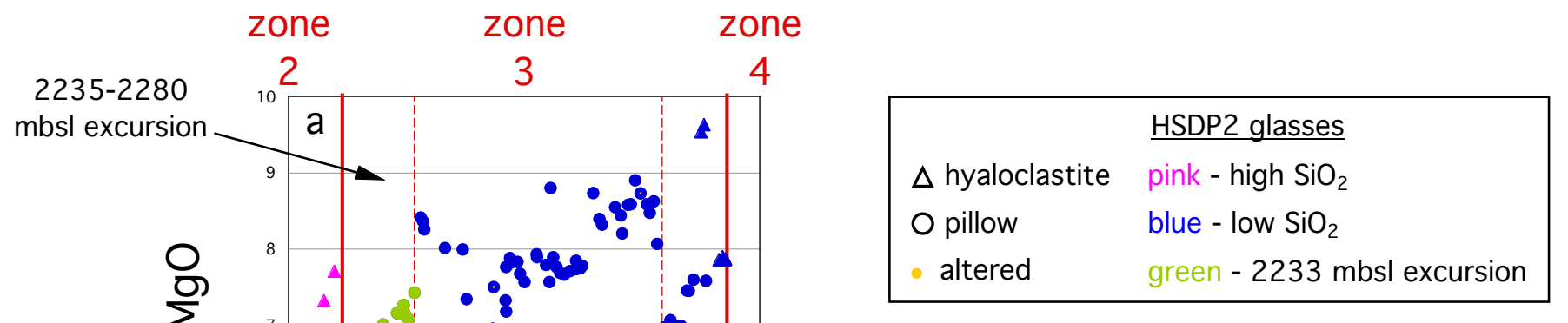

mbsl excursion

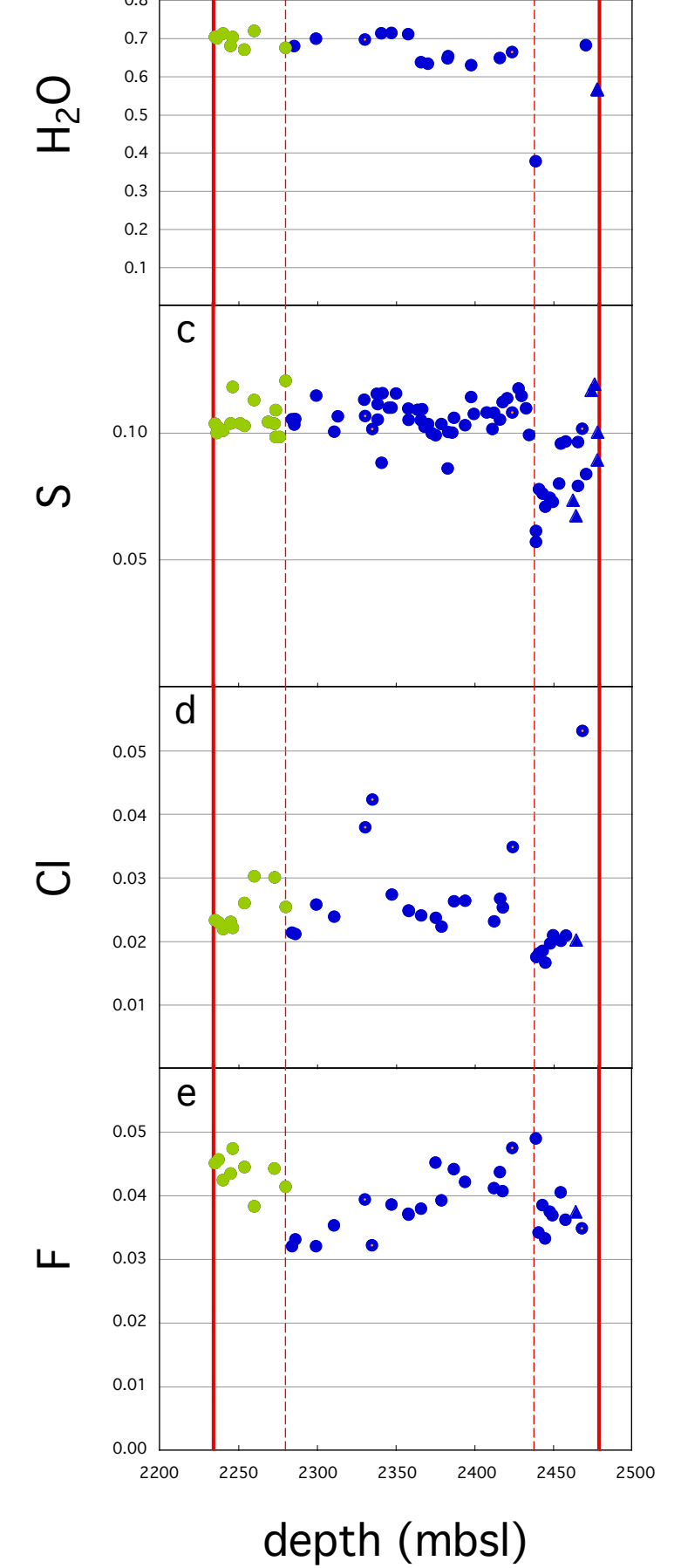

2763-2841
mbsl excursion
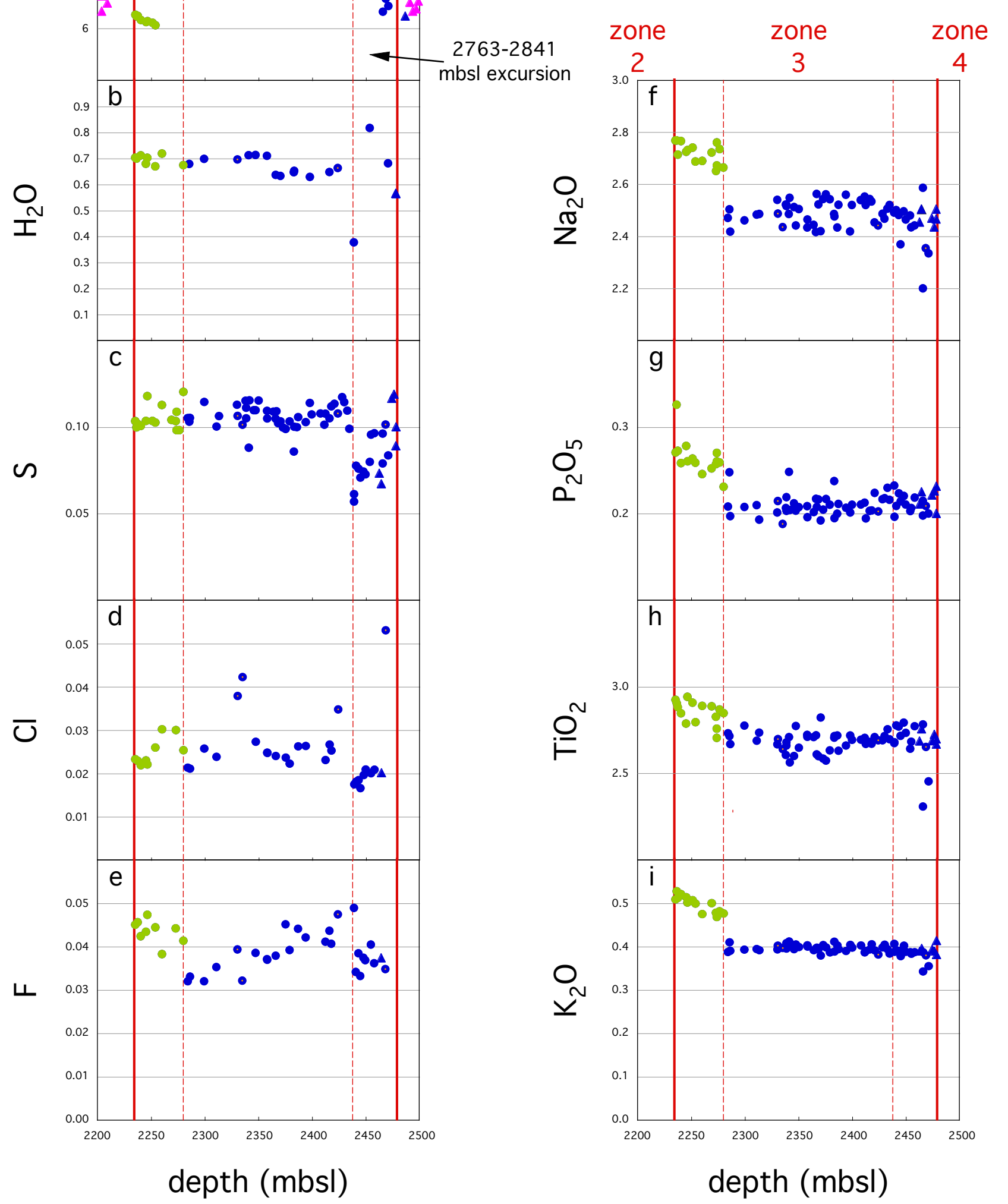

Figure 7 


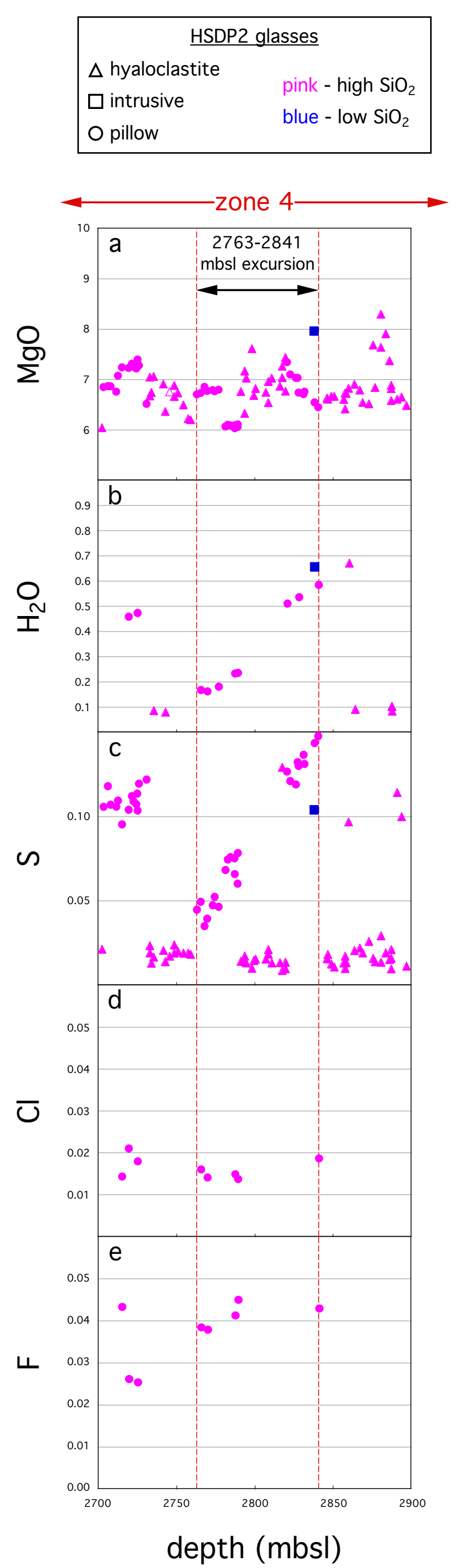




\section{zone 4 pillows}
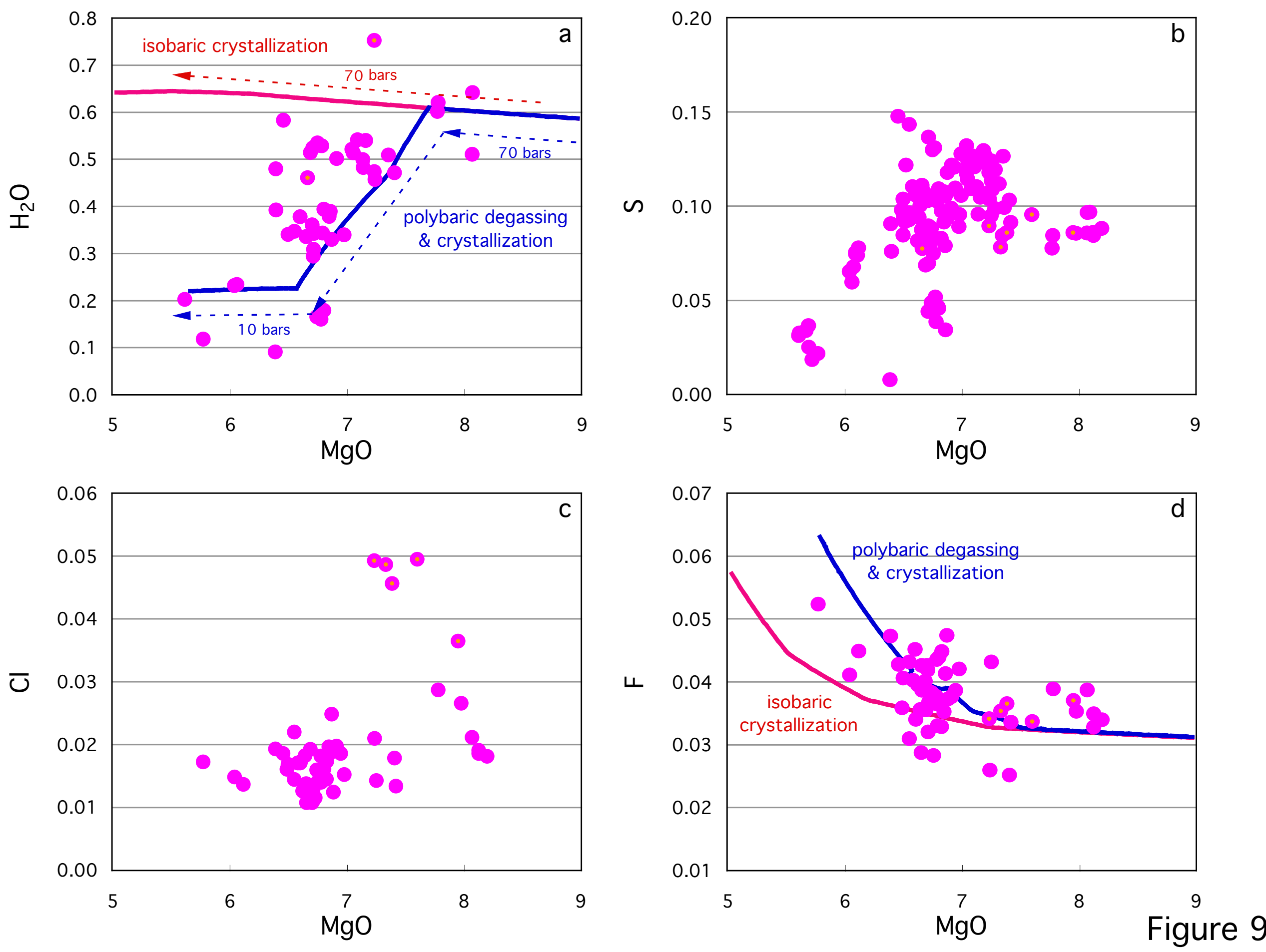


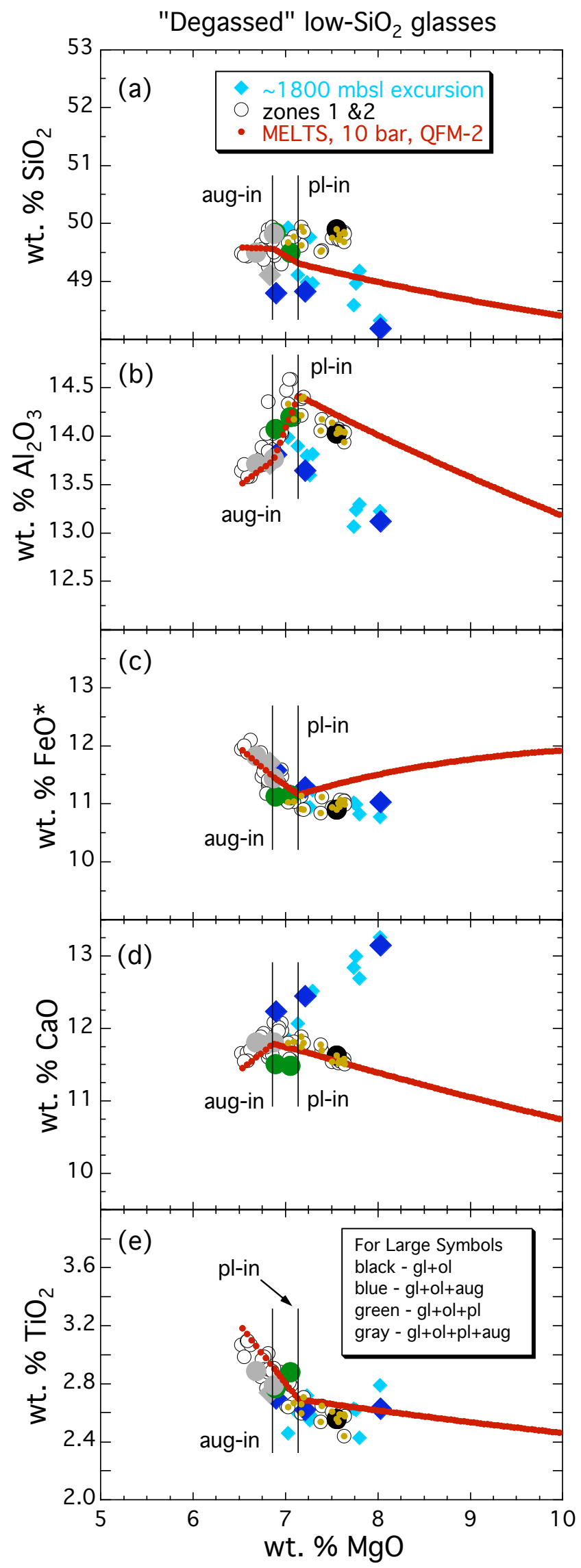

"Partially degassed \& undegassed"

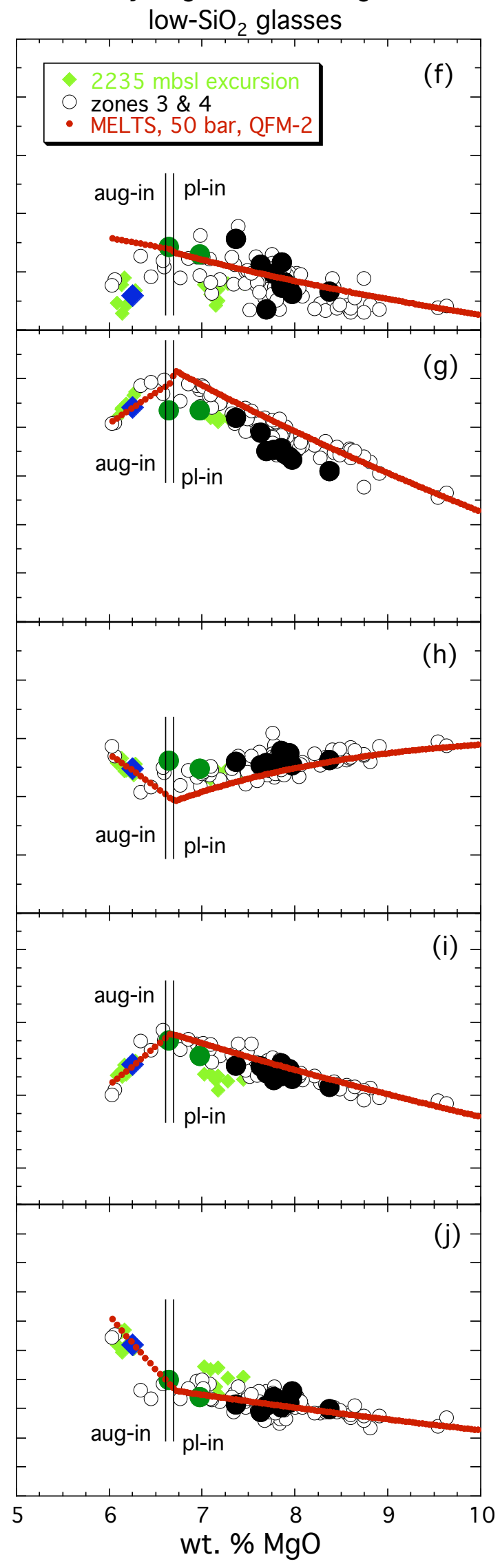

Figure $10 a-j$ 


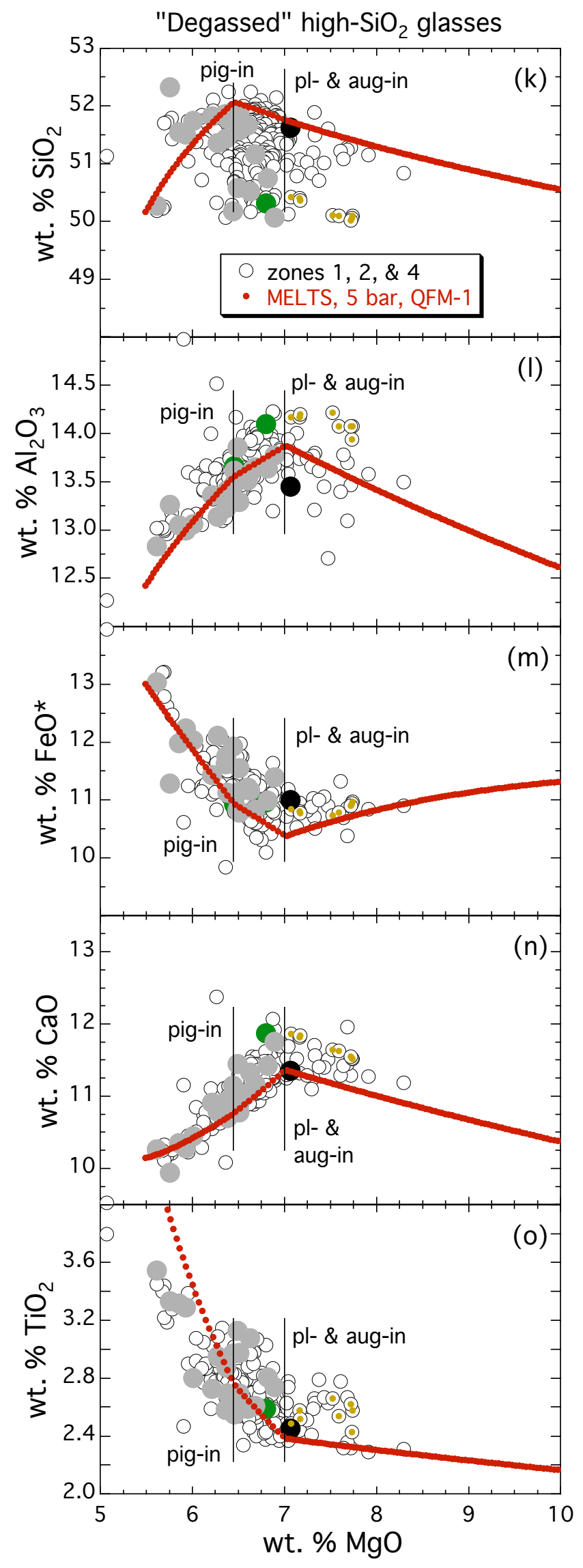

"Partially degassed \& undegassed"

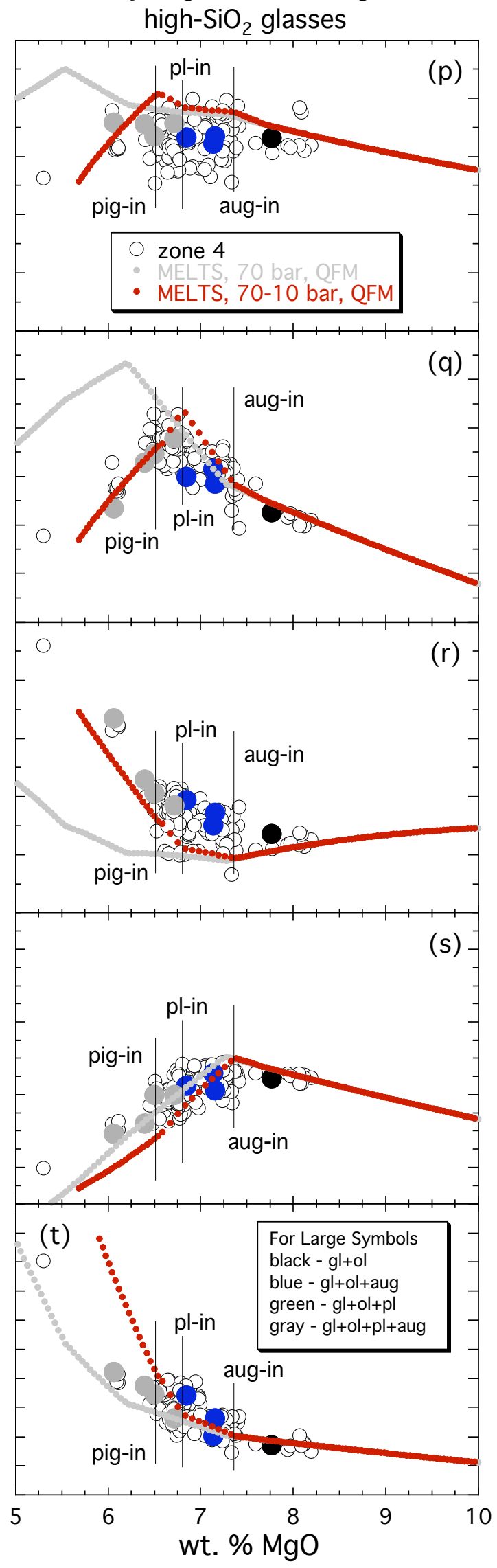

Figure $10 k-t$ 


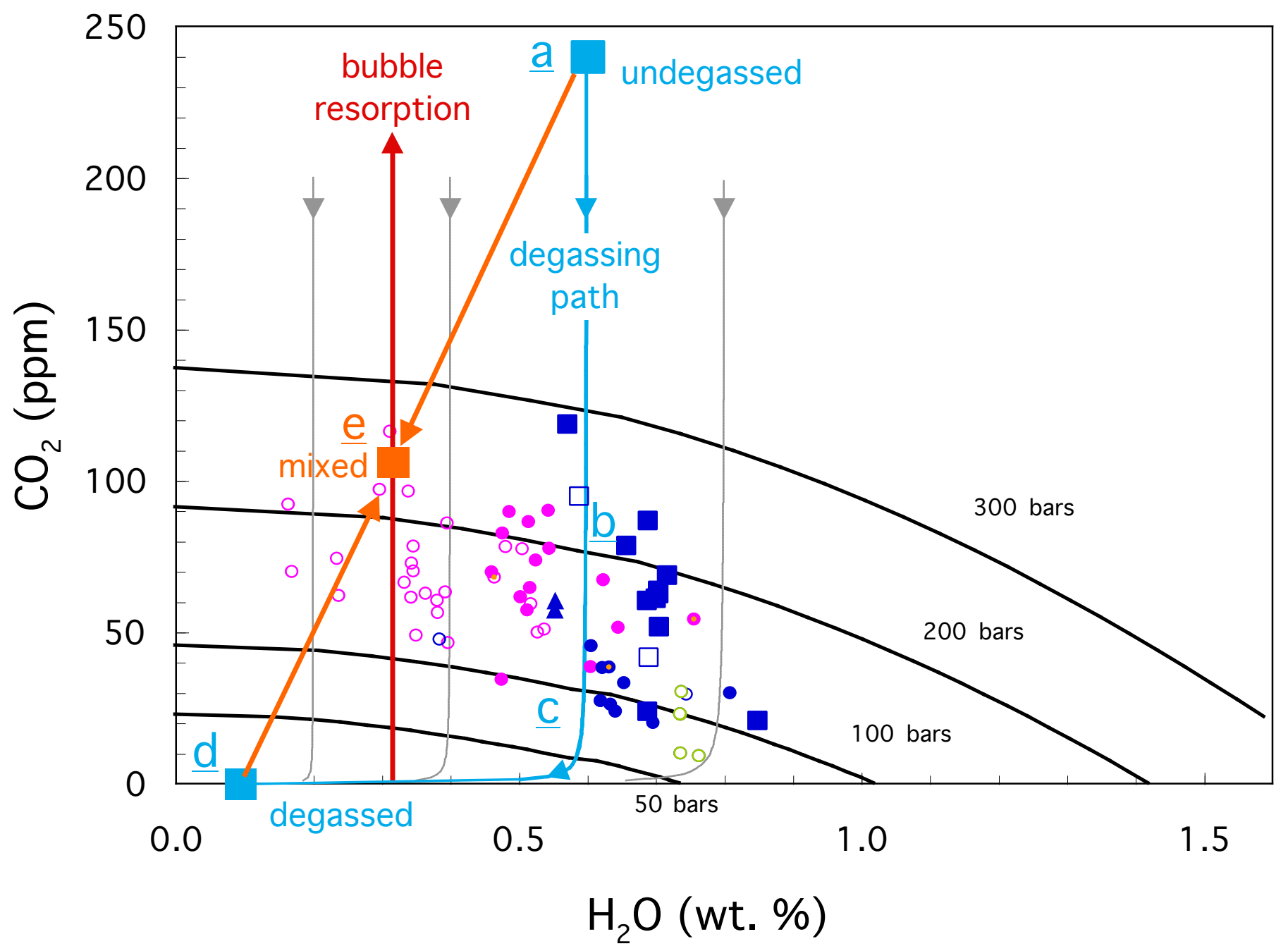

Figure 11 


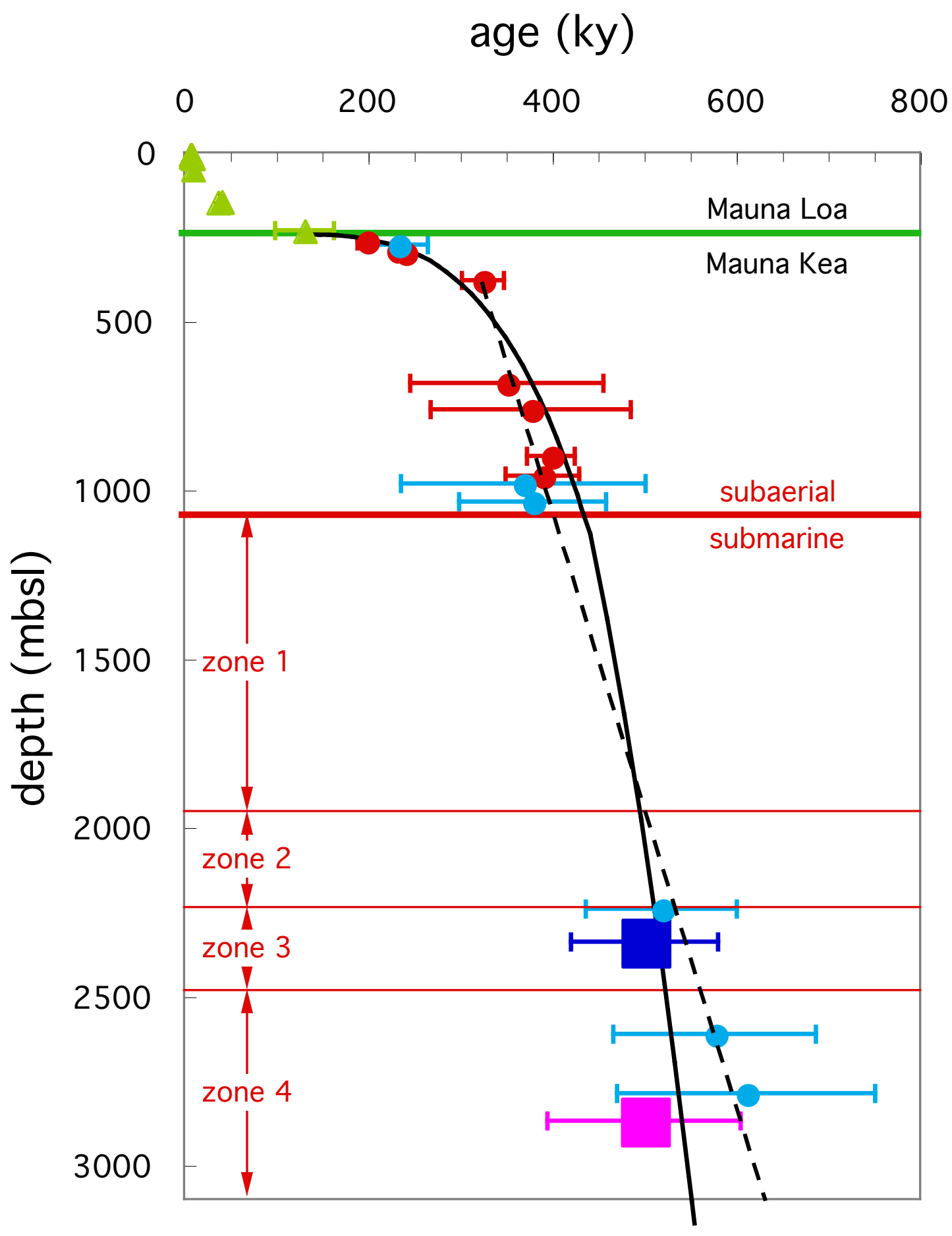

HSDP1 ages

HSDP2 ages

Mauna Loa (U-Th, C14, Ar-Ar)

Mauna Kea (Ar-Ar)

Mauna Kea (K-Ar, Ar-Ar)

average zone 3 glass (subsidence age, see text)

average zone 4 glass (subsidence age, see text) 


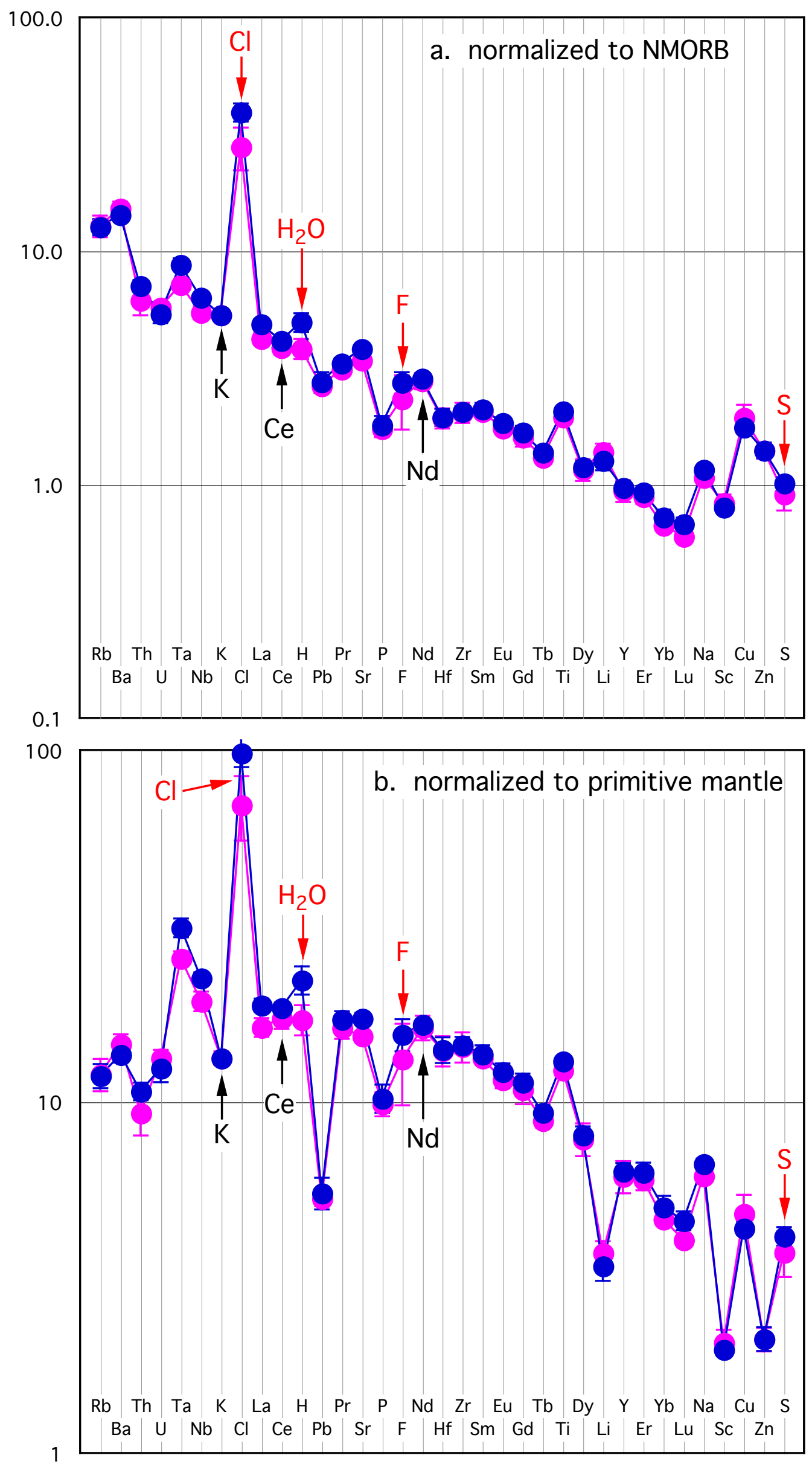

Figure 13 

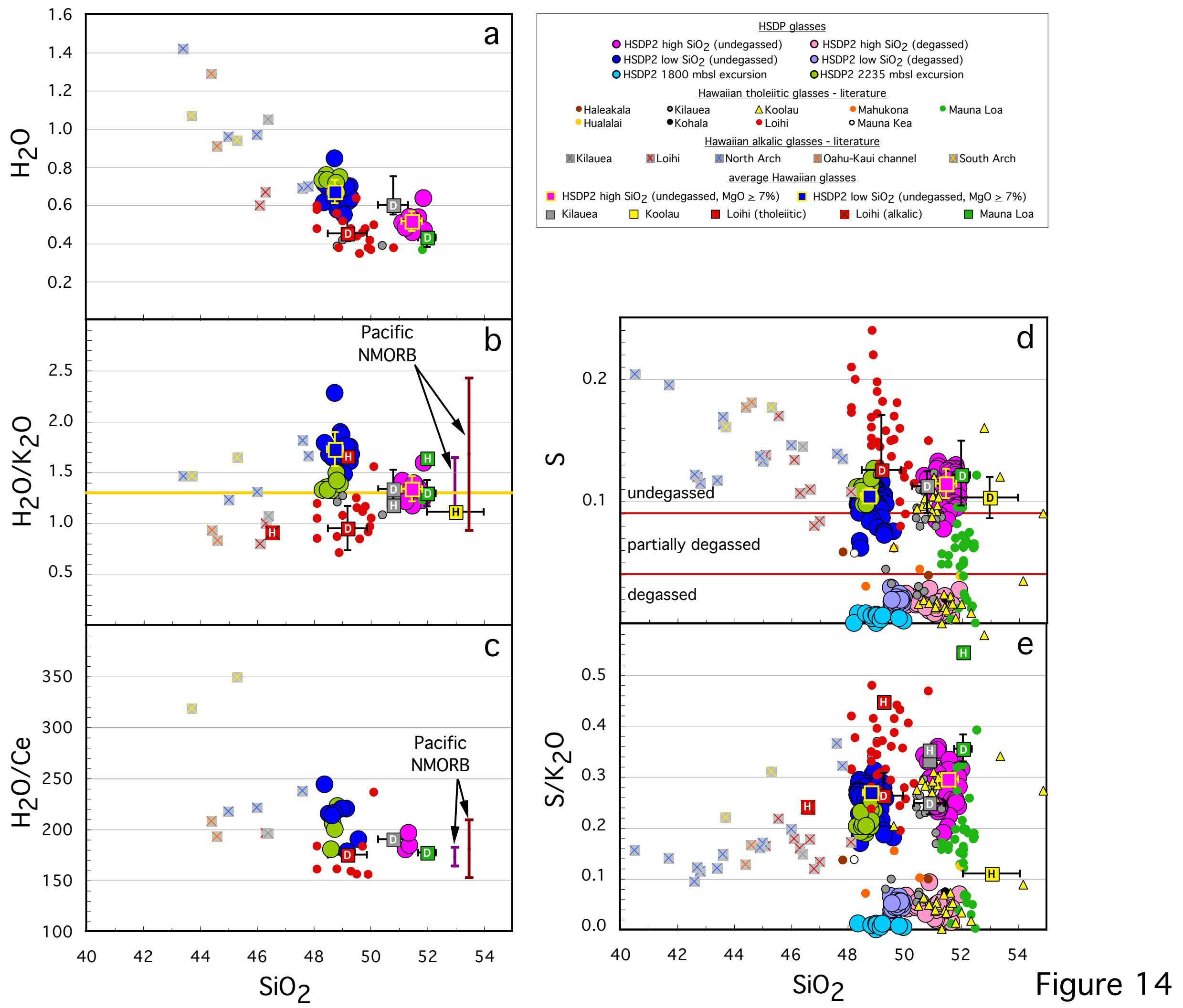